\title{
Um estudo sobre a implementação do cálculo diferencial e integral no ensino médio
}

\author{
Jaime Alves de Oliveira Junior
}




\title{
Um estudo sobre a implementação do cálculo diferencial e integral no ensino médio
}

\author{
Jaime Alves de Oliveira Junior
}

Orientadora: Profa. Dra. Michelle Fernanda Pierri Hernandez

Dissertação apresentada ao Instituto de Ciências Matemáticas e de Computação - ICMC-USP, como parte dos requisitos para obtenção do título de Mestre Programa de Mestrado Profissional em Matemática. VERSÃO REVISADA 
Ficha catalográfica elaborada pela Biblioteca Prof. Achille Bassi e Seção Técnica de Informática, ICMC/USP, com os dados fornecidos pelo(a) autor(a)

Alves de Oliveira Junior, Jaime
Um estudo sobre a implementação do cálculo
diferencial e integral no ensino médio / Jaime
Alves de Oliveira Junior; orientadora Michelle
Fernanda Pierri Hernandez. -- São Carlos, 2015.
125 p.
Dissertação (Mestrado - Programa de Pós-Graduação
em Mestrado Profissional em Matemática em Rede
Nacional) -- Instituto de Ciências Matemáticas e de
Computação, Universidade de São Paulo, 2015.
1. Limite. 2. Derivada. 3. ensino médio. I.
Pierri Hernandez, Michelle Fernanda, orient. II.
Título.


Para minha mãe,

Elenice

para minha irmã, Talita. 


\section{Agradecimentos}

À Deus. Sem Ele eu não poderia nada e com Ele eu posso tudo.

À minha família, em especial, à minha mãe, Elenice, cujo amor, dedicação e fé são a minha base e à minha irmã, Talita, cuja dedicação, amor e parceria são verdadeiros suportes para que eu sempre siga em frente.

À minha orientadora Dra. Michelle, pela dedicação, paciência e por ter compartilhado o seu conhecimento comigo.

À minha grande amiga, Maria Cleonice Sampaio Funes, que nos momentos de preocupação e ansiedade me auxiliou com seus "iluminados" conselhos.

Aos meus amigos Euza, Nina, Rodrigo e Thiago que sempre estiveram comigo durante o curso, nos bons e nos maus momentos.

Ao meu amigo Gabriel, que mesmo morando no Canadá, nunca se esqueceu de me ligar oferecendo-me incentivo e apoio nas horas difíceis.

À Sociedade Brasileira de Matemática por acreditar na formação de professores através do PROFMAT.

Por último e de forma especial, agradeço aos quinze alunos que fizeram parte desta pesquisa, sem eles, este trabalho não teria sido realizado. 


\section{Resumo}

JUNIOR, J. A. O. Um Estudo sobre a Implementação do Cálculo Diferencial e Integral no Ensino Médio. 2015. 125f. Dissertação (Mestrado) - Faculdade de Filosofia, Ciências e Letras de Ribeirão Preto, Universidade de São Paulo, Ribeirão Preto, 2015.

O objetivo deste trabalho de dissertação foi estudar a importância da implementação do Cálculo Diferencial e Integral no ensino médio. Também houve o interesse em analisar a importância no método utilizado para essa implementação. Especificamente, nos preocupamos em tentar beneficiar os alunos do ensino médio de uma maneira geral, ou seja, os alunos que pretendem continuar seus estudos em nível superior em áreas exatas ou não. Motivados por isto, foi feito um estudo de caso em que se ministrou essa disciplina para dois grupos de alunos do ensino médio (grupos 1 e 2). Para um grupo (grupo 1) a disciplina foi apresentada de maneira mais intuitiva, com muitos exemplos (algébricos ou ligados ao nosso cotidiano) e não muito formal e para o outro grupo (grupo 2) a disciplina foi apresentada de forma mais tradicional e próxima ao abordado no ensino superior. Ao final do nosso estudo verificamos que os dois grupos foram beneficiados, pois tiveram a oportunidade de enriquecer seus conhecimentos através do estudo de uma disciplina muito importante nas áreas de ciências exatas e aplicadas. No entanto, como esperávamos, conseguimos atingir nosso objetivo de maneira mais satisfatória com o grupo 1, pois percebemos que este grupo sempre mostrou mais interesse e, consequentemente, mais facilidade em aprender e aplicar o conhecimento adquirido. Dessa forma concluímos que é possível inserir o Cálculo Diferencial e Integral no ensino médio e que métodos similares ao que utilizamos com o grupo 1 poderão contribuir para qualidade do ensino da matemática no ensino médio, já que oferecem para os alunos um conhecimento mais rico e abrangente da matemática.

Palavras-chave: Limite. Derivada. Ensino Médio. 


\section{Abstract}

JUNIOR, J. A. O. A study about the implementation of the Differential and Integral Calculus in high school. 2015. 125f. Dissertação (Mestrado) - Faculdade de Filosofia, Ciências e Letras de Ribeirão Preto, Universidade de São Paulo, Ribeirão Preto, 2015.

The objective of this dissertation was to study the importance of implementing the Differential and Integral Calculus in high school. There has also been interest in analyzing the importance of the method used for its implementation. Specifically, we are concerned in trying to benefit high school students in general, that is, students who intend to continue their studies at a higher level in exact areas or not. Motivated by this, a case study in which they gave this discipline for two high school students groups was made (groups 1 and 2). For a group (group 1) the subject was presented in a more intuitive way, with many examples (algebraic or connected to our everyday) and not too formal and the other group (group 2) the discipline was presented in a more traditional and closely addressed to higher education. At the end of our study we found that both groups benefited, as had the opportunity to enrich their knowledge through the study of a very important discipline in the exact sciences and applied sciences. However, as we expected, we achieved our goal of more satisfactorily with the group 1 because we realize that this group has always shown more interest and, therefore, easier to learn and apply the knowledge gained. Thus we concluded that you can enter the Differential and Integral Calculus in high school and that similar methods to that used with the group 1 may contribute to quality of mathematics teaching in high school, as they provide for students a richer knowledge and embracing of mathematics.

Keywords: Limit. Derivative. High School. 


\section{Sumário}

$\begin{array}{ll}\text { Introdução } & 1\end{array}$

1 Metodologia Aplicada ao Grupo 1

1.1 Uma Visão geral sobre Cálculo Diferencial e Integral por meio de Aplicações no

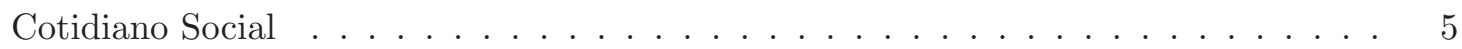

1.2 Noções de Limite . . . . . . . . . . . . . . . . . . . . . . . . . . . . . . . . . . . . . . 9

1.2 .1 Fixando a Noção de Limite . . . . . . . . . . . . . . . . . . . . . . . . 12

$1.2 .2 \quad$ Limites Laterais . . . . . . . . . . . . . . . . . . . 17

1.2 .3 Noção de Continuidade . . . . . . . . . . . . . . . . . 18

1.2.4 Propriedades dos Limites . . . . . . . . . . . . . . . . . . . 22

1.2.5 Limites Envolvendo Infinito . . . . . . . . . . . . . . . . . 22

1.2.5.1 Assíntotas Verticais e Assíntotas Horizontais . . . . . . . . . . 23

1.2.6 Uma Aplicação Financeira e o Número de Euler . . . . . . . . . . . . . . . . 31

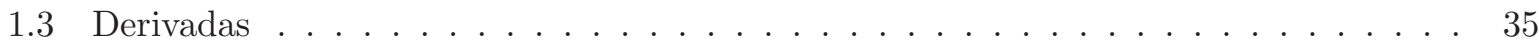

1.3.1 A Derivada Vista sob Dois Aspectos: Taxa de Variação e Inclinação da Reta

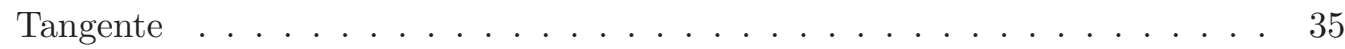

1.3.2 A derivada como um Tipo Especial de Limite . . . . . . . . . . . . . . . . . . 40

1.3.3 Regras Básicas da Diferenciação . . . . . . . . . . . . . . . . . . . . 45

1.3.3.1 A Regra da Potência . . . . . . . . . . . . . . . . . . 45

1.3.3.2 A Derivada de Funções do $1^{\circ}$ Grau e Funções Constantes . . . . . . 46

1.3.3.3 A Regra da Soma . . . . . . . . . . . . . . . . . . . 47

1.3.3.4 A Regra do Produto . . . . . . . . . . . . . . . . . 48

1.3.3.5 A Regra do Quociente . . . . . . . . . . . . . . . 50 
1.3.4 Pontos Críticos de uma Função e Pontos de Máximo e Mínimo . . . . . . . . 51

1.3.5 Pontos de Inflexão . . . . . . . . . . . . . . . . . . . . . . . . . . . 55

1.3.5.1 Noção Intuitiva sobre o que é um Ponto de Inflexão . . . . . . . . . 56

1.3.5.2 Justificativa e Procedimento Algébrico para Encontrar o Ponto de Inflexão . . . . . . . . . . . . . . . . . . . . . 57

1.3.6 Usando as Ferramentas do Cálculo para Entender o Comportamento das Curvas 61

1.3.7 O Melhor do Cálculo: Algumas Aplicações . . . . . . . . . . . . . . . . . . . . . 64

1.3.7.1 Velocidade e Aceleração . . . . . . . . . . . . . . . . . . . . 65

2 Metodologia Aplicada ao Grupo $2 \quad 71$

2.1 Noções de Limite . . . . . . . . . . . . . . . . . . . . . . . . . . . . . . 72

2.1 .1 Noção Intuitiva de Limites . . . . . . . . . . . . . . . . . . . . . 72

2.1 .2 Limites Laterais . . . . . . . . . . . . . . . . . . . . . . 74

2.1 .3 Propriedade dos Limites . . . . . . . . . . . . . . . . 76

2.1 .4 Limites Infinitos $\ldots \ldots \ldots \ldots \ldots \ldots$

2.1 .5 Limites no Infinito $\ldots \ldots \ldots \ldots$

2.1 .6 Continuidade . . . . . . . . . . . . . . . . . . . . 84

2.1.7 Propriedades das Funções Contínuas . . . . . . . . . . . . . . . . . . . 84

2.2 Derivadas . . . . . . . . . . . . . . . . . . . . 86

2.2 .1 A Reta Tangente e a Derivada . . . . . . . . . . . . . . . . . 87

$2.2 .2 \quad$ Regras de Derivação . . . . . . . . . . . . . . . . . . . . . . . . . . . . . . 89

2.2 .3 Aplicações de Derivada . . . . . . . . . . . . . . . . . . . . . . . . . . 91

2.2.3.1 Pontos Críticos de uma Função e Pontos de Máximo e Mínimo . . . 91

2.2.3.2 O Teste da Primeira Derivada . . . . . . . . . . . . . . . . 97

2.2.3.3 Concavidades e Pontos de Inflexão . . . . . . . . . . . . . . . . . . . 99

2.2.4 Algumas Aplicações do Cálculo: Velocidade e Aceleração . . . . . . . . . . . 103

2.2.4.1 A Velocidade Instantânea e sua Relação com a Primeira Derivada . 103

2.2.4.2 A Aceleração Instantânea e sua Relação com a Segunda Derivada 103

3 Análise dos Dados $\quad 107$

Conclusão 


\section{Introdução}

O Cálculo Diferencial e Integral é uma das áreas mais importantes da Matemática. Sua importância se deve, essencialmente, pelo fato que as ferramentas matemáticas oferecidas pelo Cálculo permitem o estudo de inúmeras aplicações. Em áreas puras podemos citar, por exemplo, equações diferenciais, análise complexa, geometria, dentre muitas outras. No entanto, para a maioria das áreas aplicadas o Cálculo também se comporta como uma ferramenta eficiente e essencial como, por exemplo, na Física, Química, Biologia, Medicina, Economia, etc. Observamos ainda que dentro do contexto de áreas aplicadas podemos considerar situações do nosso cotidiano, como a velocidade ou aceleração de um carro, juros, impostos, movimentações bancárias, dinâmica de população (indice de natalidade ou mortalidade), dentre outras.

Apesar da importância apresentada acima e de ser tão abrangente, o Cálculo Diferencial e Integral é abordado somente no ensino superior e, em geral, em cursos de áreas exatas. Mais ainda, na maioria desses cursos essa disciplina é oferecida em período semestral, o que muitas vezes não permite o desenvolvimento de muitos exemplos e aplicações. Isto, juntamente com os conceitos formais e o rigor nas ferramentas matemáticas dessa disciplina, não permitem uma boa compreensão dos conceitos abordados e causam desmotivação por parte dos alunos pelos cursos superiores escolhidos. Este fato pode ser verificado pelos altos índices de reprovação nessa disciplina.

Atualmente muitos pesquisadores da área de educação estudam possibilidades para que o Cálculo Diferencial e Integral seja inserido no currículo do ensino médio, com o objetivo de mostrar a importância da Mátemática como uma ciência que faz parte no nosso cotidiano e deixe de ser vista como algo difícil e desconexa com outras áreas. Veja, por exemplo,[3],[8],[9]

Os fatos acima motivaram o desenvolvimento deste trabalho de dissertação em que o objetivo foi estudar a importância da implementação do Cálculo Diferencial e Integral no ensino médio. 
Também houve o interesse em analisar a importância no método utilizado para essa implementação. Especificamente, nos preocupamos em tentar beneficiar os alunos do ensino médio de uma maneira geral, ou seja, os alunos que pretendem continuar seus estudos em nível superior em áreas exatas ou não. Para isto, foi feito um estudo de caso em que se ministrou essa disciplina para dois grupos de alunos do ensino médio (grupos 1 e 2). Para um dos grupos (grupo 1) optamos em adotar um método em que a disciplina fosse apresentada de maneira mais intuitiva, com estímulo para a reflexão e com muitos exemplos algébricos ou ligados a outras disciplinas como, por exemplo, a Física e ao nosso cotidiano (sempre que possível). Já para o outro grupo (grupo 2) a disciplina foi apresentada de forma mais tradicional e próxima ao abordado no ensino superior. No entanto, houve a preocupação no cuidado com o excesso de formalismo para que os alunos não se sentissem desestimulados ou desistissem de participar da pesquisa.

Com os dois grupos, cada um na metodologia adotada, abordou-se os conceitos de limite, derivadas e integrais. No entanto, para não estender este trabalho omitiremos os detalhes do que foi desenvolvido com relação ao conceito de integrais.

Os dois grupos eram constituídos por 7 alunos, regularmente matriculados no terceiro ano do Ensino Médio (período da manhã), da Escola Estadual Professora Suely Machado da Silva, localizada na cidade de Franca, na qual conta com salas de aulas disponíveis, sala de informática devidamente equipada, sistema de $\mathrm{Wi} F i$, projetores portáteis e máquinas para fotocópias e impressões. O curso teve uma duração de 4 meses (de Agosto a Novembro), com aulas ministradas das $19 \mathrm{~h}$ às $22 \mathrm{~h}$, nas segundas - feiras, para o primeiro grupo e nas quartas - feiras para o segundo grupo.

De maneira mais específica, introduziu-se inicialmente aos alunos a noção de limites finitos, limites infinitos e no infinito e continuidade. Além disso, reforçou-se a importância dos limites para encontrarmos, caso existam, assíntotas verticais e horizontais, fundamentais para a construção do gráfico de uma função. Em seguida, abordou-se o estudo da derivada, mostrando aos alunos a importância do limite na construção da definição de derivada, bem como as principais regras de derivação. Ainda dentro do contexto de derivadas, abordou-se os conceitos de pontos de máximo e mínimo e pontos de inflexão e a importância desses conceitos na construção de gráficos de funções. Também desenvolveu-se um tópico voltado especialmente para uma aplicação da derivada na Física, através do estudo dos conceitos de velocidade e aceleração instantâneas. Posteriormente, apresentou- 
se aos alunos o conceito de integral e algumas de suas aplicações. Finalmente, foi desenvolvida uma avaliação, envolvendo os principais assuntos abordados durante as aulas. Esta avaliação foi aplicada aos dois grupos, em que para sua resolução cada grupo pôde contar com a participação de todos os integrantes.

É importante observar que considerou-se como dados importantes para esta pesquisa a observação do professor com relação à participação, interesse e aprendizado dos alunos durante as aulas, bem como o desempenho dos dois grupos na avaliação aplicada no final da pesquisa.

Esta dissertação está dividida em três capítulos e uma conclusão final.

No Capítulo 1 apresentamos detalhadamente os conceitos desenvolvidos com o grupo 1 através de uma metodologia intuitiva e contextualizada, como já especificado anteriormente.

No Capítulo 2 apresentamos os conceitos desenvolvidos com o grupo 2 a partir de uma metodologia mais tradicional, também já especificado anteriormente.

No Capítulo 3 apresentamos a avaliação desenvolvida com os dois grupos, bem como a resolução apresentada por eles e a análise do desempenho de cada grupo feita pelo professor. Além disso, nesse capítulo o professor apresenta sua análise comparativa com relação à participação, interesse e aprendizado dos dois grupos durante as aulas ministradas.

Finalmente, apresentamos uma conclusão final em que, a partir da análise dos dados acima, comentamos sobre a importância da implementação do Cálculo Diferencial e Integral no ensino médio e a importância no método utilizado para essa implementação. Brevemente, acreditamos que os dois grupos foram beneficiados, pois tiveram a oportunidade de enriquecer seus conhecimentos através do estudo de uma disciplina importante nas áreas de ciências exatas e aplicadas. No entanto, como esperávamos, conseguimos atingir nosso objetivo (beneficiar "todos" os alunos) de maneira mais satisfatória com o grupo 1, pois percebemos que este grupo sempre mostrou mais interesse e, consequentemente, mais facilidade em aprender e aplicar o conhecimento adquirido. Assim, concluímos que é possível inserir o Cálculo Diferencial e Integral no ensino médio e que métodos similares ao que utilizamos com o grupo 1 poderão contribuir para qualidade do ensino da matemática no ensino médio, já que oferecem aos alunos um conhecimento mais rico e abrangente da matemática. 


\title{
Capítulo 1
}

\section{Metodologia Aplicada ao Grupo 1}

\begin{abstract}
Resumo
Neste capítulo, descreveremos a metodologia aplicada durante as aulas ministradas ao grupo 1. Essa experiência foi baseada em referenciais teóricos de visão construtivista. Sendo assim, a cada nova situação de aprendizagem, preocupou - se que o aluno construísse o seu conhecimento ativamente, participando do seu processo de síntese. Nosso objetivo aqui é que o aluno observe o Cálculo Diferencial e Integral como uma continuação dos conteúdos abordados no ensino médio. Ao se introduzir os principais assuntos do Cálculo Diferencial e Integral, como o estudo dos limites, derivadas e integrais teve - se como principal preocupação criar situações - problemas concretos, algumas relacionadas com o dia a dia, outras com aplicações em diversas áreas da ciência como o cálculo da velocidade e da aceleração em Física. Para introduzir o desenvolvimento dos nossos estudos, partiu - se dos conhecimentos prévios dos alunos, como por exemplo, o estudo da trigonometria, geometria e álgebra básica.
\end{abstract}

\subsection{Uma Visão geral sobre Cálculo Diferencial e Integral por meio de Aplicações no Cotidiano Social}

Cálculo é divertido, e é muito fácil; Eu não entendo porque tanto auê - Sam Einstein, bisneto de Einstein 
Introduzimos nossas atividades de maneira expositiva, apresentando algumas aplicações do Cálculo. Comentou-se que este tema está presente no trabalho desenvolvido por diversos profissionais, por meio de suas ferramentas de trabalho, lazer e organização socioeconômica.

Especificamente, debateu-se com os alunos um artigo publicado pela revista Cálculo, ver [10]. Durante a leitura do artigo foi possível observar a importância do Cálculo no cotidiano da empresa Ebasco, uma empresa de engenharia, responsável por projetar e construir unidades geradoras de eletricidade.

Este artigo apresenta exemplos práticos que mostram a importância do Cálculo na tomada de decisões. Os estudantes analisaram inúmeros dados baseados nos comentários de Michael Marchlik, conforme descrito pelo anexo 1. Verificou-se que o grupo percebeu a aplicabilidade indispensável do Cálculo Diferencial e Integral em diversos segmentos dessa empresa e que, um erro de cálculo pode ocasionar prejuízos financeiros e fatais à vida.

Logo, os alunos se conscientizaram sobre a importância dessa disciplina em diversos segmentos profissionais. Consequentemente notou-se o despertar da curiosidade nos alunos, o que motivou o estudo do Cálculo Diferencial e Integral.

Inicialmente, observou-se que, de uma forma geral, o Cálculo utiliza as regras e conhecimentos da geometria e da álgebra, conteúdos abordados no ensino médio com a finalidade de desenvolver ferramentas para a resolução de problemas mais complexos. Por exemplo, enquanto na matemática básica construímos gráficos de funções simples, como funções do $1^{\circ}$ e do $2^{\circ}$ grau, no cálculo conseguiremos esboçar gráficos mais complexos. No ensino básico conseguimos encontrar a área de diversas figuras geométricas planas, como o retângulo, o losango, o trapézio, entre outras, já com o desenvolvimento do cálculo diferencial e integral é possível criar métodos que nos auxiliam a encontrar a área de figuras irregulares.

Com a finalidade de apresentar aos alunos o Cálculo Diferencial e Integral como um avanço dos estudos da álgebra e da geometria, dois exemplos foram abordados.

Exemplo 1.1.1. Neste exemplo apresentou-se inicialmente aos alunos, a figura de um indivíduo empurrando uma caixa numa rampa com uma inclinação reta (Figura 1.1). 


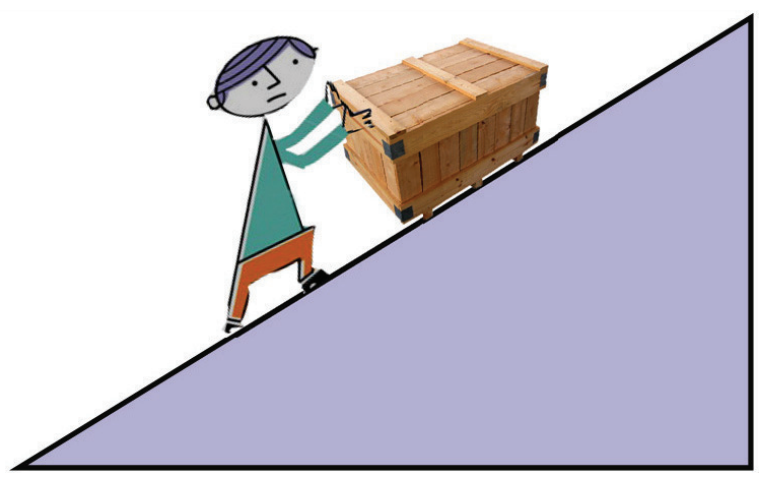

Figura 1.1: Problema de matemática regular.

Em seguida foi apresentada a figura de um indivíduo empurrando a mesma caixa numa rampa em que a inclinação não se apresentava de forma reta (Figura 1.2).

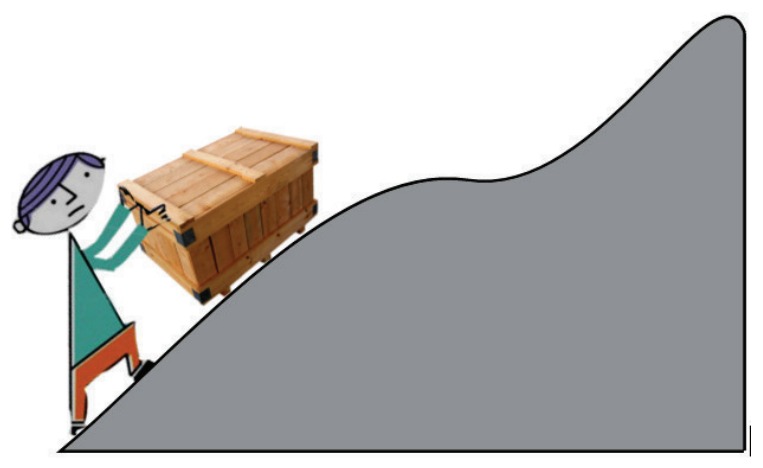

Figura 1.2: Problema de cálculo.

Solicitou-se que os alunos imaginassem que deveriam encontrar a quantidade de energia gasta pelo indivíduo para empurrar a caixa até o topo em cada uma das situações descritas acima.

Sabemos que, para qualquer pessoa que empurre um objeto, a força aplicada raramente é constante. Basta imaginar que o garoto que desloca a caixa na rampa com inclinação reta, pare por um instante para descansar. Assim, para voltar ao movimento, é preciso uma força maior do que para manter a caixa em deslocamento. Uma força que não se mantém constante é uma força variável.

Entretanto, para facilitar o raciocínio, supomos que a caixa na figura 1.1 se mova por meio de uma força constante, ou seja, a força é a mesma para qualquer tempo considerado. Diante dessa situação podemos calcular a energia gasta através de algumas fórmulas simples da Física e da 
Matemática Básica. Podemos até mesmo calcular quantas calorias de energia são necessárias para empurrar a caixa na rampa.

Em relação à situação representada pela Figura 1.2, a inclinação passa por mudanças, consequentemente, a força aplicada sobre caixa está constantemente mudando. Logo, a quantidade de energia gasta sofre alterações a todo o momento.

Para a situação descrita na Figura 1.2, os conhecimentos do ensino de Física básica não são suficientes para o cálculo da quantidade de energia gasta pelo individuo. No entanto, comentou-se com os alunos que o cálculo nos fornece ferramentas importantes, que tornam possível calcular a força aplicada pelo garoto em um instante exato de tempo. Com as definições e conceitos apresentados também será possível descobrir qual foi a energia total gasta durante todo o percurso.

Exemplo 1.1.2. Neste exemplo o problema apresentado foi o de calcular a área de dois telhados, conforme mostram as Figura 1.3 e 1.4 .

Usando a matemática básica, podemos calcular facilmente a área do telhado, expresso pela Figura 1.3, pois basta observar que o mesmo pode ser dividido em retângulos.

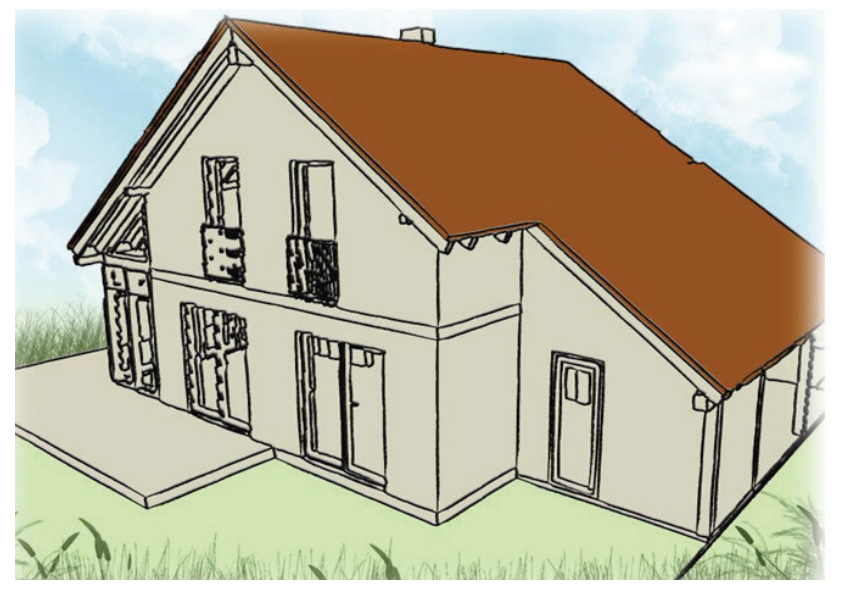

Figura 1.3: Calculando a área do telhado por meio da matemática básica.

Fonte:www.srv.br

Entretanto, a situação se complica quando temos telhados mais complexos, como o apresentado na Figura 1.4, mas com a aplicação do Cálculo, podemos obter a área deste e de muitos outros telhados.

A arquitetura da casa expressa pela Figura 1.4 foi desenvolvida por Fernando Carneiro, que utilizou-se de elementos curvos, com destaque para o telhado. Para a sua construção, foi necessário 


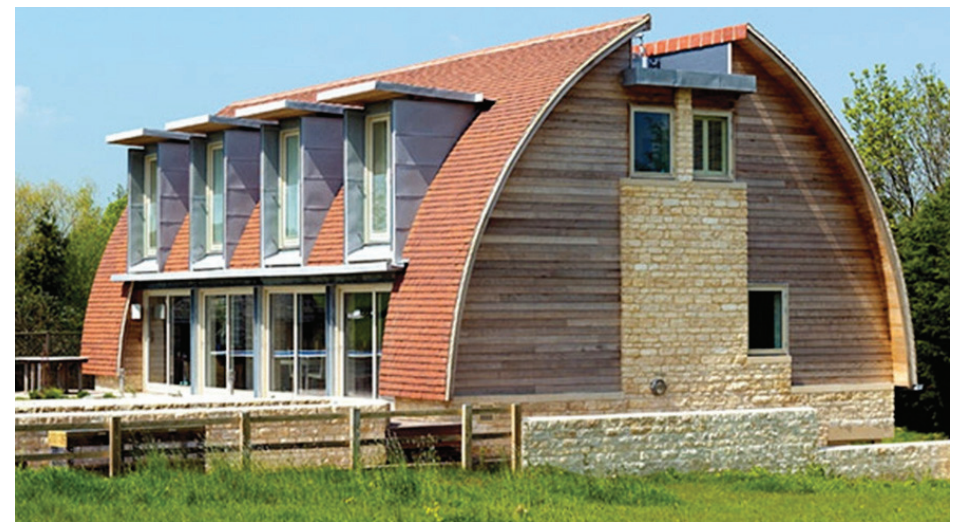

Figura 1.4: Determinando a área de um telhado usando cálculo.

Fonte:www.dicassobre.com.br/modelos-de-telhados

saber a área do telhado para determinar o custo de materiais e para descobrir o seu peso. E é o Cálculo Diferencial e Integral que proporciona conhecimento para que o arquiteto consiga encontrar a área do telhado.

Os exemplos apresentados acima mostram a importância da matemática em práticas profissionais importantes para a sociedade, como na engenharia civil e na arquitetura. Logo, refletem uma pequena amostra da aplicabilidade do Cálculo em benefício de todos.

Após o desenvolvimento desses exemplos, introduzimos os principais conceitos do Cálculo Diferencial e Integral.

\subsection{Noções de Limite}

Iniciamos o estudo do Cálculo através do conceito de limite, pois grande parte dos conceitos importantes, como por exemplo, o de derivada, continuidade, integral, convergência e divergência são definidos a partir do estudo de limites. Antes de apresentarmos a definição de limite, desenvolveu-se o exemplo 1.2.1. Nosso objetivo foi explorar a importância do lúdico na construção do conhecimento defendida por Baquero, ver [4].

\section{Exemplo 1.2.1 (Introdução à Noção de Limite).}

Este exemplo foi apresentado aos alunos através de uma atividade prática. Utilizando uma fita métrica, solicitou-se que os alunos medissem o tamanho do azulejo do chão da sala de aula. Os alunos constataram que o piso possuía 1 metro de comprimento por 1 metro de largura. Em 
seguida, com o uso de papel crepom azul, solicitou-se que preenchessem metade do azulejo, conforme a Figura 1.5.

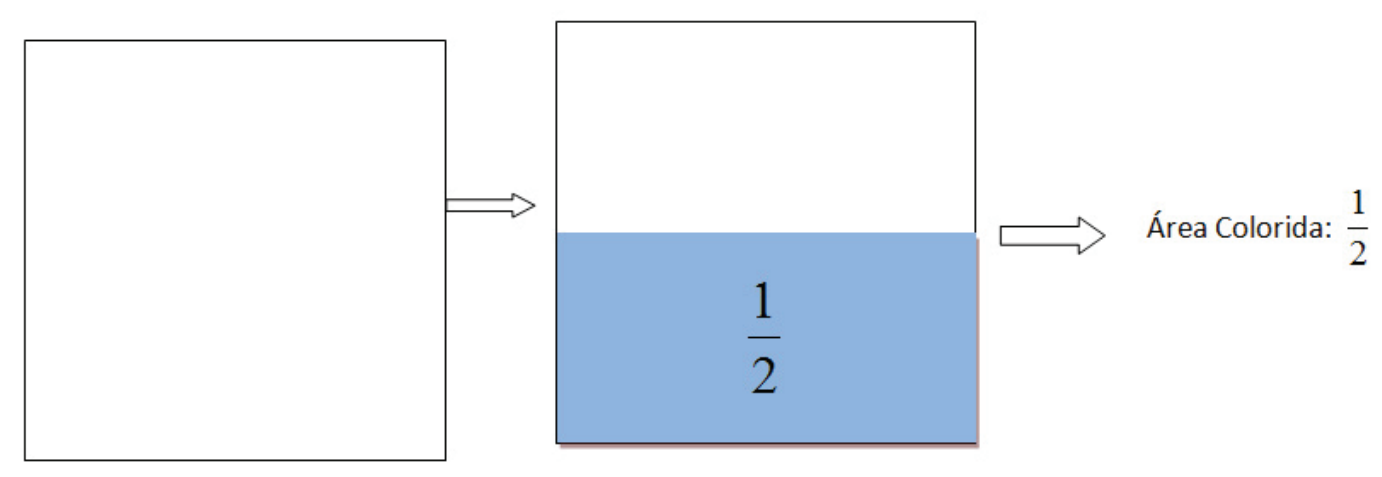

Figura 1.5: Preenchimento de metade do piso.

Feito isso, o professor propôs que os alunos colorissem de amarelo, a metade do azulejo que ficou em branco. Constatou-se que a área total preenchida foi de $\frac{3}{4}$, conforme ilustrado pela Figura 1.6.

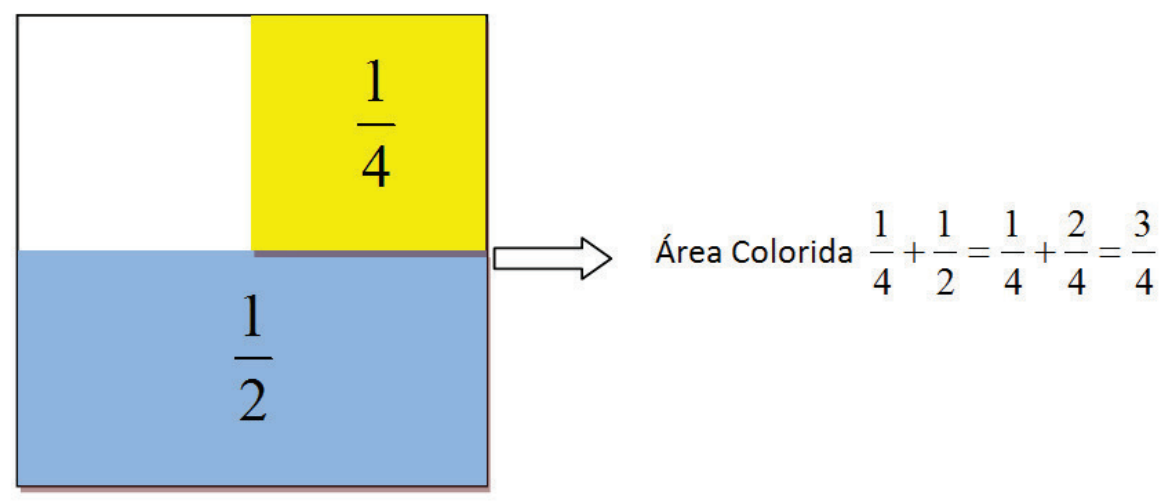

Figura 1.6: Preenchimento de $\frac{3}{4}$ do piso.

Em seguida, o professor solicitou aos alunos que colorissem de vermelho, a metade do azulejo que restou em branco. Assim, os estudantes verificaram que já haviam preenchido $\frac{7}{8}$ do piso. Conforme ilustrado pela Figura 1.7.

Posteriormente, questionou-se aos alunos o que aconteceria se continuássemos preenchendo a metade da parte branca que estava sobrando. Em um primeiro momento os alunos comentaram que iríamos conseguir preencher todo o quadrado. Diante da resposta apresentada o professor expôs a seguinte situação descrita abaixo: 


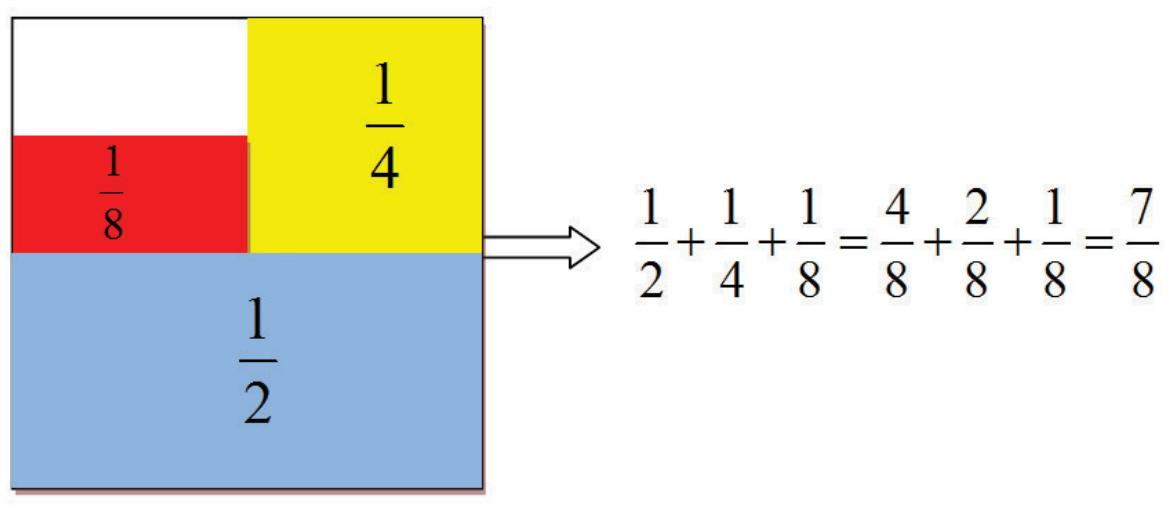

Figura 1.7: Preenchimento de $\frac{7}{8}$ do piso.

1) $\frac{1}{2}=0,5$ - situação exposta na Figura 1.5;

2) $\frac{1}{2}+\frac{1}{4}=\frac{3}{4}=0,75$ - situação exposta na Figura 1.6;

3) $\frac{3}{4}+\frac{1}{8}=\frac{7}{8}=0,875$ - situação exposta na Figura 1.7 .

Se continuássemos o processo acima teríamos:

4) $\frac{1}{2}+\frac{1}{4}+\frac{1}{8}+\frac{1}{16}=\frac{15}{16}=0,9375$;

5) $\frac{1}{2}+\frac{1}{4}+\frac{1}{8}+\frac{1}{16}+\frac{1}{32}=\frac{31}{32}=0,96875$;

6) $\frac{1}{2}+\frac{1}{4}+\frac{1}{8}+\frac{1}{16}+\frac{1}{32}+\frac{1}{64}=\frac{63}{64}=0,984375$.

Os alunos notaram claramente que a área que estávamos preenchendo estava se aproximando de $1 m^{2}$. No entanto, continuando a atividade, pediu-se que os alunos observassem através dos itens de 1 a 6 que obtivemos a seguinte sequência: $\frac{1}{2}, \frac{3}{4}, \frac{7}{8}, \frac{15}{16}, \frac{31}{32}, \frac{63}{64}, \ldots$ e questionou-se a possibilidade deles descobrirem quais seriam as próximas frações, sem a utilização de um aparelho eletrônico.

Os alunos verificaram, primeiramente, que o numerador é menor do que o denominador em apenas uma unidade. Em seguida dois estudantes observaram que o denominador representava potências de base 2. A partir desse comentário, todos os integrantes do grupo conseguiram descobrir a sequência numérica, representada abaixo.

$$
\frac{1}{2}, \frac{3}{4}, \frac{7}{8}, \frac{15}{16}, \frac{31}{32}, \frac{63}{64}, \frac{127}{128}, \frac{255}{256}, \frac{511}{512}, \frac{1023}{1024}, \ldots
$$

Então, o professor questionou o grupo sobre o que aconteceria se continuássemos essa sequência numérica de forma sucessiva. Todos os integrantes do grupo, em um primeiro instante, perceberam 
que seria impossível obter uma fração igual a 1, já que o numerador é sempre menor que o denominador em 1 unidade. Consequentemente, observaram que a área da região colorida se aproxima de 1 sem, no entanto, assumir esse valor. Finalmente, comentamos, que no caso exemplificado acima, o "limite" dessa soma é igual a 1.

De forma satisfatória, o grupo conseguiu compreender o significado do termo "limite" no uso matemático.

Com a intenção de passar essa ideia lúdica para uma linguagem matemática, apresentou-se aos alunos a noção de limites através de representação gráfica e de tabelas.

\subsubsection{Fixando a Noção de Limite}

No cálculo e suas aplicações, é importante estudar o comportamento das funções em torno de determinados números do seu domínio ou de valores que não estão em seu domínio. Com o objetivo de relacionar o conceito de limite a partir de uma representação gráfica desenvolveu-se o seguinte exemplo:

Exemplo 1.2.2. Dada a função $f(x)=x+2$, solicitou-se que o grupo atribuísse valores a $x$, para avaliar o comportamento dessa função. Para essa análise, escolhemos de forma aleatória $x=4$. Logo estudou-se o comportamento dessa função quando $x$ se aproxima de 4 , tanto pela direita quanto pela esquerda, conforme ilustrado pela Tabela 1.1.

Tabela 1.1: Valores de $f(x)$, quando $x$ se aproxima de 4

\begin{tabular}{llllllllllll}
\hline \multicolumn{4}{c}{$x$ se aproxima de 4 pela esquerda } & \multicolumn{5}{c}{$x$ se aproxima de 4 pela direita } \\
\hline$x$ & 3,8 & 3,9 & 3,92 & 3,99 & 3,9991 & $\mathbf{4}$ & 4,002 & 4,003 & 4,05 & 4,07 & 4,1 \\
$y=f(x)$ & 5,8 & 5,9 & 5,92 & 5,99 & 5,991 & $\mathbf{6}$ & 6,002 & 6,003 & 6,05 & 6,07 & 6,1 \\
$y=f(x)$ & & & &
\end{tabular}

Assim os alunos perceberam que, à medida que $x$ se aproxima de $4, f(x)$ se aproxima de 6 . Com a intenção de que os estudantes tivessem uma visão mais precisa sobre o comportamento de $f(x)$ quando $x$ tende a 4 , os alunos esboçaram o gráfico de $f(x)$ conforme expresso na Figura 1.8. 


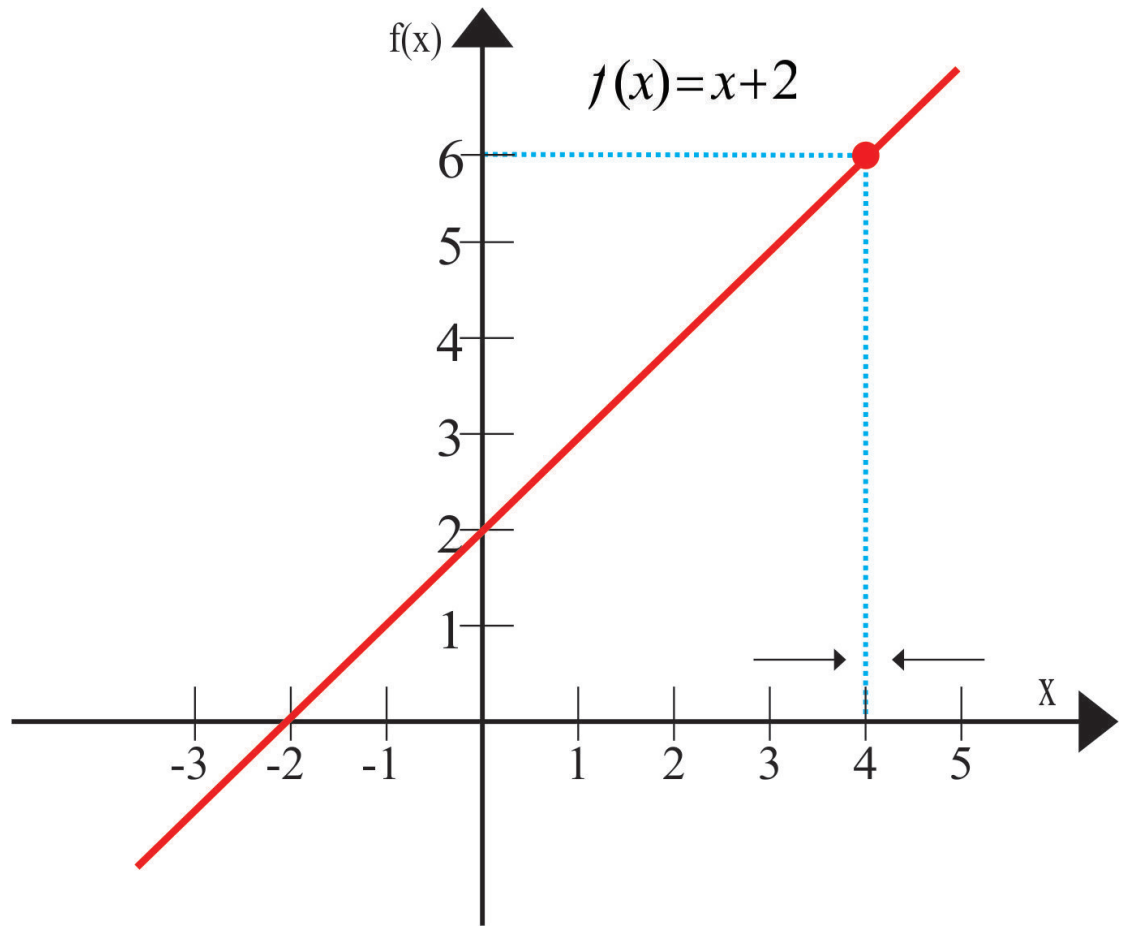

Figura 1.8: Gráfico de $f(x)=x+2$.

A partir da análise da Tabela 1.1 e da Figura 1.8, concluímos que à medida que $x$ se aproxima de 4 , pela esquerda ou pela direita, $f(x)=y$ se aproxima de 6 . Assim, o grupo comentou que o limite de $f(x)=x+2$ quando $x$ está bem próximo de 4 é igual a 6 . Para representarmos essa situação em linguagem matemática, utilizamos a seguinte notação.

$$
\lim _{x \rightarrow 4}(x+2)=6
$$

Os alunos observaram que, neste exemplo, bastaria colocar o 4 no lugar de $x$ e a situação estaria resolvida. Entretanto, existem algumas situações em que não basta substituir o valor de $x$ na expressão que define o limite, como veremos no próximo exemplo.

Exemplo 1.2.3. Inicialmente, a turma foi desafiada a fazer uma análise sobre o comportamento de $g(x)=\frac{x^{2}-2 x-8}{x-4}$, quando $x$ se aproxima de 4 , tanto pela esquerda quanto pela direita. Para obter mais agilidade nos cálculos, utilizou-se a planilha eletrônica do software Excel, conforme mostra a Tabela 1.2. 
Tabela 1.2: Comportamento da função quando $x$ se aproxima de 4

\begin{tabular}{|c|c|c|c|c|c|c|c|c|c|c|c|}
\hline \multicolumn{6}{|c|}{$x$ se aproxima de 4 pela esquerda } & \multicolumn{6}{|c|}{$x$ se aproxima de 4 pela direita } \\
\hline$x$ & 3 , & 3 , & 3,9 & 30 & . & 4 & 4,002 & 4,003 & 5 & 4,07 & 1 \\
\hline$J(x)$ & 5,8 & 5 , & 5,92 & 5,99 & 5,991 & \# DIV/0! & 2 & 3 & 6 , & 6,07 & 6,1 \\
\hline \multicolumn{6}{|c|}{ aproxima de 6 pela esquerda } & \multicolumn{6}{|c|}{$y=f(x)$ se aproxima de 6 pela direita } \\
\hline
\end{tabular}

Observou-se pela tabela 1.2 que o programa Excel não divulgou o resultado para $x=4$. Isto foi facilmente compreendido pelos alunos, pois constataram que ao substituirem $x=4 \mathrm{em} g$ teriam como solução $g(4)=\frac{0}{0}$, e como sabemos, não é possível realizar uma divisão por zero.

Em seguida, foi apresentado o gráfico dessa função com o objetivo de que os alunos observassem o comportamento de $g(x)$ próximo de $x=4$, conforme mostra a Figura 1.9.

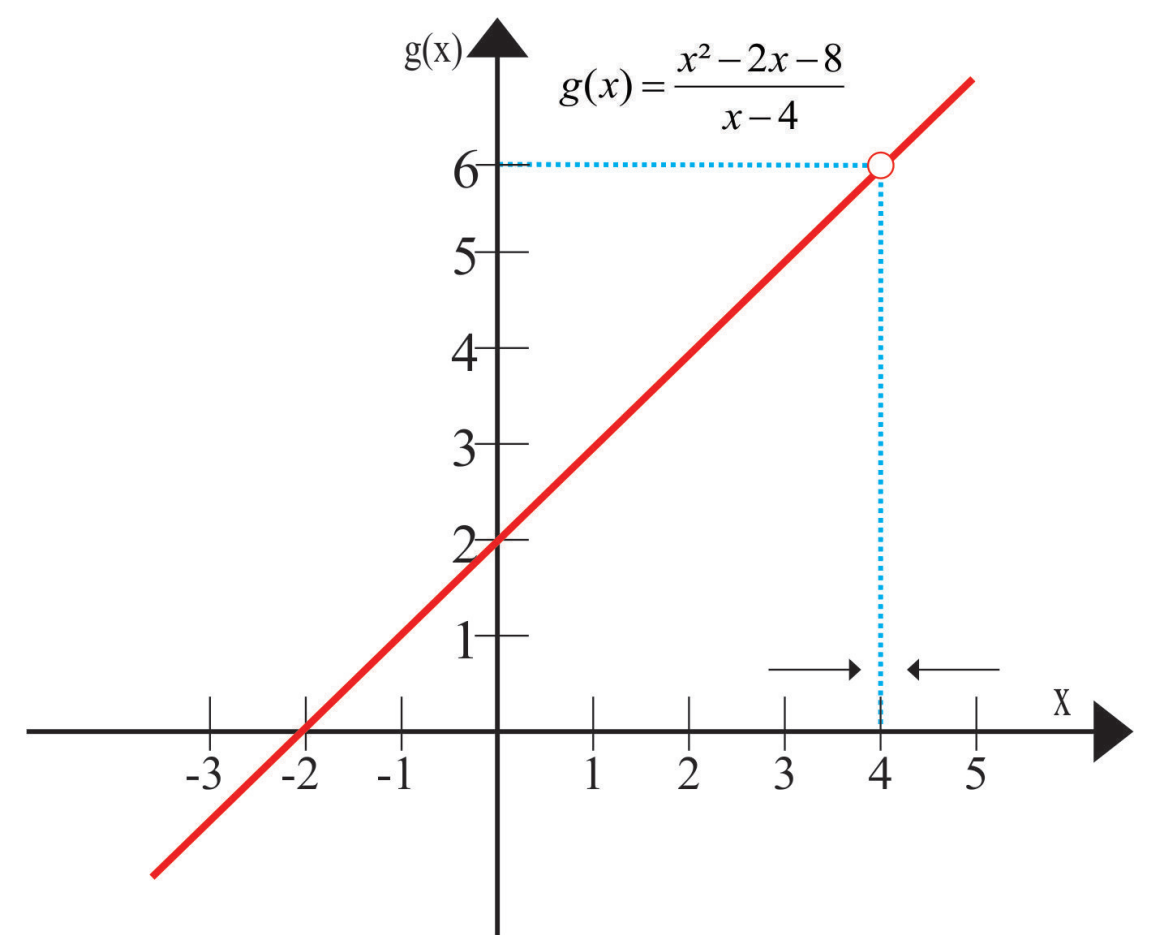

Figura 1.9: Plotagem do gráfico da função $g(x)$.

Para o esboço da função $g(x)$, utilizou-se o software Geogebra, pois os alunos, até esse exato momento, não possuem conhecimento adquirido sobre como desenhar manualmente gráficos de funções racionais e também pela agilidade que se adquire na aula com o uso da tecnologia. 
Com o desenvolvimento dessa situação de aprendizagem, os alunos observaram que a função $g(x)$ é idêntica à função do exemplo 1.2.2, exceto pela interrupção que existe no ponto $(4,6)$. Ou seja, $f(x)$ tem como domínio todos os números reais, enquanto $g(x)$ tem como domínio $\mathbb{R}-\{4\}$. Os alunos também perceberam que, apesar de $g(x)$ não estar definida em $x=4$, o seu limite quando $x$ tende a 4 existe.

Posteriormente, o professor pediu que os alunos observassem que não poderiam calcular o $\lim _{x \rightarrow 4} g(x)$ substituindo $x=4$, pois $g(4)$ não está definida. Porém, ao analisar a função $g$ é fácil verificar que $x=4$ é raiz do polinômio do numerador e do denominador, visto que $g(4)=\frac{0}{0}$. Diante dessa explicação, os alunos perceberam que o numerador e o denominador têm um fator comum, que é $x-4$ e poderiam reescrever o limite de $g(x)$ como:

$$
\lim _{x \rightarrow 4} \frac{x^{2}-2 x-8}{x-4}=\lim _{x \rightarrow 4} \frac{(x-4)(x+2)}{(x-4)}
$$

Assim, o professor complementou que ao calcular o limite quando " $x$ tende a 4", temos que $x-4 \neq 0$ e, assim, $x \neq 4$. Portanto, podemos cancelar o fator comum e calcular o limite, como segue:

$$
\lim _{x \rightarrow 4} \frac{(x-4)(x+2)}{(x-4)}=\lim _{x \rightarrow 4}(x+2)=4+2=6 .
$$

O objetivo principal dessa atividade foi mostrar aos alunos que o limite de uma função pode existir em um determinado número, mesmo que a função não esteja definida neste número. Como vimos em $g(x)$, a função não está definida para $x=4$, porém o que nos interessa é o que está acontecendo nas proximidades desse número.

Para reforçar que, ao estudar limites, temos que observar o que acontece ao redor de um determinado número, elaborou-se o seguinte exemplo.

Exemplo 1.2.4. Nesse exemplo solicitou-se que os alunos imaginassem o que aconteceria se tivéssemos uma função $h(x)$ igual à função $f(x)$ do exemplo 1.2.2, entretanto com o ponto $(4,6)$ movido para $(4,3)$, ou seja,

$$
h(x)= \begin{cases}x+2 & , x \neq 4 \\ 3 & , x=4\end{cases}
$$

conforme ilustrado pela Figura 1.10. 


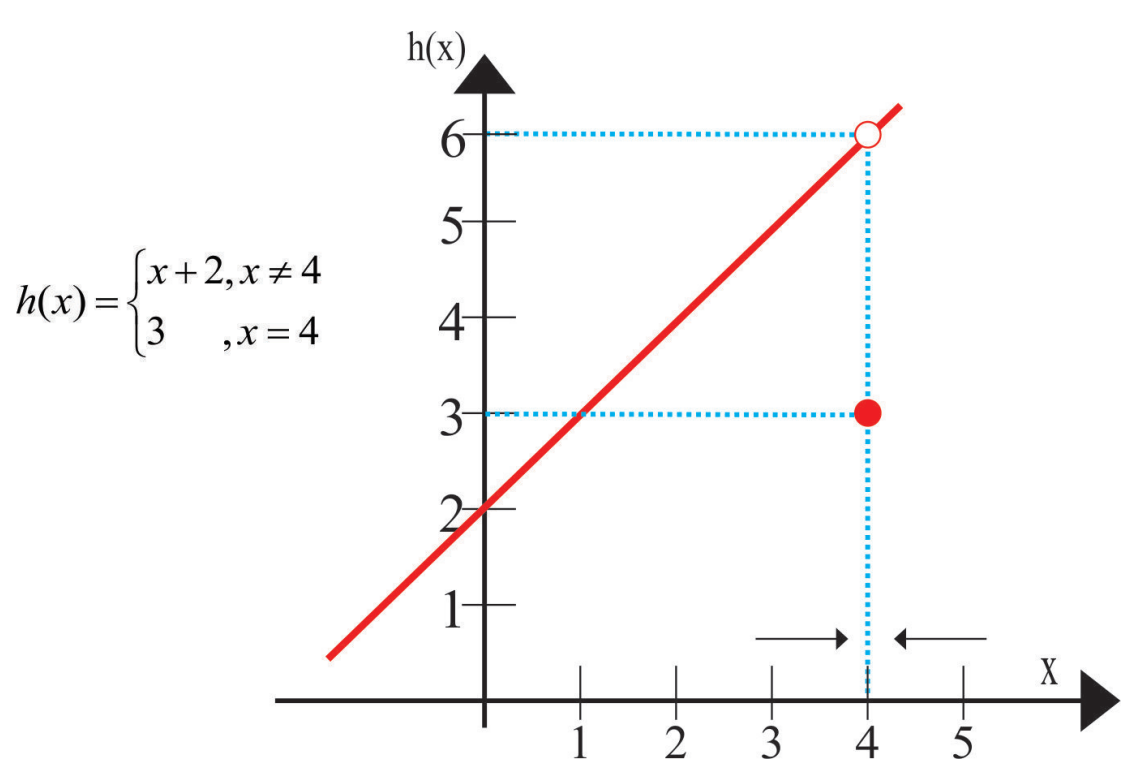

Figura 1.10: O gráfico de $h(x)$.

Se analisarmos o comportamento de $h(x)$ na proximidade de $x=4$, pela esquerda ou pela direita, $h(x)$ se aproxima de 6 , ou seja, $\lim _{x \rightarrow 4} h(x)=6$, no entanto, $h(4)=3$.

Para finalizar, o professor fez algumas observações, comparando os resultados nos exemplos 1.2.2, 1.2.3 e 1.2.4, como segue:

1) no Exemplo 1.2.2 temos que $f(4)=6$ e $\lim _{x \rightarrow 4} f(x)=6$;

2) no Exemplo 1.2.3 temos que $g(4)$ não está definida e $\lim _{x \rightarrow 4} g(x)=6$;

3) no Exemplo 1.2.4 temos que $h(4)=3$ e $\lim _{x \rightarrow 4} h(x)=6$.

Diante dessas observações, o grupo percebeu que ao estudar limites, a ideia fundamental é que se analise o comportamento nas proximidades desse ponto, mesmo que a função não esteja definida no mesmo.

No desenvolvimento das atividades contidas nos três exemplos acima, houve uma boa participação de todos os alunos. Ressalta-se que foi feito o uso de diferente material tecnológico existente na escola, como por exemplo softwares, gráficos e planilhas eletrônicas. Os alunos deixaram de se preocupar em desenvolver cálculos, passando a valorizar o debate do comportamento de um ponto em uma dada função, concomitantemente com a análise das tabelas apresentadas. 


\subsubsection{Limites Laterais}

Para introduzir o estudo dos limites laterais, o professor comentou que, estudar o comportamento de uma função ao redor de um número, tanto pela esquerda ou pela direita, é o que chamamos de limites laterais. Para indicá-los, usamos a notação $\lim _{x \rightarrow a^{+}} f(x)$ para o limite pela direita, indicando que $x$ se aproxima de $a$ pela direita e $\lim _{x \rightarrow a^{-}} f(x)$ para o limite pela esquerda, indicando que $x$ se aproxima de $a$ pela esquerda.

Para que fosse possível justificar a importância do estudo de limites laterais, desenvolveu-se o seguinte exemplo, elaborado a partir de uma situação fictícia.

Exemplo 1.2.5. Propôs-se que um dos integrantes do grupo imaginasse que conquistou uma vaga de estágio na USP, no setor de almoxarifado, como responsável pelo controle de papel para fotocópias, para facilitar o seu trabalho, o estagiário desenvolveu um gráfico que expressa o nível do estoque de papel num período de 60 dias, dado que a cada 20 dias se fazia uma encomenda de 500 resmas, conforme mostra a Figura 1.11.

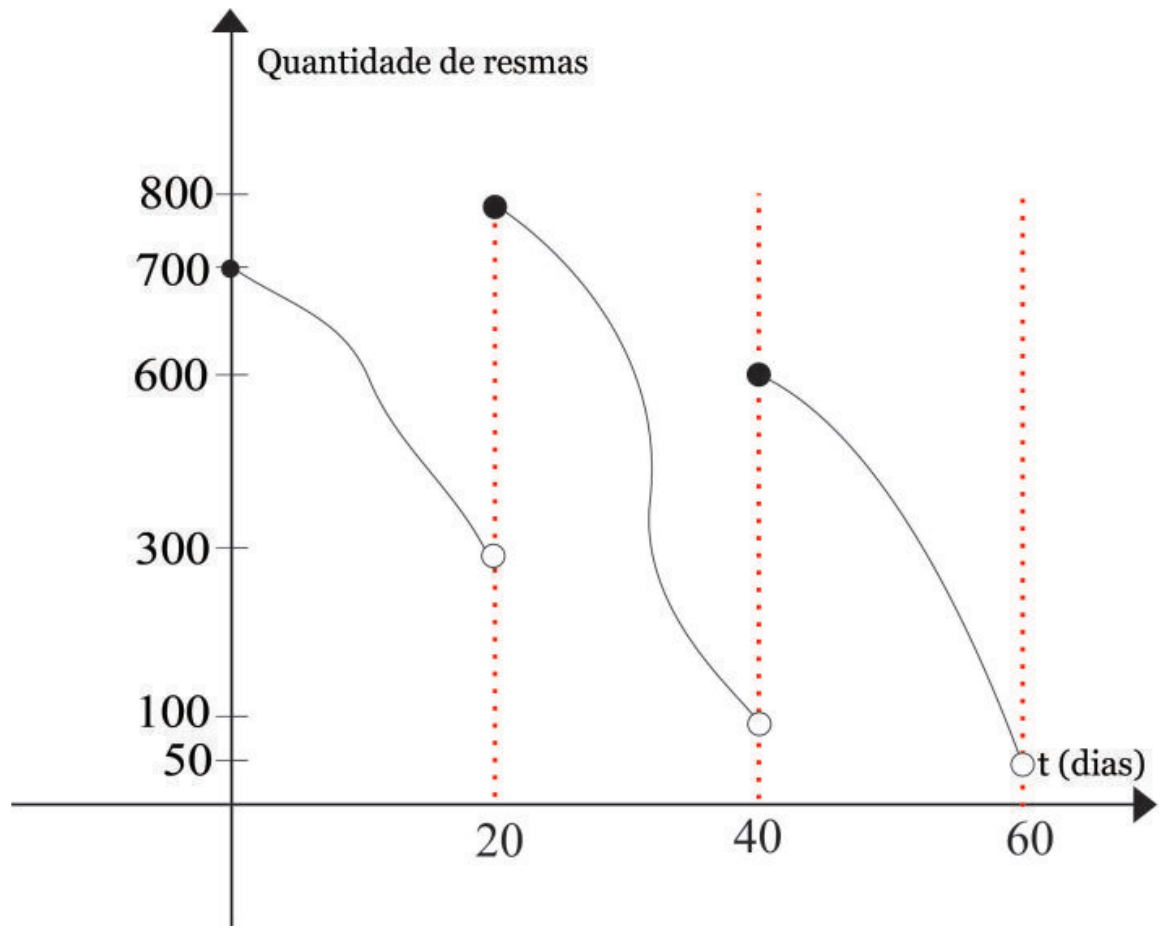

Figura 1.11: Quantidade de resmas em função do tempo. 
Para que os alunos percebessem que o limite de uma função só existe quando os seus limites laterais também existem e são iguais, solicitou-se que estudassem o comportamento da função ilustrada na Figura 1.11, no momento em que $t=20, t=40$ e $t=60$.

De forma satisfatória, comentou-se que, à medida que $t$ se aproxima de 20 dias, a quantidade de resmas se aproxima de 300. Matematicamente escrevemos $\lim _{t \rightarrow 20^{-}} f(t)=300$. Como a cada 20 dias o estoque era reabastecido com 500 resmas, no vigésimo dia haveria 800 resmas em estoque. Logo, ao analisarmos o comportamento da função próximo ao ponto $t=20$, pela direita, detectamos uma quantidade próxima de 800 resmas de papéis. Matematicamente escrevemos $\lim _{t \rightarrow 20^{+}} f(t)=800$.

A forma como essa situação de aprendizagem foi descrita ajudou os estudantes a perceberem que, nas proximidades do ponto $t=20$, os limites laterais são diferentes, ou seja, $\lim _{t \rightarrow 20^{+}} f(t)=800 \neq$ $\lim _{t \rightarrow 20^{-}} f(t)=300$. De forma intuitiva, o grupo concluiu que o limite da função, quando estudado em $t=20$, não existe. De forma análoga analisou-se os pontos $t=40$ e $t=60$.

Posteriormente, retomou-se a Figura 1.10, apresentada no exemplo 1.2.4, com o intuito de que o aluno fizesse uma comparação com a situação desenvolvida no exemplo 1.2.5. Analisando as duas situações, apresentadas pela Figura 1.10 e Figura 1.11, foi possível observar a importância dos limites laterais para a existência do limite, visto que na primeira situação o limite da função na proximidade do ponto $x=4$ tende sempre a 6 , seja pela esquerda ou pela direita, chegando-se à conclusão de que o limite da função existe para $x=4$. Já na segunda situação dizemos que o limite não existe para $t=20$, visto que seus limites laterais são diferentes.

Matematicamente, dado $q(x)$ uma função qualquer e $a, L \in \mathbb{R}$, dizemos que o limite dessa função no ponto $a$ existe e escrevemos $\lim _{x \rightarrow a} q(x)=L$, se os seus limites laterais existirem e forem iguais. Em outras palavras, $\lim _{x \rightarrow a^{-}} q(x)=\lim _{x \rightarrow a^{+}} q(x)$.

Em seguida, optamos por introduzir o estudo de continuidade, com a finalidade de apresentar uma ideia básica sobre os termos "continuidade" e "descontinuidade" a partir do Exemplo 1.2.5, desenvolvido acima.

\subsubsection{Noção de Continuidade}

O termo continuidade em matemática tem correspondência semelhante ao seu termo popular, ou seja, um processo é contínuo quando não existem interrupções.

Para introduzir o estudo das funções contínuas, bem como sua definição retomamos a situação 
ilustrada no Exemplo 1.2.5, da seção anterior.

Analisando o gráfico apresentado na Figura 1.11 a primeira situação observada foi que quando atingimos o ponto $(20,300)$ existe uma interrupção na curva da função e passamos a obter o ponto $(20,800)$. Neste caso dizemos que a função é descontínua em $t=20$. Em outras palavras, quando nos aproximamos de 20 dias, a quantidade de resmas de papéis se aproxima a uma quantidade de 300, e quando atingimos o vigésimo dia passamos a ter 800 resmas de papéis. De forma análoga é possível perceber que há descontinuidade em $t=40$ e $t=60$.

Após introduzir a noção intuitiva de continuidade e descontinuidade, desenvolveu-se o exemplo abaixo. Iniciou-se essa atividade com a exposição do gráfico de quatro funções. Durante a abordagem sobre o comportamento dessas funções, apresentou-se a definição formal de continuidade e algumas conclusões, que os alunos obtiveram de forma independente.

Exemplo 1.2.6 (Continuidade e Descontinuidade de Funções). Expôs-se à turma, com o uso de um projetor, quatro funções com seus respectivos gráficos, conforme ilustra a Figura 1.12.

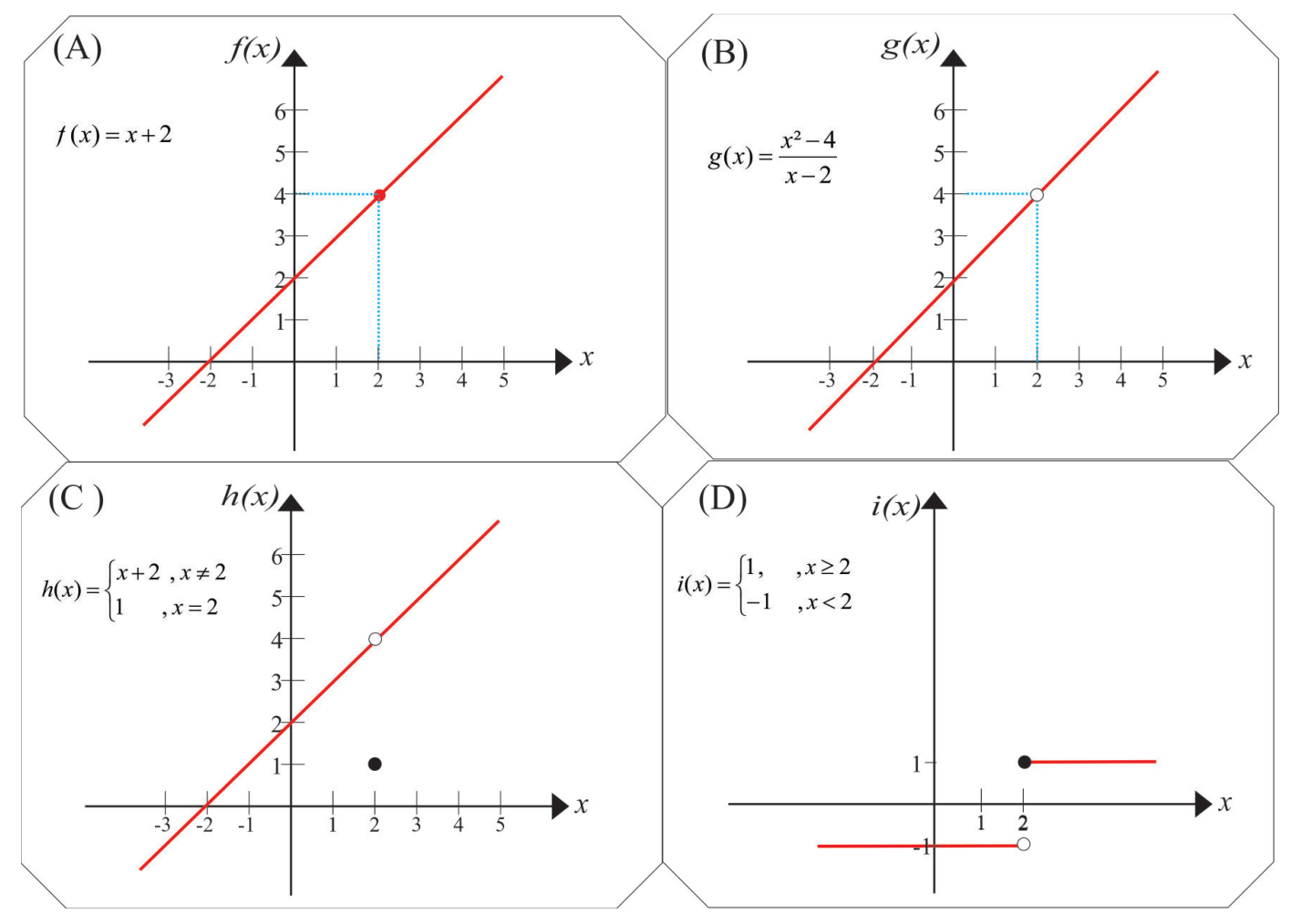

Figura 1.12: Os gráficos de $f(x), g(x), h(x)$ e $i(x)$. 
Em seguida, solicitou-se que os alunos observassem cada uma das funções, em especial, nas proximidades do ponto $x=2$.

Ao observar a função $f(x)=x+2$, na Figura 1.12 (A) foi constatado que a mesma não tem interrupções. De forma natural, os alunos comentaram que essa função é contínua em todo o seu domínio, sem conhecerem a definição formal de continuidade.

Quanto à $g(x)=\frac{x^{2}-4}{x-2}$, esquematizada pela Figura $1.12(\mathrm{~B})$, percebeu-se que essa função não está definida para $x=2$. Porém, pediu-se que o grupo calculasse o seu limite na proximidade desse ponto.

Ao resolver os limites laterais observou-se que $\lim _{x \rightarrow 2^{-}} g(x)=4$ e $\lim _{x \rightarrow 2^{+}} g(x)=4$. Ou seja, os limites laterais de $g(x)$ existem e são iguais. Logo $\lim _{x \rightarrow 2} g(x)=4$. Outro fato que foi de fácil percepção aos alunos é que $g(2)$ não está definido, simplesmente, pela condição de existência apresentada na função racional.

Após os comentários feitos para a função $g(x)$ os alunos perceberam que existe uma interrupção em $x=2$ e, portanto, concluíram que em $x=2$ existe uma descontinuidade. Dentro desse contexto apresentou-se a definição formal de continuidade.

Uma função é contínua em um ponto $a$ se o $\lim _{x \rightarrow a} g(x)=g(a)$.

Após obterem o conhecimento sobre a definição, o grupo constatou que $\lim _{x \rightarrow 2} g(x) \neq g(2)$. Sendo assim, puderam confirmar a descontinuidade que existe no ponto $x=2$.

O mesmo estudo foi feito para a função

$$
h(x)= \begin{cases}x+2 & , x \neq 2 \\ 1 & , x=2\end{cases}
$$

da Figura 1.12 (C). Cada integrante do grupo analisou essa função ao redor do ponto $x=2$, e observaram que $\lim _{x \rightarrow 2} h(x)=4$, porém $h(2)=1$, ou seja, $\lim _{x \rightarrow 2} h(x) \neq h(2)$. Com isso, os alunos concluíram que $h(x)$ é descontínua no ponto $x=2$. Por uma observação gráfica, observaram que a função é contínua para todos os demais pontos.

Por fim, solicitou-se que os alunos estudassem a continuidade de

$$
i(x)=\left\{\begin{aligned}
1 & , x \geq 2 \\
-1 & , x<2
\end{aligned}\right.
$$

da Figura 1.12 (D) ao redor do ponto $x=2$. 
Ao solucionarem o cálculo do $\lim _{x \rightarrow 2} i(x)$ verificou-se que esse limite não existe, pois $\lim _{x \rightarrow 2^{-}} i(x)=-1$ e $\lim _{x \rightarrow 2^{+}} i(x)=+1$. Como o limite da função não existe, já que seus limites laterais são diferentes, concluiu-se que a função apresenta uma descontinuidade no ponto $x=2$.

Posteriormente, o professor comentou com o grupo sobre algumas situações cotidianas que se apresentam contínuas. Como exemplo, podemos citar o tempo. De $9 h$ para $9 h 01$ o tempo se mantém contínuo, não existe uma interrupção nesse momento. Deixando cair um objeto do alto de um prédio, encaramos o seu movimento como contínuo. Outro exemplo citado refere-se aos fenômenos físicos que são geralmente contínuos, aos quais podemos perceber que o deslocamento e a velocidade de um veículo variam continuamente com o tempo.

Por último, apresentamos ao grupo um exemplo para fixar a compreensão sobre a definição formal de continuidade.

Exemplo 1.2.7. Determine $a$ para que a função

$$
w(x)= \begin{cases}\frac{x^{2}-5 x+6}{x-2} & , x \neq 2 \\ a & , x=2\end{cases}
$$

seja contínua em $x=2$.

Ao aplicar essa atividade esperava-se que os alunos a realizassem sem o auxílio do professor e esse objetivo foi atingido com êxito. Os alunos observaram primeiramente que $w(2)=a$ e para que $w(x)$ fosse contínua deveríamos ter $\lim _{x \rightarrow 2} w(x)=w(2)$.

Ao resolverem $\lim _{x \rightarrow 2} w(x)$, os alunos perceberam que a função $w(x)=\frac{x^{2}-5 x+6}{x-2}$ não está definida para $x=2$. Sendo assim, observaram que poderiam simplificar a fração racional de $w(x)$, visto que $x=2$ é raiz do polinômio do numerador e do denominador. Logo, obtiveram

$$
\lim _{x \rightarrow 2} \frac{x^{2}-5 x+6}{x-2}=\lim _{x \rightarrow 2} \frac{(x-2)(x-3)}{(x-2)}=\lim _{x \rightarrow 2}(x-3)=-1 .
$$

Ou seja, $\lim _{x \rightarrow 2} w(x)=-1$ e $w(2)=a$. Pela definição de continuidade sabemos que $\lim _{x \rightarrow 2} w(x)=$ $w(2)$, logo concluíram que, para que $w(x)$ seja contínua em $x=2$, devemos ter $a=-1$.

No exemplo acima constatou-se que os alunos compreenderam de maneira eficiente os conceitos até aqui apresentados, pois conseguiram de forma independente utilizar as técnicas para a determinação de limites, e não apresentaram dificuldade em estudar a continuidade e descontinuidade de uma função em um determinado número. 


\subsubsection{Propriedades dos Limites}

Introduzimos esse tópico comentando com o grupo que muitas funções podem ser expressas como somas, diferenças, produtos e quocientes de outras funções e que muitas vezes precisamos calcular os limites das mesmas.

Apresentamos essas propriedades sem expor uma demonstração formal, apenas as enunciamos, seguidas de um exemplo numérico. Enfatizamos ao grupo que essas propriedades são válidas desde que seus limites existam.

1) O limite da soma (diferença) é a soma (diferença) dos limites.

$$
\lim _{x \rightarrow 2}\left(x^{2}+4 x-5\right)=\lim _{x \rightarrow 2} x^{2}+\lim _{x \rightarrow 2} 4 x-\lim _{x \rightarrow 2} 5=4+8-5=7
$$

2) O limite de um produto é o produto dos limites.

$$
\lim _{x \rightarrow 2}\left[x^{2}(x-1)^{2}\right]=\lim _{x \rightarrow 2} x^{2} \cdot \lim _{x \rightarrow 2}(x-1)^{2}=4.1=4
$$

3) O limite do quociente é o quociente dos limites (desde que o limite do denominador não seja zero).

$$
\lim _{x \rightarrow 2} \frac{x^{2}}{\left(x-1^{2}\right)}=\frac{\lim _{x \rightarrow 2} x^{2}}{\lim _{x \rightarrow 2}(x-1)^{2}}=\frac{4}{1}=4
$$

4) O limite de uma constante multiplicando uma função é a constante multiplicando o limite desta função.

$$
\lim _{x \rightarrow 2}\left(100 x^{2}\right)=100 . \lim _{x \rightarrow 2} x^{2}=100.4=400
$$

Para finalizar, apresentamos uma lista de atividades envolvendo o cálculo de limites. Com a correção desses exercícios foi possível detectar que os alunos conseguiram utilizar de forma eficiente as propriedades dos limites.

\subsubsection{Limites Envolvendo Infinito}

Até este momento os alunos tiveram contato com limites da forma $\lim _{x \rightarrow a} f(x)=L$, onde $a \in \mathbb{R}$ e $L \in \mathbb{R}$, ou seja, o limite é um número real e $x$ também tende a um número real. Entretanto, existem situações em que $x$ ou $f(x)$ irão crescer ou decrescer indefinidamente. Nesse contexto foi introduzida a noção de limite infinito e limite no infinito. 
Ao desenvolver o estudo de limites envolvendo infinito optamos por relacioná-los com a definição de assíntotas verticais e horizontais, conceitos fundamentais na construção de gráficos. Acreditamos que ao introduzir o estudo de limites, envolvendo infinito simultaneamente com a noção de assíntotas, a aprendizagem se torna mais eficaz.

Inicialmente, apresentou-se ao grupo o significado do termo "infinito", visto que esse conceito é pouco discutido no ensino básico. O professor comentou com os alunos que o "infinito", representado pelo símbolo $\infty$, causou muita discussão e polêmica pelos matemáticos, físicos, filósofos e teólogos na antiguidade. Vários estudiosos tentaram compreender o significado desse termo, mas não obtiveram grande êxito.

Para que os alunos tivessem uma noção sobre o significado da palavra "infinito", debateu-se com o grupo o seguinte trecho de uma matéria jornalística, divulgada pela revista Super Interessante; Veja [13].

...dois meninos estão discutindo na escola. Coisa de criança, mas não para eles. Após um impasse, um deles resolve expressar uma opinião forte: "Você é bobo". O outro não pode se ver atrás. "Você é 10 vezes mais", ele rebate, com ar convicto. Mas a alegria dura pouco. "Você é 1000 vezes mais", afirma o primeiro. Então, eis que vem um xeque: "Você é bobo ao infinito". Oh-oh. Que fazer disso? O último a ser ofendido não tem muitas dúvidas: "E você, você é bobo ao infinito vezes infinito". Silêncio triunfal. Salvador Nogueira, Revista Super Interessante (02/2006).

A discussão entre os dois meninos pode parecer irrelevante, no entanto a ideia de infinito, embutida na citação, continua sendo um tema discutido e debatido por grandes teóricos até a atualidade. Talvez por ser algo tão abstrato e progressivo.

Ao estudar limites infinitos, a nossa atenção esteve em analisar o comportamento de uma função racional quando $x$ tende ao infinito tanto pela direita quanto pela esquerda, isto é, cresce indefinidamente para ambos os lados, e os limites cujo resultado é o infinito. Graficamente, encontrar a solução desses limites permite descobrir as assíntotas verticais e horizontais existentes.

\subsubsection{Assíntotas Verticais e Assíntotas Horizontais}

Uma assíntota é uma reta da qual o gráfico de uma função se aproxima quando $x$ ou $f(x)$ tende ao infinito, mas nunca a toca. Para que os alunos assimilassem de maneira eficaz esse conceito apresentou-se o seguinte exemplo. 
Exemplo 1.2.8. Dada a função racional

$$
f(x)=\frac{(x+2)(x-5)}{(x-3)(x+1)},
$$

esboçamos o seu gráfico com o uso do software Winplot. Veja Figura 1.13.

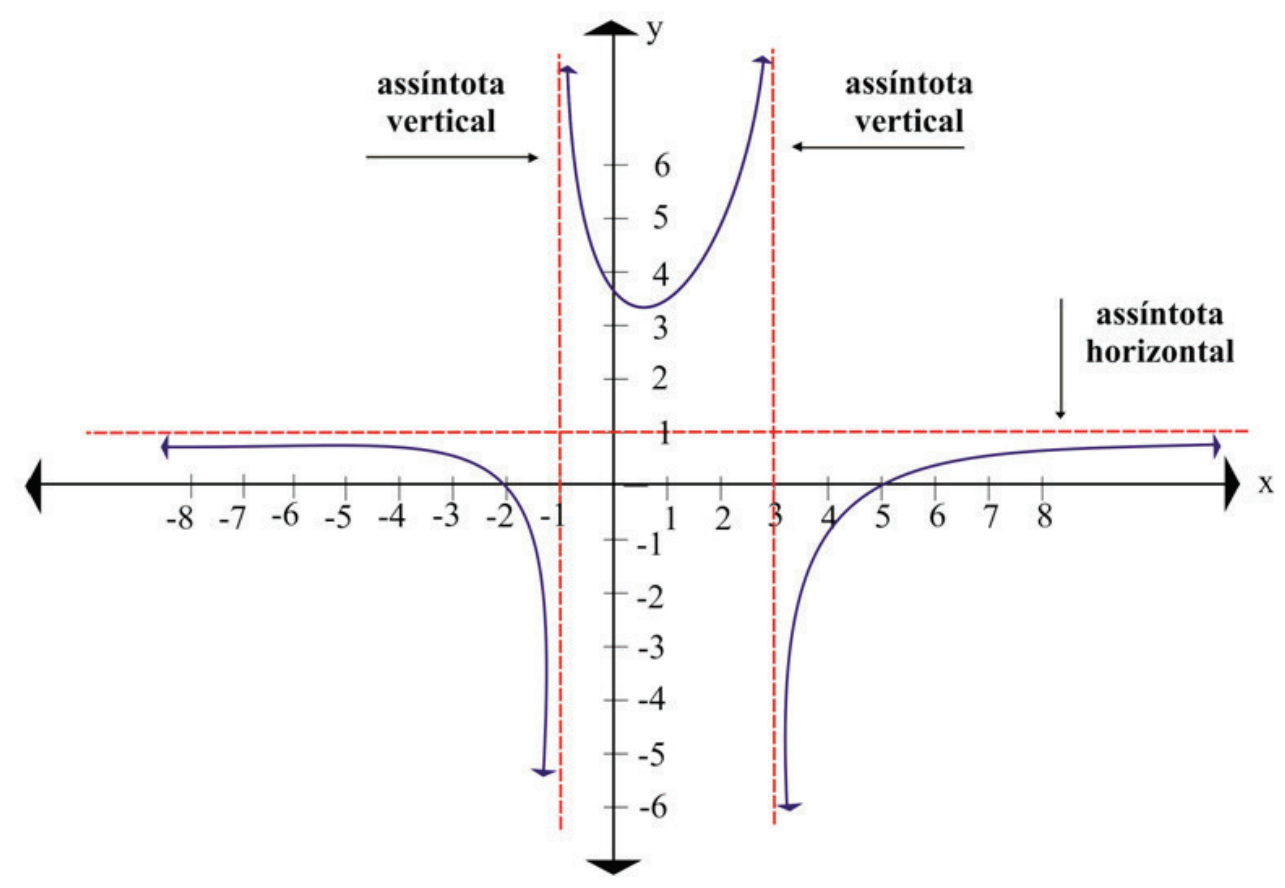

Figura 1.13: Gráfico de $f(x)=\frac{(x+2)(x-5)}{(x-3)(x+1)}$.

Em seguida, os alunos constataram que à medida que $x$ se aproxima de -1 pela direita e de 3 pela esquerda, $f(x)$ cresce indefinidamente, sem nunca tocar nas retas $x=1$ e $x=3$. O professor complementou dizendo que essas retas são denominadas assíntotas verticais.

Posteriormente, pediu-se que os alunos analisassem o comportamento de $f(x)$ à medida que $x$ cresce e decresce indefinidamente. Os alunos perceberam que quando $x$ cresce ou decresce indefinidamente, $f(x)$ se aproxima da reta $y=1$, sem atingir essa reta. Essa reta é chamada de assíntota horizontal.

Por fim, explicou-se ao grupo que o nosso objetivo não se resume em apenas observar o gráfico e identificar as assíntotas. Muitas vezes, teremos uma função $f(x)$ e para esboçar, de forma completa, o gráfico dessa função, utilizaremos o cálculo dos limites, que irão nos auxiliar a descobrir as assíntotas verticais e horizontais de $f(x)$, caso a função possua assíntotas. 
Com a intenção de explorar esse procedimento foram desenvolvidos os próximos exemplos, nos quais tratamos dos conceitos referentes a assíntotas verticais (exemplo 1.2.9) e assíntotas horizontais (exemplo 1.2.10, 1.2.11 e 1.2.12).

Exemplo 1.2.9 (Assíntotas Verticais). Ao analisar o gráfico de $f(x)$ do exemplo anterior, ilustrado pela Figura 1.13, foi possível verificar duas assíntotas verticais, no caso, $x=-1$ e $x=3$, ou seja, quando $x$ se aproxima de -1 pela esquerda $f(x)$ tende $-\infty$ e quando $x$ se aproxima de -1 pela direita $f(x)$ tende $+\infty$. De forma análoga, comentou-se o comportamento da função $f(x)$ nas proximidades do número $x=3$. Matematicamente, podemos escrever que $\lim _{x \rightarrow-1^{-}} f(x)=-\infty$, $\lim _{x \rightarrow-1^{+}} f(x)=+\infty, \lim _{x \rightarrow 3^{+}} f(x)=-\infty$ e $\lim _{x \rightarrow 3^{-}} f(x)=+\infty$.

Neste exemplo, apresentou-se aos alunos o procedimento que deveria ser feito para encontrarem as assíntotas verticais da função $f(x)=\frac{(x+2)(x-5)}{(x-3)(x+1)}$.

É possível observar que o domínio da função $f$ é $\mathbb{R}-\{-1,3\}$ e não existe nenhum fator comum no numerador e no denominador. Sendo assim, não podemos realizar uma simplificação. Nesse caso dizemos que as retas $x=-1$ e $x=3$ são candidatas a assíntotas verticais. Para verificar se isto ocorre algebricamente devemos estudar o limite de $f(x)$ nos pontos $x=-1$ e $x=3$.

Os alunos indagaram como fariam esse cálculo, visto que $f(-1)$ e $f(3)$ não estão definidas e não é possível realizar uma simplificação na função $f(x)$. Como resposta, o professor comentou que deveriam calcular os limites laterais da função quando $x$ tende a -1 e 3 , como veremos abaixo:

É importante ressaltar que durante o procedimento desenvolvido a seguir, buscou-se a capacidade de raciocínio lógico intuitivo do aluno, conforme podemos observar nos itens (i) e (ii) descritos abaixo.

(i) $\lim _{x \rightarrow-1^{-}} \frac{(x+2)(x-5)}{(x-3)(x+1)}$

Se $x$ está próximo de -1 , mas é menor que -1 , então o numerador $(x+2)(x-5)$ é um número negativo próximo a -6 . O denominador $(x-3)(x+1)$ é um número positivo e pequeno (próximo de zero). Portanto, a divisão $\frac{(x+2)(x-5)}{(x-3)(x+1)}$ é um número negativo grande, então intuitivamente, temos que $\lim _{x \rightarrow-1^{-}} f(x)=-\infty$.

(ii) $\lim _{x \rightarrow-1^{+}} \frac{(x+2)(x-5)}{(x-3)(x+1)}$

Neste caso, $x$ está próximo de -1 , mas é maior que -1 , então o numerador $(x+2)(x-5)$ é um número negativo próximo a -6 , e o denominador $(x-3)(x+1)$ é um número negativo 
e pequeno (próximo de zero). Portanto, a divisão $\frac{(x+2)(x-5)}{(x-3)(x+1)}$ é um número positivo grande, então intuitivamente, temos que $\lim _{x \rightarrow-1^{+}} f(x)=+\infty$. Logo $x=-1$ é uma assíntota vertical. O professor complementou dizendo que uma reta $x=a$, com $a \in \mathbb{R}$, é uma assíntota vertical de um gráfico $f(x)$ se $\lim _{x \rightarrow a^{-}} f(x)= \pm \infty$ ou $\lim _{x \rightarrow a^{+}} f(x)= \pm \infty$.

Posteriormente os alunos desenvolveram o mesmo raciocínio para o estudo do $\lim _{x \rightarrow 3^{-}} f(x)$ e $\lim _{x \rightarrow 3^{+}} f(x)$. Em seguida fizeram uma comparação entre as respostas obtidas com o gráfico de $f(x)$ esquematizado pela Figura 1.13.

A turma percebeu que o $\lim _{x \rightarrow 1} f(x)$ e o $\lim _{x \rightarrow 3} f(x)$ não existem, visto que seus limites laterais são diferentes, porém encontrar esses limites nos traz valiosas informações sobre o comportamento da curva.

Até agora observamos os limites em que o $x$ se aproxima de um número finito. Mas $x$ também pode se aproximar de $+\infty$ ou $-\infty$. Estudar os limites quando $x \rightarrow \pm \infty$ nos ajudará a encontrar as assíntotas horizontais de uma função, caso ela exista. Para estudar as assíntotas horizontais, apresentamos três exemplos, conforme podemos observar abaixo:

Exemplo 1.2.10 (Assíntota Horizontal da Função $g(x)=\frac{1}{x}$ ). Neste exemplo discutiu-se o comportamento da função $g(x)=\frac{1}{x}$ à medida que $x$ cresce e decresce indefinidamente, e isso foi realizado de forma intuitiva.

Inicialmente, solicitou-se que os alunos imaginassem um bolo inteiro e tivessem a missão de dividir esse bolo, primeiramente a um grupo de dez pessoas, e é lógico que dependendo do tamanho do bolo, teríamos um tamanho razoável para cada pessoa, porém, se esse mesmo bolo fosse dividido para um grupo de cem pessoas o tamanho da fatia servida a cada pessoa seria dez vezes menor do que o tamanho da fatia servida ao grupo composto por dez pessoas.

Questionou-se o que aconteceria se esse mesmo bolo fosse repartido a um grupo de pessoas cada vez maior e, satisfatoriamente, os discentes concluíram que a fatia ficaria cada vez menor e menor, ou seja, o tamanho da fatia chegaria cada vez mais próximo de zero. Diante disso, os alunos perceberam que $\lim _{x \rightarrow \infty} \frac{1}{x}=0$.

Em seguida, aplicou -se uma atividade em que os alunos fizeram, com o uso de uma calculadora, sucessivas divisões do tipo $\frac{1}{x}, x \in \mathbb{R}_{-}^{*}$ e concluíram que, à medida que $x$ se tornava cada vez mais negativo o quociente se aproximava cada vez mais de zero. 
Finalizando, o grupo concluiu que $\lim _{x \rightarrow \pm \infty} \frac{1}{x}=0$. Com o uso do software gráfico Winplot, os alunos esboçaram o gráfico da função $g(x)$ e puderam constatar que $x=0$ é uma assíntota horizontal.

Exemplo 1.2.11 (Assíntota Horizontal da Função $\left.f(x)=\frac{(x+2)(x-5)}{(x-3)(x+1}\right)$. Ao analisar o gráfico da função $f(x)$ do exemplo 1.2.8 (Figura 1.13) foi possível verificar a assíntota horizontal $y=1$. Especificamente quando $x$ cresce ou decresce indefinidamente, a função se aproxima cada vez mais de $y=1$. Matematicamente podemos escrever que: $\lim _{x \rightarrow-\infty} f(x)=1$ e $\lim _{x \rightarrow+\infty} f(x)=1$.

Neste exemplo, apresentou-se aos alunos o procedimento que deveria ser feito para que encontrassem a assíntota horizontal da função $f(x)=\frac{(x+2)(x-5)}{(x-3)(x+1)}$, abordada no Exemplo 1.2.8.

Inicialmente, pedimos que os alunos desenvolvessem o produto dos fatores indicados na função $f(x)$. Como solução obtiveram

$$
f(x)=\frac{x^{2}-3 x-10}{x^{2}-2 x-3} .
$$

O grupo percebeu que, para encontrar a assíntota horizontal da função $f$, seria necessário calcular o $\lim _{x \rightarrow \pm \infty} f(x)$. Como complementação, o professor explicou que deveriam dividir o numerador e o denominador pelo maior expoente do denominador, conforme detalhado pela equação abaixo:

$$
\begin{aligned}
& \lim _{x \rightarrow \infty} \frac{x^{2}-3 x-10}{x^{2}-2 x-3} \\
= & \lim _{x \rightarrow \infty} \frac{\frac{x^{2}-3 x-10}{x^{2}}}{\frac{x^{2}-2 x-3}{x^{2}}} \\
= & \lim _{x \rightarrow \infty} \frac{\frac{x^{2}}{x^{2}}-\frac{3 x}{x^{2}}-\frac{10}{x^{2}}}{\frac{x^{2}}{x^{2}}-\frac{2 x}{x^{2}}-\frac{3}{x^{2}}} \\
= & \lim _{x \rightarrow \infty} \frac{1-\frac{3}{x}-\frac{10}{x^{2}}}{1-\frac{2}{x}-\frac{3}{x^{2}}} \\
= & \frac{1-0-0}{1-0-0}=1 .
\end{aligned}
$$

O cálculo do $\lim _{x \rightarrow-\infty} f(x)$ foi realizado de forma semelhante. Por fim, os alunos entenderam o processo algébrico a ser desenvolvido para encontrarem a assíntota horizontal de uma função.

Para finalizar o estudo sobre as assíntotas horizontais, apresentou-se o Exemplo 1.2.12. Neste Exemplo o professor descreveu aos alunos um método dedutivo e intuitivo para o cálculo das assíntotas horizontais, baseado em uma observação quanto ao grau do polinômio disposto no numerador e no denominador de uma função racional. 
Exemplo 1.2.12 (Assíntotas Horizontais Estudadas de forma Intuitiva). Neste exemplo analisou-se duas funções. No item $(i)$ expôs-se uma função racional $p(x)$, em que o grau do numerador é menor que o grau do denominador. Já no item (ii) apresentou-se uma função $q(x)$, na qual o grau do numerador é maior que o grau do denominador. A partir desses dois casos, algumas observações e conclusões foram feitas, como segue abaixo:

(i) O grau do numerador é menor que o grau do denominador.

Para este caso, apresentou-se ao grupo como exemplo, a função

$$
p(x)=\frac{2 x^{2}+8}{6 x^{4}+x^{3}-7} .
$$

Para estudar intuitivamente o cálculo do $\lim _{x \rightarrow \pm \infty} p(x)$, elaborou-se uma tabela com o uso do programa Excel. Nessa tabela, os alunos atribuíram valores cada vez maiores, tanto positivos quanto negativos a $x$, obtendo valores para $p(x)$.

A turma observou que, à medida que $x$ aumenta ou diminui indefinidamente, obtemos um valor cada vez mais próximo de zero.

Em seguida o professor complementou esclarecendo que, quando realizamos uma divisão na qual o grau do polinômio do denominador cresce mais rapidamente do que o grau do polinômio do numerador, o quociente se aproxima cada vez mais de zero.

Para justificar a explicação acima, o docente comentou que, quando realizamos uma divisão entre polinômios na qual $x$ tende ao $-\infty$ ou $+\infty$, as parcelas de soma ou subtração de menor expoente desses polinômios se tornam insignificantes. Nesse caso, pode-se dizer que quem dita o crescimento ou o decrescimento do numerador e do denominador são as parcelas de maior expoente, conforme ilustramos na equação abaixo.

$$
\lim _{x \rightarrow+\infty} \frac{2 x^{2}+8}{6 x^{4}+x^{3}-7}=\lim _{x \rightarrow+\infty} \frac{2 x^{2}}{6 x^{4}}=\lim _{x \rightarrow+\infty} \frac{1}{3 x^{4}}=0 .
$$

De forma semelhante, os alunos observaram que $\lim _{x \rightarrow-\infty} p(x)=0$. Assim, o grupo percebeu que $\lim _{x \rightarrow \pm \infty} p(x)=0$ e comentaram que a reta $y=p(x)=0$ é a assíntota horizontal da função em questão e de qualquer outra função racional na qual o grau do polinômio do numerador se apresente menor que o grau do polinômio do denominador.

Por fim, foi apresentado o gráfico de $p(x)$. Veja Figura 1.14. 


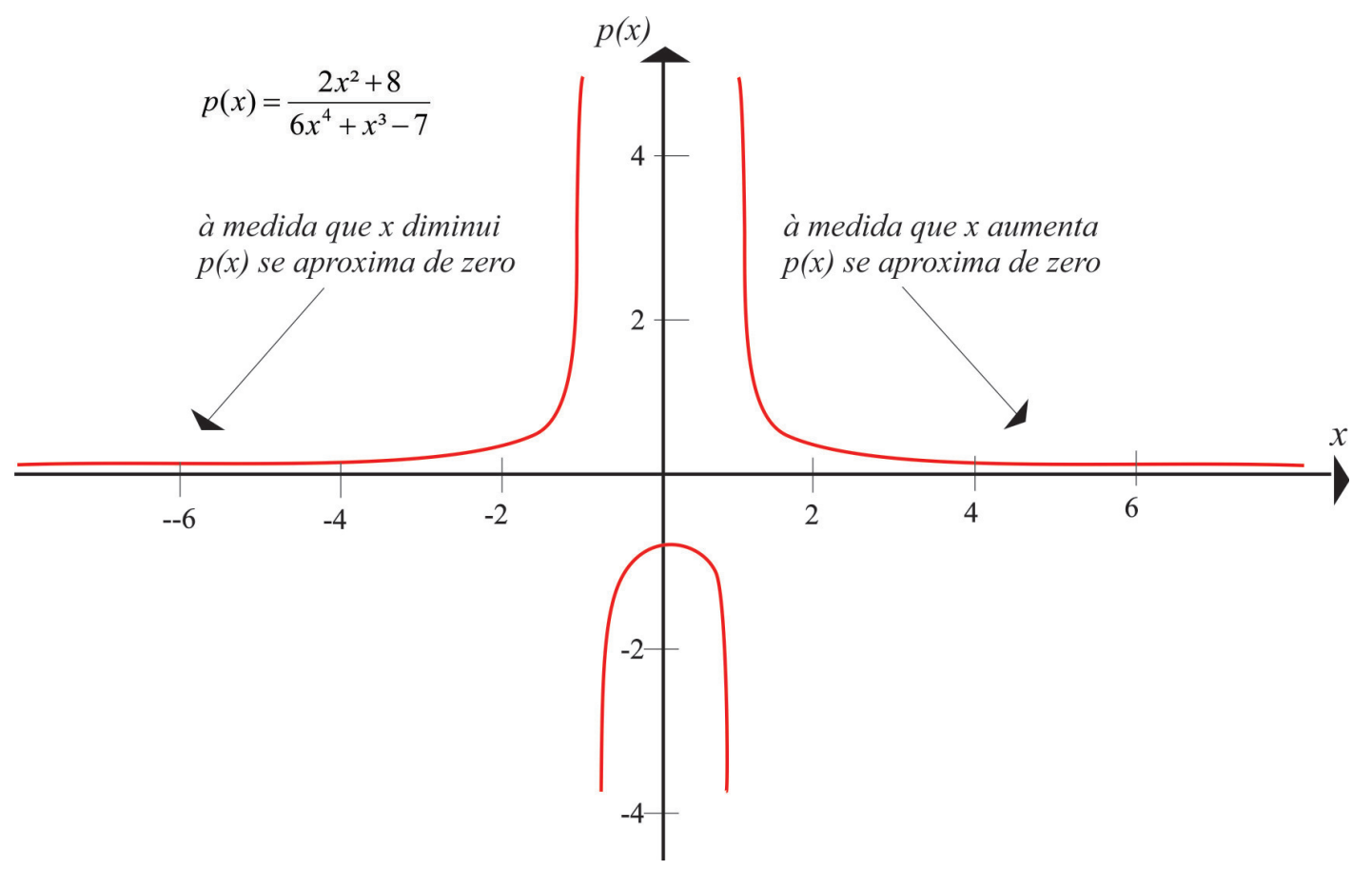

Figura 1.14: Gráfico da função $p(x)$.

(ii) O grau do numerador é maior que o grau do denominador.

Inicialmente os alunos foram convidados a irem à lousa e solicitou-se que resolvessem uma série de divisões com o seguinte padrão: o numerador cresce mais rapidamente que o denominador, tanto para um valor cada vez mais positivo, quanto negativo (módulo). Através desses cálculos os alunos constataram que o resultado dessa divisão crescia de forma positiva ou negativa indefinidamente.

Após essa observação, o docente apresentou ao grupo a função

$$
q(x)=\frac{6 x^{4}+x^{3}-7}{2 x^{2}+8}
$$

e questionou o que aconteceria com esta função, se atribuíssemos valores cada vez maiores a $x$. Como resposta, os alunos afirmaram que o numerador apresentaria um valor muito maior que o denominador e, ao se realizar essas divisões, obteriam um número muito grande, que poderia ser tanto positivo quanto negativo. Em seguida, o docente deixou claro que, quando realizamos uma divisão na qual o grau do polinômio do numerador cresce mais rapidamente do que o grau do polinômio do denominador, o quociente cresce ou decresce indefinidamente. 
Como já vimos, podemos interpretar o limite da seguinte forma:

$$
\begin{aligned}
& \lim _{x \rightarrow+\infty} \frac{6 x^{4}+x^{3}-7}{2 x^{2}+8}=\lim _{x \rightarrow+\infty} \frac{6 x^{4}}{2 x^{2}}=\lim _{x \rightarrow+\infty} 3 x^{2}=\infty \mathrm{e} \\
& \lim _{x \rightarrow-\infty} \frac{6 x^{4}+x^{3}-7}{2 x^{2}+8}=\lim _{x \rightarrow-\infty} \frac{6 x^{4}}{2 x^{2}}=\lim _{x \rightarrow-\infty} 3 x^{2}=\infty
\end{aligned}
$$

O grupo percebeu que, como reduzimos o polinômio a um monômio no qual a variável $x$ está elevada ao quadrado, obteríamos sempre um numero muito grande e positivo.

Neste instante, observou - se que alguns alunos comentaram que o resultado seria sempre $+\infty$ e o professor pediu que os alunos atentassem ao fato de que todo número, positivo ou negativo, elevado a um expoente par, é sempre positivo. Complementou dizendo que se tívessemos $\lim _{x \rightarrow+\infty} 3 x^{5}$ e $\lim _{x \rightarrow-\infty} 3 x^{5}$, teríamos como solução $+\infty$ e $-\infty$, respectivamente

Em seguida, com uso do software Geogebra, desenhou-se o gráfico da função $q(x)$ para que o grupo conseguisse interpretar geometricamente o resultado do limite. E através da observação gráfica, os alunos conseguiram concluir que quando o grau do polinômio do numerador for maior do que o grau do polinômio do denominador, a função não apresenta assíntota horizontal, como mostra a Figura 1.15.

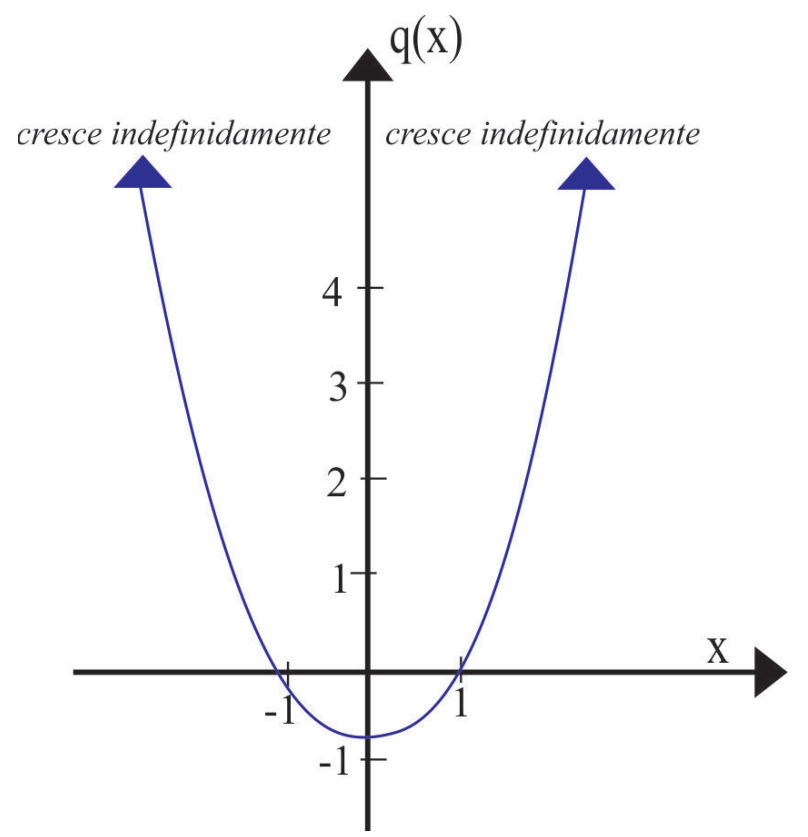

Figura 1.15: Gráfico da função $q(x)$. 
O gráfico apresentado na Figura 1.15 foi de grande importância, pois os alunos conseguiram, sem a necessidade de desenvolver cálculos algébricos, observar a ausência das assíntotas horizontais.

Por fim, ressaltou-se que, a forma de resolução apresentada neste exemplo é apenas uma maneira intuitiva, mas que no ensino superior, resolveria tais limites de uma forma semelhante à apresentada no exemplo 1.2.11.

Para finalizar o estudo de limites infinitos, dividiu-se a sala em três grupos, e foi solicitado aos alunos que apresentassem um seminário no qual cada grupo deveria expor o desenho gráfico de uma função semelhante às desenvolvidas nos exemplos anteriores. O resultado desse seminário serviu como base para que o professor concluísse que os estudantes conseguiram atingir o objetivo esperado.

Com o objetivo de apresentar pelo menos mais um item sobre a importância dos limites, o docente optou em comentar com os alunos sobre o número Neperiano ou número de Euler $(e)$. A principal motivação para o desenvolvimento desse assunto foi a de apresentar mais uma aplicação dos limites, visto que ao final, os alunos passariam a conhecer uma importante constante da matemática, com propriedades interessantes: a constante $(e)$.

\subsubsection{Uma Aplicação Financeira e o Número de Euler}

Para introduzir esse tópico optou-se em apresentar o problema do capital acumulado em um fundo de investimento, conforme podemos observar no exemplo abaixo.

Exemplo 1.2.13. Inicialmente, solicitou-se que os alunos imaginassem uma quantia de $R \$ 100$, aplicada a um sistema de juros composto. Esse dinheiro seria capitalizado anualmente a uma taxa de $20 \%$.

Dos estudos do ensino médio, sabe-se que para o cálculo do montante utilizamos a fórmula

$$
M=C \cdot(1+i)^{t},
$$

na qual $M$ representa o montante (capital + juros), $C$ o capital aplicado, $i$ a taxa de juros e $t$ o tempo de aplicação.

Com o auxílio de uma calculadora científica desenvolveu-se a Tabela 1.3. Nessa tabela calculou-se o montante ao final de cada ano, no sistema de juros compostos. 
Tabela 1.3: Aplicação de 100 reais durante um período de 4 anos

\begin{tabular}{ll}
\hline Tempo $(t)$ & Montante $(M)$ \\
\hline Após 1 ano & $M=C(1+i)^{t} \rightarrow M=100(1+0,2)^{1} \rightarrow M=120$ \\
Após 2 ano & $M=C(1+i)^{t} \rightarrow M=120(1+0,2)^{2} \rightarrow M=144$ \\
Após 3 ano & $M=C(1+i)^{t} \rightarrow M=144(1+0,2)^{3} \rightarrow M=172,8$ \\
Após 4 ano & $M=C(1+i)^{t} \rightarrow M=172,8(1+0,2)^{4} \rightarrow M=207,36$ \\
\hline
\end{tabular}

Ao realizar e observar os cálculos apresentados na Tabela 1.3, o grupo percebeu que em um período próximo de quatro anos o dinheiro aplicado irá dobrar.

Em seguida, o professor comentou que no mundo financeiro existe todo tipo de periodicidade. No exemplo acima, o dinheiro rende juros a cada um ano. No entanto, esse rendimento poderia ser mensal, trimestral, semestral ou até mesmo diário.

Se o dinheiro fosse capitalizado semestralmente, em um ano teríamos duas capitalizações, porém, a taxa oferecida se reduziria pela metade, ou seja, ao invés de $0,2 \%$ ao ano, teríamos $0,1 \%$ ao semestre.

O mesmo raciocínio pode ser feito para qualquer outro período. Suponhamos que um banco decida usar uma periodicidade $n$ por ano, assim a taxa $i$ será dividida por $n$ e cobrada $n$ vezes no período de $t$ anos, e a expressão passaria para

$$
M=C \cdot\left(1+\frac{i}{n}\right)^{t \cdot n}
$$

Considerando essa aplicação por um período $t=1$, o capital de $R \$ 100$ e a taxa de juros sendo de 0,2 a.a., e $n$ a quantidade de vezes que iremos capitalizar os 100 reais, em um período de um ano teríamos a seguinte expressão:

$$
M=100 \cdot\left(1+\frac{0,2}{n}\right)^{1 . n}
$$

Para que os alunos percebessem que à medida que a periodicidade $n$ aumenta, o montante também aumenta, mas que a partir de um determinado $n$ esse aumento se torna irrelevante, desenvolveu-se a Tabela 1.4, com uso do software Excel. 
Tabela 1.4: Montante de uma aplicação de 100 reais com diferentes periodicidades

\begin{tabular}{llll}
\hline Periodicidade & $n$ & $\frac{0,2}{n}$ & Montante \\
\hline Anual & 1 & 0,2 & $M=100(1+0,2)^{1}=120$ \\
Semestral & 2 & 0,1 & $M=100(1+0,1)^{2}=121$ \\
Trimestral & 4 & 0,05 & $M=100(1+0,05)^{4}=121,55$ \\
Mensal & 12 & $0,01666 \ldots$ & $M=100(1+0,01666 \ldots)^{12}=121,939$ \\
Semanal & 52 & $0,003846 \ldots$ & $M=100(1+0,003846 \ldots)^{52}=122,0934$ \\
Diária & 365 & 0,000547945 & $M=100(1+0,000547945)^{365}=122,13$ \\
\hline
\end{tabular}

Uma parte dos alunos se surpreendeu com os resultados, pois não imaginaram que o montante quase não se modificaria, visto que se o dinheiro fosse capitalizado anualmente teríamos ao final um montante de 120 reais, e ao capitalizar diariamente os 100 reais, passamos a ter um montante de 122,13 reais.

O professor complementou que poderíamos capitalizar esse dinheiro em períodos de tempo cada vez menores quanto se queira, por exemplo, a cada uma hora e, mesmo assim, o montante continuaria muito próximo de 122,13.Nesse momento, alguns alunos comentaram que íriamos desenvolver um raciocínio relacionado a algum tipo de limite.

Logo após, o professor pediu que os alunos considerassem que o capital aplicado não fosse de 100 reais. Chamando de $C$ um capital qualquer, passamos a obter a seguinte expressão

$$
C \cdot\left(1+\frac{i}{n}\right)^{n} \text {. }
$$

Essa expressão quando multiplicada por um capital $(C)$, retorna o valor do montante para um período de um ano, com diferentes capitalizações.

Para relacionar a expressão desenvolvida no parágrafo anterior com o número de Euler, escolheuse o caso particular de uma taxa percentual de $100 \%(i=1)$, na qual obtemos a seguinte expressão:

$$
\left(1+\frac{i}{n}\right)^{n}=\left(1+\frac{100 \%}{n}\right)^{n}=\left(1+\frac{1}{n}\right)^{n}
$$

Em seguida, com o auxílio do software Excel, a expressão

$$
\left(1+\frac{1}{n}\right)^{n}
$$

foi desenvolvida, variando a periodicidade $n$, conforme ilustra a Tabela 1.5 . 
Tabela 1.5: O número de Euler na matemática financeira

\begin{tabular}{ll}
\hline$n$ & $\left(1+\frac{1}{n}\right)^{n}$ \\
\hline 1 & 2 \\
2 & 2,25 \\
4 & 2,44140625 \\
5 & 2,48832 \\
10 & 2,59374246 \\
50 & 2,691588029 \\
100 & 2,704813829 \\
1000 & 2,716923932 \\
10000 & 2,718145927 \\
100000 & 2,718268237 \\
\hline
\end{tabular}

Após uma análise na Tabela 1.5, ficou claro para os alunos que, depois de um determinado valor, qualquer acréscimo na periodicidade pouco afetará o montante. O professor complementou dizendo que, se permitirmos que $n$ aumente sem limites, a soma de dinheiro $M$, obtida a partir da fórmula

$$
M=C \cdot\left(1+\frac{i}{n}\right)^{t . n},
$$

parece aproximar-se de um certo limite. O limite para $C=1, t=1$ e $i=1$, é aproximadamente 2,718, e esse número é chamado de número de Euler ou número Neperiano, representado pela letra e. Em outras palavras, podemos representar toda essa situação descrita, usando a notação de limite, conforme esquematizado pela equação abaixo

$$
\lim _{n \rightarrow \infty}\left(1+\frac{1}{n}\right)^{n}=2,71828 \ldots=e
$$

Ressaltamos ao grupo que este foi um caso particular que associa o número de Euler ao cálculo dos juros compostos. Observou - se que aplicar a noção de limite dentro de uma situação financeira foi grande importância para a motivação e participação dos alunos. Além do mais, o grupo revisou conceitos importantes desenvolvidos no ensino médio como o estudo dos juros compostos e a sua aplicabilidade no cotidiano. 


\subsection{Derivadas}

Este estudo foi desenvolvido em quatro seções. Ao abordar cada seção houve a preocupação sobre o que poderia ser feito para que os alunos se interessassem pelo tema proposto e empregassem esforço e dedicação durante o processo de ensino aprendizagem.

$\mathrm{Na}$ primeira seção foram expostos aos alunos exemplos relacionados ao conceito de "taxa de variação" e "inclinação da reta tangente" e apresentou-se a partir desses exemplos uma noção intuitiva de derivada. Ao final, relacionamos esses dois conceitos. O objetivo principal dessa abordagem foi de que o aluno, ao se deparar com o termo "derivada", não o visse de forma isolada, e sim, relacionado com situações do seu cotidiano e a alguns assuntos que já trabalhados no ensino médio.

$\mathrm{Na}$ segunda etapa apresentamos um exemplo que analisa a altura de um recém - nascido até a sua fase adulta. O objetivo desse exemplo foi ilustrar aos alunos um tipo especial de limites, usado para definir derivadas. Além disso, abordou-se as regras de derivação, usando a definição de limites.

$\mathrm{Na}$ terceira seção formulamos uma atividade com o objetivo de introduzir aspectos importantes da derivada como, por exemplo, "pontos de máximo e mínimo" e "pontos de inflexão".

Finalmente, a quarta seção teve o objetivo de apresentar aos alunos como a derivada pode nos auxiliar no estudo da física, especificamente, quando tratamos de velocidade e aceleração. Relacionamos a velocidade instântanea com o conceito de primeira derivada e a aceleração instantânea com a noção de segunda derivada.

\subsubsection{A Derivada Vista sob Dois Aspectos: Taxa de Variação e Inclinação da Reta Tangente}

O objetivo desta seção foi introduzir aos alunos conceitos importantes para a definição de derivada, com a finalidade de que se sentissem motivados para o estudo desse conceito.

Inicialmente o professor apresentou aos alunos alguns exemplos de variações que ocorrem em nosso cotidiano. Começou comentando que as coisas "tomam forma", crescem, se movem e aceleram. Como exemplo de variações, citou atletas em competições olímpicas que aceleram na hora da partida (largada). Passado algum tempo a velocidade se mantém quase constante, o que significa que a aceleração cai para aproximadamente zero. Outro exemplo citado foram os metais que se dilatam depois de aquecidos. A partir desse processo o comprimento e a largura de uma barra de ferro, 
por exemplo, sofrem variações à medida que a temperatura aumenta. A cintura de uma pessoa que adquire pequenas ou grandes variações de acordo em que ganham ou perdem peso foi outro exemplo de variação apresentada.

Além disso, comentou-se que as variações podem ser impactantes como a aceleração de um míssil no lançamento, ou tranquilas como o aquecimento de um metal. Elas podem ser perceptíveis como o peso acrescentado a uma cintura que ganhou massa corporal, mas também invisíveis como o vaivém de uma corrente elétrica em seu condutor.

Enfim, observou-se que o processo de variação é inevitável para compreender as leis da natureza. Por outro lado, o Cálculo, em especial o estudo da derivada, nos fornece ferramentas importantes para analisarmos as mais diversas taxas de variações.

Com o intuito de abordar, matematicamente, o significado de taxa de variação, simulou - se uma situação fictícia em um parque de diversão. Nesta situação estávamos interessados em analisar o movimento da gangorra e de duas crianças ao se divertirem no brinquedo.

Exemplo 1.3.1 (Taxa de Variação). Imagine dois meninos em uma gangorra, Caio e Pedrinho. Considere que eles possuam a mesma massa corporal de 42 quilos. Se estiverem sentados cada um em extremidade da gangorra, é claro que a gangorra ficará balanceada, conforme mostra a Figura 1.17 .

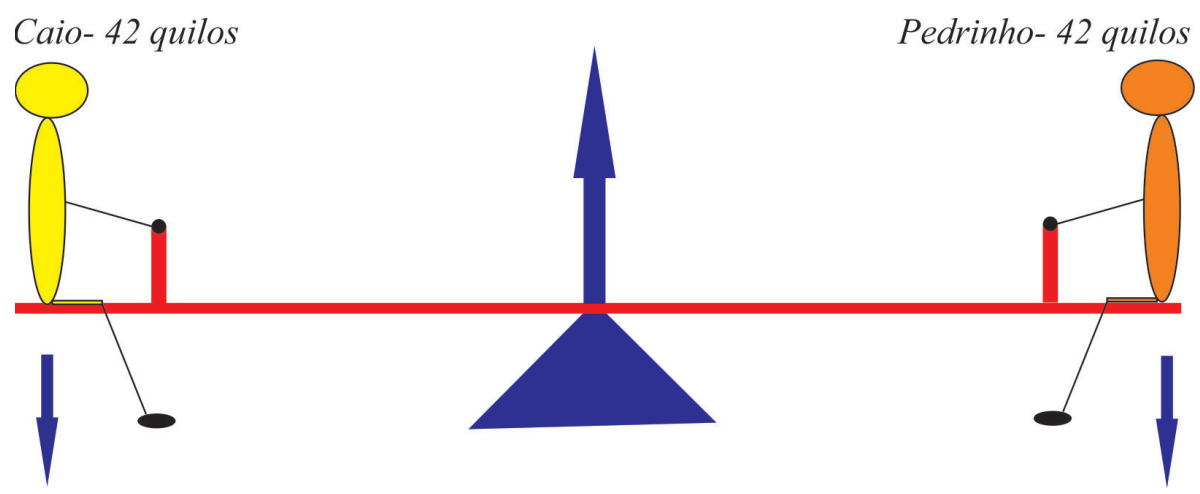

Figura 1.16: Caio e Pedrinho com massas corporais iguais.

Se as massas corporais de Caio e Pedrinho fossem diferentes, eles não estariam na mesma altura do chão. Por exemplo, se Pedrinho tivesse uma massa corporal de 84 Kg teríamos uma situação semelhante à Figura ??. 


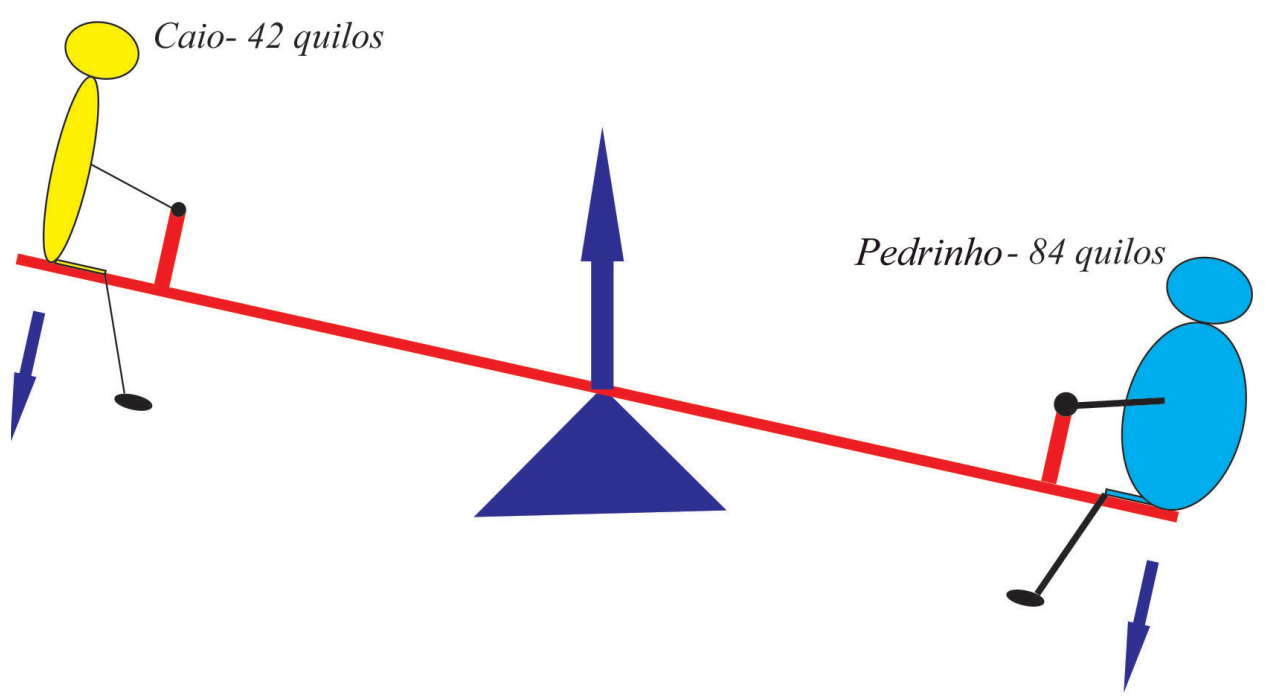

Figura 1.17: Caio e Pedrinho com massas corporais diferentes.

Diante desta nova situação, indagou-se ao grupo o que deveria acontecer para que houvesse novamente um equilíbrio na gangorra. Os alunos responderam que o garoto mais pesado deveria aproximar-se a uma certa distância para o centro da gangorra. O professor complementou apresentando a Figura 1.18 e algumas observações a respeito desta Figura.

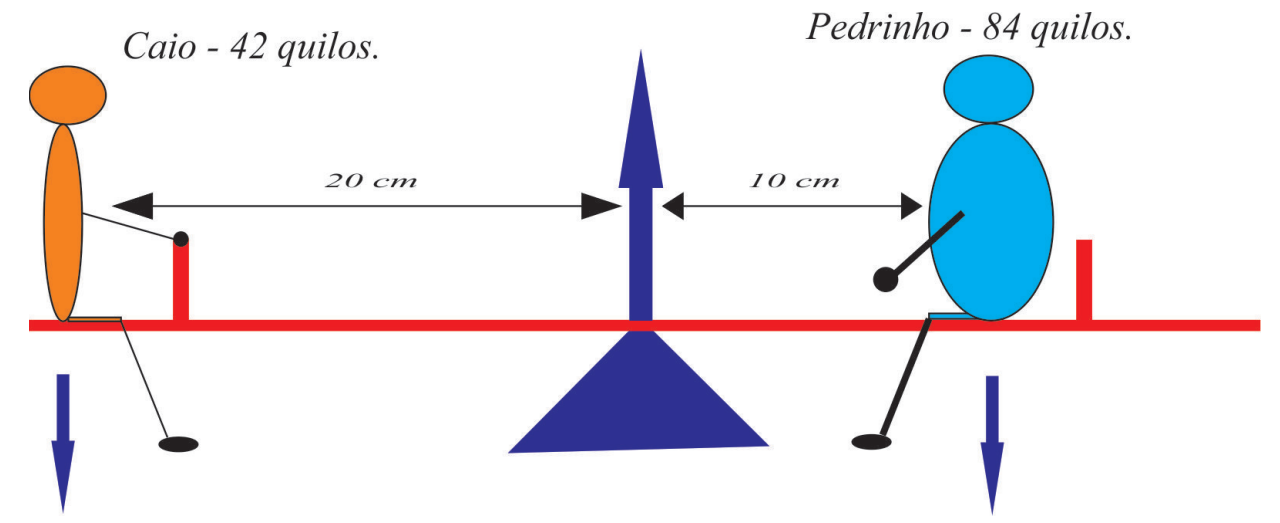

Figura 1.18: Pedrinho aproximando - se do centro da gangorra.

Dentre as observações apresentadas, merecem destaque:

1) se Pedrinho se posicionar a dez centímetros do centro da gangorra, Caio terá que ficar a vinte centímetros do centro para que haja um equilíbrio, visto que Pedrinho pesa o dobro que Caio;

2) se Pedrinho deslocar-se um centímetro, ficando a uma distância de nove centímetros do centro 
da Gangorra, Caio deverá se deslocar dois centímetros em relação ao centro, posicionando-se a dezoito centímetros do centro da gangorra.

A partir dessas observações os alunos conseguiram perceber que, para cada centímetro que Pedrinho se movia para o centro da gangorra, Caio deveria se mover dois centímetros. Logo, pode-se concluir que para manter o equilíbrio na balança, Caio $(C)$ deve mover se duas vezes mais rápido do que Pedrinho $(P)$.

Se imaginarmos que $d C$ é a variação na posição de Caio e $d P$ a de Pedrinho, para que haja equilíbrio, matematicamente, podemos dizer que $d C=2 . d P$.

Foi comentado pelo professor que a situação descrita pela equação $d C=2 . d P$ pode ser representada de outras formas. Por exemplo, dividindo ambos os lados dessa equação por $d P$ ou por $d C$ temos, respectivamente:

$$
\frac{d C}{d P}=2 \text { ou } \frac{d P}{d C}=\frac{1}{2}
$$

Ao dizer que

$$
\frac{d C}{d P}=2,
$$

estamos dizendo que a variação do movimento de Caio em relação ao de Pedrinho é 2. Neste instante o professor comentou que esta situação representa um exemplo de taxa de variação constante, ou seja, a cada um centímetro que Pedrinho se move, Caio se desloca dois centímetros, para manter o equilíbrio. O docente complementou esclarecendo que o símbolo

$$
\frac{d C}{d P}=2
$$

será chamado de derivada e que pode ser interpretada da seguinte forma: a derivada de Caio em relação à de Pedrinho é igual a 2.

Da mesma forma, ao observar a equação

$$
\frac{d P}{d C}=\frac{1}{2},
$$

o professor comentou que essa variação será chamada de derivada, e podemos interpretá-la como sendo a derivada de Pedrinho em relação a de Caio e é igual a $\frac{1}{2}$. Em outras palavras, a cada 1 unidade que Caio se move, Pedrinho se desloca $\frac{1}{2}$ unidade para que o equilíbrio seja mantido.

Nessa situação pôde-se observar a ideia de derivada expressa pela medida do quanto uma distância varia quando comparada com outra. Em resumo, foi possível perceber que os alunos 
atingiram o objetivo esperado: obter uma noção intuitiva sobre o que é derivada, sob o ponto de vista de taxa de variação, especificamente, taxa de variação constante.

No exemplo 1.3.2 apresentou-se uma noção intuitiva sobre derivadas, sob o ponto de vista de inclinação da reta tangente.

Exemplo 1.3.2 (Inclinação da Reta Tangente). Para abordar esse tema, optou-se em partir da situação descrita no exemplo 1.3.1, para que, ao final, fosse possível relacionar o termo "taxa de variação" com "inclinação de reta tangente".

Como Caio se move duas vezes mais que Pedrinho, essa situação pode ser representada pela equação $c=f(p)=2 p$, onde $p$ representa a distância de Pedrinho ao centro da gangorra e $c=f(p)$ é a distância de Caio ao centro da mesma. O professor esboçou o gráfico dessa função, conforme ilustrado pelas Figuras 1.19A e 1.19B.

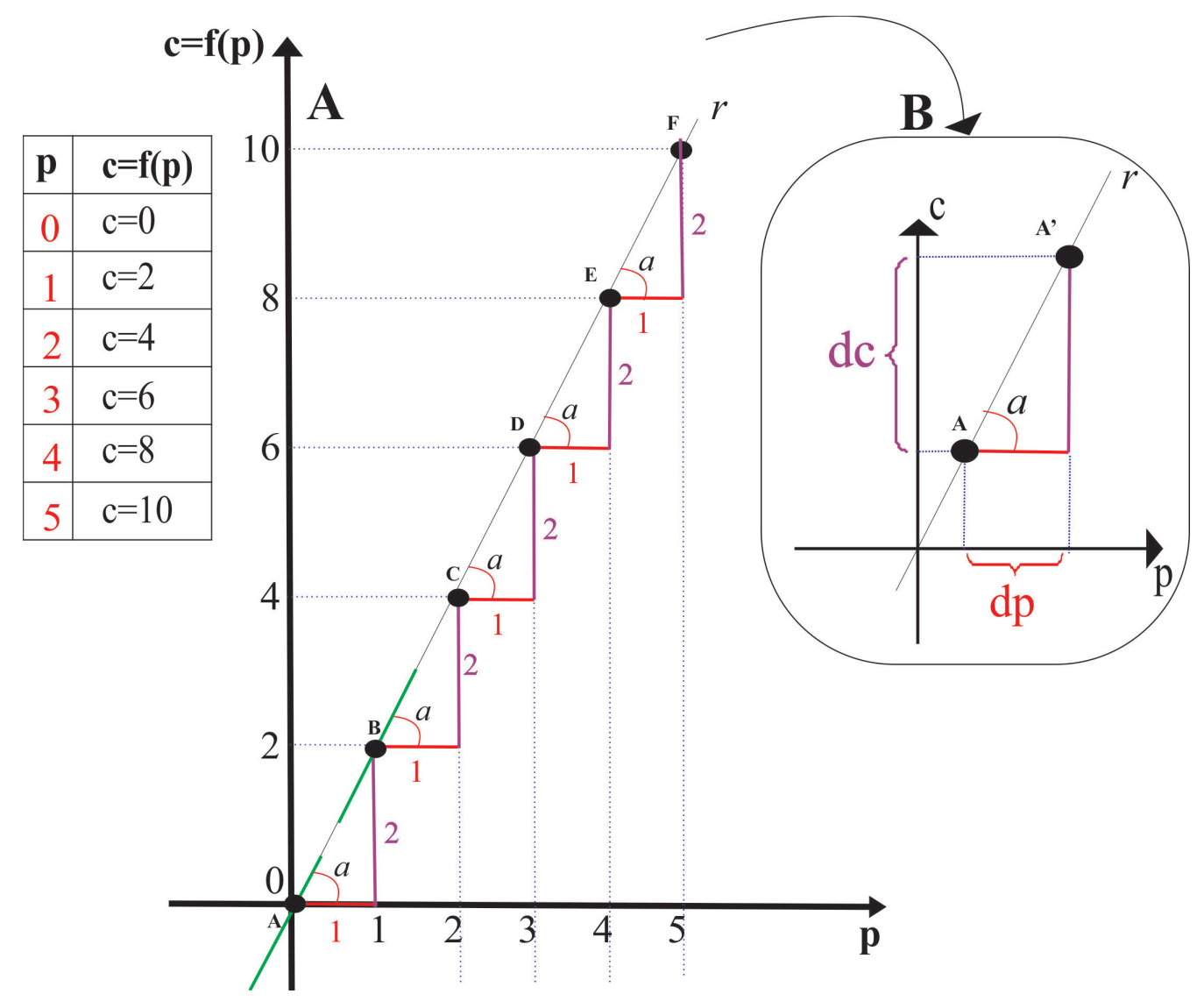

Figura 1.19: Gráfico de $c=f(p)$. 
Ao observar a Figura 1.19A, os alunos verificaram que a cada unidade que $p$ avança para a direita, $c=f(p)$ sobe (verticalmente) duas unidades. Isto é, à maneira que Pedrinho se desloca uma unidade do centro da gangorra, Caio se move duas unidades.

Neste instante, o professor pediu que os alunos observassem que a situação descrita pela Figura 1.19B, representa um exemplo de variação constante, isto é, se desenharmos retas tangentes em qualquer ponto da função $c=2 p$, a inclinação da reta será sempre a mesma, ou seja, para quaisquer dois pontos escolhidos aleatoriamente nessa reta tem-se uma inclinação $\alpha$, onde $\alpha$ representa o ângulo que a reta forma com o eixo $x$.

Observando a Figura 1.19B, os alunos perceberam que $d p$ é o cateto adjacente ao ângulo $\alpha$, e $d c$ é o cateto oposto a $\alpha$, portanto,

$$
\operatorname{tg} \alpha=\frac{d c}{d p}=2
$$

ou seja,

$$
\frac{d c}{d p}=2
$$

A partir dos dados acima, o professor comentou que o número 2 é chamado de coeficiente angular da reta $r$ e o representamos pela letra $m$. Diante disso, os alunos, com o auxílio do docente, concluíram que, se a derivada de Caio em relação a Pedrinho é igual a 2 , ou seja, $\frac{d c}{d p}=2$, e a situação expressa pela função $c=2 p$ representa o movimento de Caio em função ao de Pedrinho, então em uma função do primeiro grau, o coeficiente angular da reta representa a sua derivada.

Com esse exemplo foi possível observar que os alunos compreenderam a relação existente entre os termos "taxa de variação" e "inclinação da reta" e que esses dois termos estão relacionados com um assunto de grande importância na matemática: o estudo das derivadas.

\subsubsection{A derivada como um Tipo Especial de Limite}

Ao apresentar o gráfico da função $c=2 p$ foi possível introduzir com os alunos o conceito de variação constante, uma noção sobre o significado de inclinação de uma reta. Entretanto a maioria dos casos observados no nosso dia a dia não se limita às taxas de variações constantes. Diante disso, abordou-se o exemplo abaixo, no qual apresentou-se o crescimento de um recém-nascido até a sua fase adulta. O objetivo desse exemplo foi mostrar aos alunos a existência de taxas de variações não constantes. 


\section{Exemplo 1.3.3 (O Crescimento de um Recém-Nascido até os 20 Anos de Idade).} Inicialmente solicitou-se que os alunos imaginassem o crescimento de uma pessoa da infância até a fase adulta. O objetivo desta atividade foi despertar a atenção dos alunos sobre o processo de variação que ocorre quando uma criança nasce e se desenvolve. Para que o aluno percebesse de forma independente esse processo de taxa de variação, solicitamos a atenção do mesmos para a Figura 1.20.

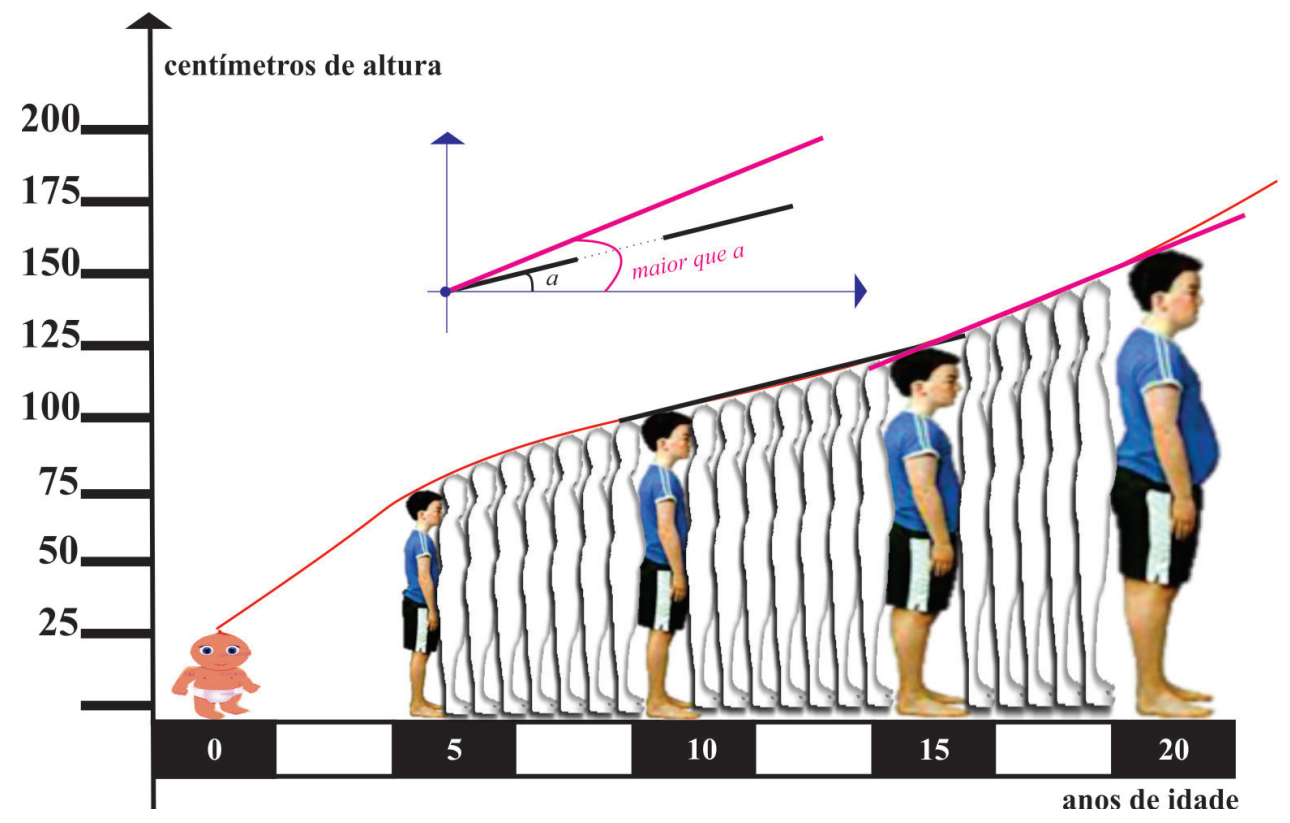

Figura 1.20: Estimativa do crescimento da infância até a fase adulta.

Na Figura 1.20, observa-se que, no período de 10 até 15 anos (reta secante preta) e no período de 15 até 20 anos (reta secante vermelha), as inclinações das retas secantes são diferentes, isto é, em um determinado período o garoto apresentou um crescimento maior do que no outro período.

Visto que, dos estudos do ensino médio e de conceitos abordadas neste trabalho, os alunos já tinham conhecimento de como proceder para o cálculo da inclinação de retas secantes, pediu-se que calculassem a taxa de variação do garoto no período de 10 a 15 anos e de 15 a 20 anos. Com isso, verificaram que a razão média de crescimento no período entre 10 e 15 anos é

$$
\frac{125 \mathrm{~cm}-100 \mathrm{~cm}}{10 \mathrm{anos}-5 \mathrm{anos}}=5 \mathrm{~cm} / \text { ano }
$$


e no período entre 15 e 20 anos é

$$
\frac{175 \mathrm{~cm}-125 \mathrm{~cm}}{10 \text { anos }-5 \text { anos }}=10 \mathrm{~cm} / \text { ano. }
$$

Os alunos foram orientados a observar que, ao se afirmar que o garoto, no período de 10 a 15 anos, cresceu $5 \mathrm{~cm} /$ ano, não significa que, por exemplo, o menino cresceu $5 \mathrm{~cm}$ entre 11 e 12 anos. O resultado encontrado representa apenas uma média, havendo períodos que o crescimento foi maior, e outros em que foi menor que $5 \mathrm{~cm}$. Além disso, o professor comentou que no estudo das derivadas, conseguimos analisar a variação de crescimento dessa pessoa em espaços de tempo menores, ou seja, 1 ano, 6 meses, 1 mês, 1 dia, etc. Mais ainda, é possível determinar a taxa de variação em um exato momento de tempo.

Com a finalidade de explicar de forma detalhada a situação acima, expôs-se a figura 1.21.

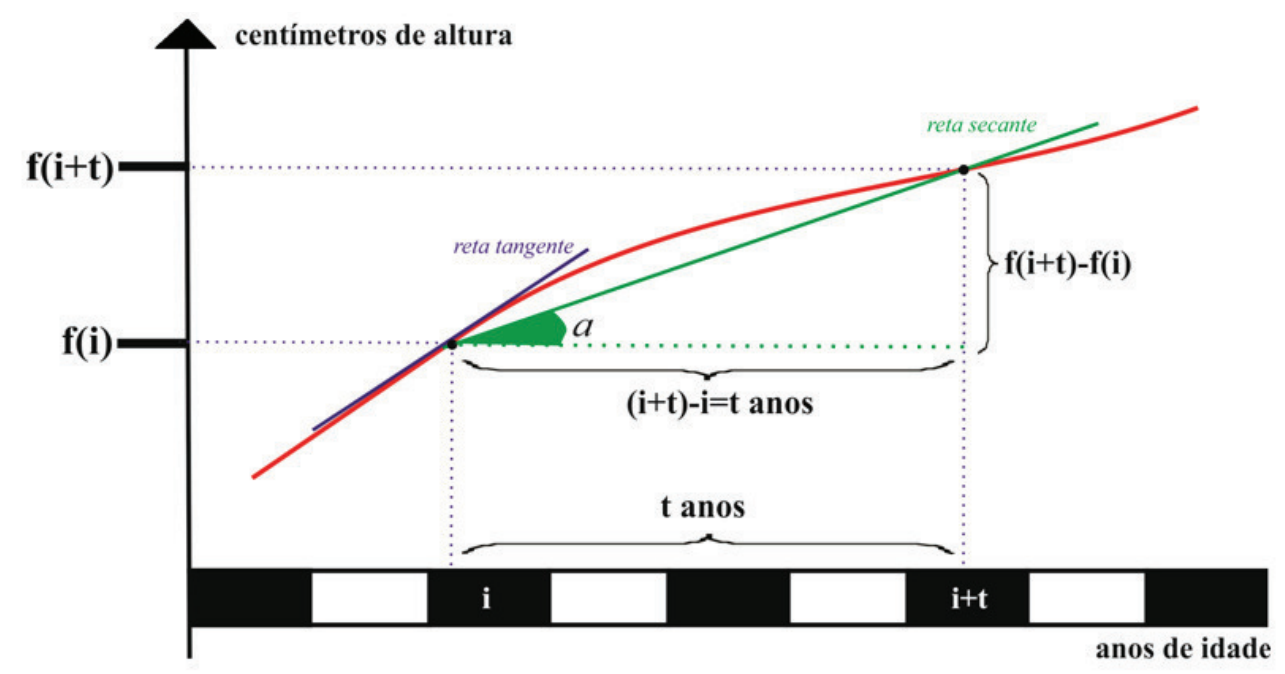

Figura 1.21: Comparando a reta secante com a reta tangente.

Ao analisar a Figura 1.21, alguns comentários foram feitos pelos alunos, dentre eles destacamos:

1) a reta secante passa por dois pontos da curva, o ponto $(i, f(i))$ e o ponto $(i+t, f(i+t))$.

2) com esses dois pontos é possível encontrar a média de crescimento dessa pessoa, recorrendo à definição de tangente, da seguinte forma:

$$
\operatorname{tg} \alpha=m=\frac{f(i+t)-f(i)}{i+t-i}=\frac{f(i+t)-f(i)}{t} .
$$


Em seguida o professor desafiou o grupo a desenvolver uma estratégia para tentar calcular a taxa de crescimento do garoto em um exato instante de tempo, isto é, exatamente no ponto $(i, f(i))$, sobre este ponto traçamos uma reta tangente.

Não houve nenhuma sugestão feita pelo grupo, apenas comentaram que, se utilizassem a fórmula apresentada na equação (1.1), necessitariam de dois pontos. Nesse momento o professor auxiliou os alunos apresentando a Figura 1.22.

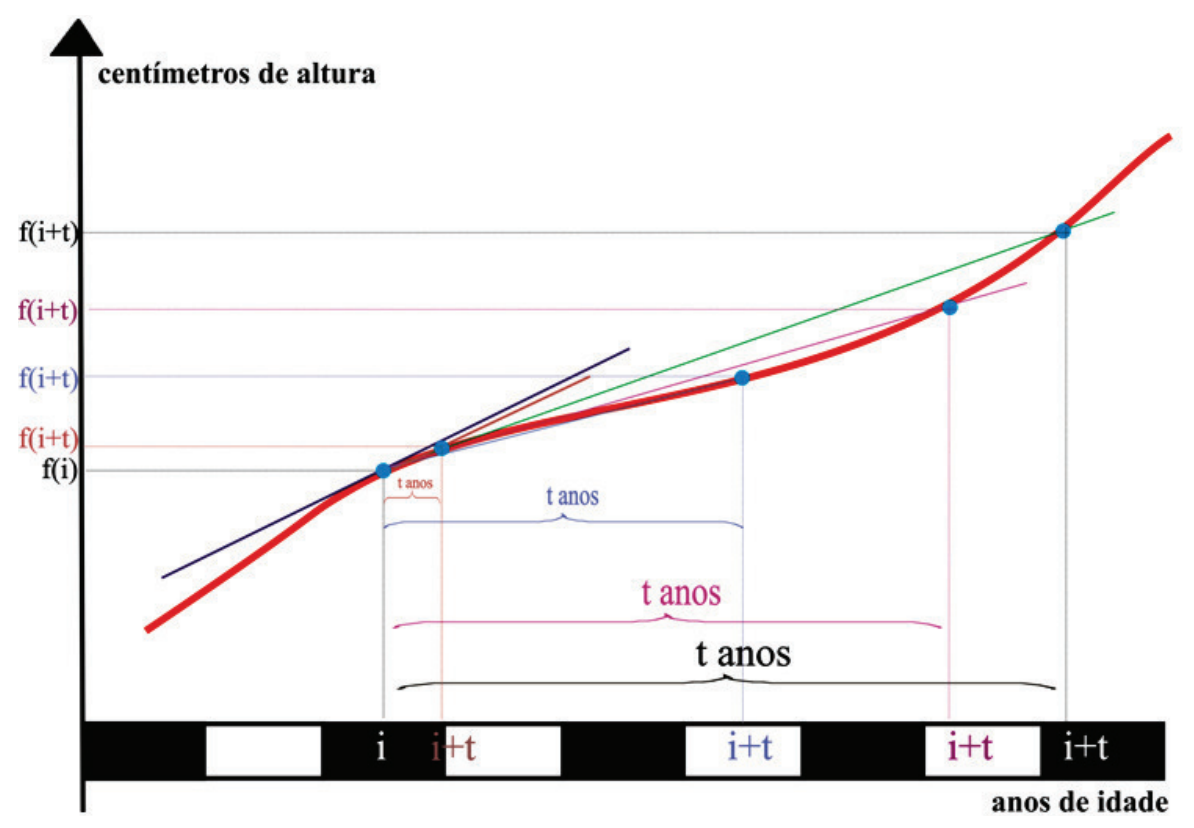

Figura 1.22: Aproximando a reta secante da reta tangente.

Em seguida o professor comentou que a estratégia seria tentar encontrar o coeficiente angular da reta tangente ao ponto . Para isto, deveriam escolher valores cada vez menores de $t$, de forma que a reta secante se aproxime da reta tangente.

Ao analisar o gráfico acima, verificamos que à medida que diminuímos os valores de $t, f(i+t)$ se aproxima de $f(i)$. Assim, é possível observar que a inclinações das retas secantes vão se aproximando da reta tangente.

Os alunos perceberam que, se quisermos encontrar as inclinação da reta tangente em um ponto exato, no caso $(i, f(i))$, devemos pensar no limite das inclinações das retas secantes $\left(\frac{f(i+t)-f(i)}{t}\right)$ quando $t$ tende a zero. Ou seja,

$$
\lim _{t \rightarrow 0} \frac{f(i+t)-f(i)}{t}
$$


A expressão acima permite encontrar a taxa de crescimento do garoto exatamente no tempo $t_{0}=i$. A esse limite chamamos de derivada de $f$ em $t=i$. Existem inúmeros símbolos para representar esse limite, um dos mais usados é $f^{\prime}(i)$.

Nesse momento, o professor reforçou com os alunos a situação abordada nos Exemplos 1.3.1 e 1.3.2, reforçando que $\frac{d c}{d p}=t g \alpha=2$ representa a derivada de Caio em relação a Pedrinho, sendo que $\frac{d c}{d p}$ é outra simbologia utilizada para representar o limite definido acima, chamado de derivada. Ao representar o movimento de Caio em relação ao de Pedrinho pela equação $c=f(p)=2 p$, poderíamos utilizar outros símbolos para a derivada, por exemplo, $c^{\prime}=2$ ou $f^{\prime}(p)=2$.

Exemplo 1.3.4. Considere os pontos $A=(x, f(x))$ e $B=((x+h), f(x+h))$ pertencentes à curva $f(x)=x^{2}$. Pelos pontos A e B traçamos uma reta secante, e por A uma reta tangente, conforme mostra a Figura 1.23.

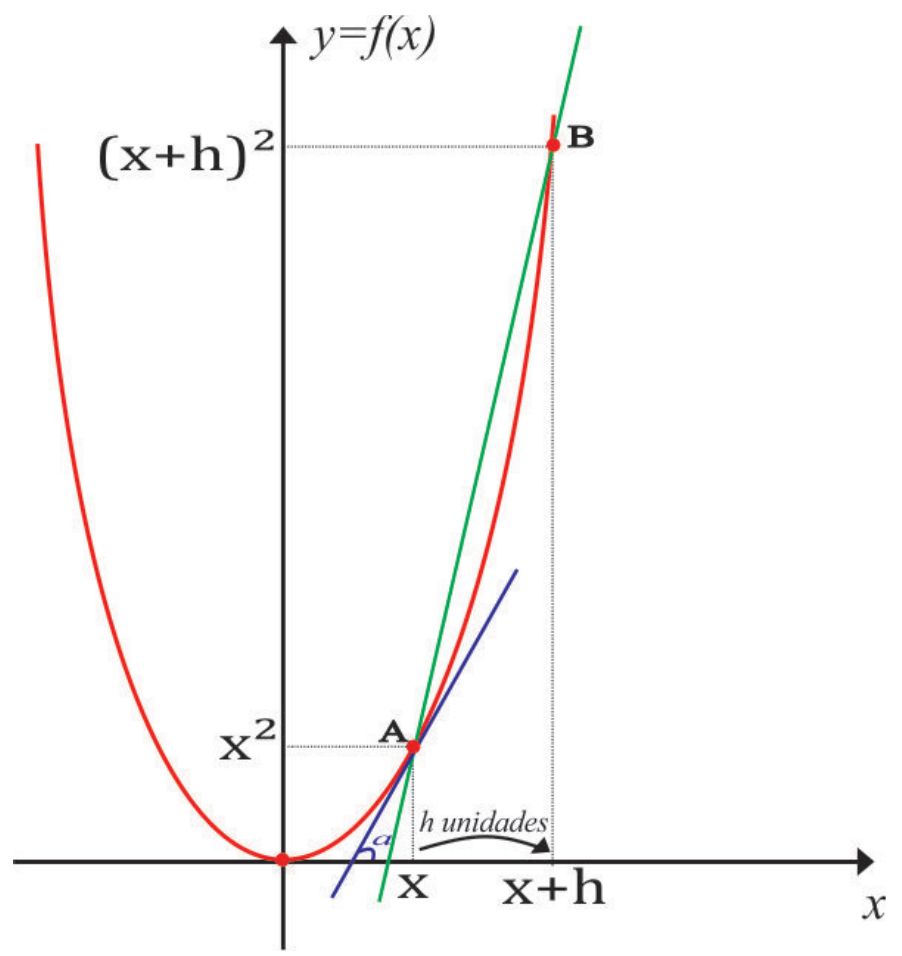

Figura 1.23: Gráfico de $f(x)=x^{2}$.

Solicitou-se que os alunos descobrissem o valor da inclinação da reta tangente no ponto A. A partir da ideia desenvolvida acima, os alunos seguiram o seguinte raciocínio:

$$
m=t g \alpha=\lim _{h \rightarrow 0} \frac{f(x+h)-f(x)}{x+h-x}=\lim _{h \rightarrow 0} \frac{(x+h)^{2}-x^{2}}{h}=\lim _{h \rightarrow 0} \frac{2 x h+h^{2}}{h}=\lim _{h \rightarrow 0} 2 x+h=2 x .
$$


Em outras palavras, $f^{\prime}(x)=2 x$.

Em seguida, para fixar o cálculo de derivadas, à partir da definição, organizou-se a sala em duplas e solicitou-se que cada dupla calculasse a derivada de uma função. As funções propostas eram constantes, do $1^{\circ}, 2^{\circ}$ e $3^{\circ}$ graus. Com o auxílio do professor, todos conseguiram calcular as derivadas das funções dadas.

Finalmente, foi realizado um debate entre os alunos, em que cada dupla comentou suas dificuldades e facilidades sobre o assunto aqui tratado. A maioria concluiu que o desenvolvimento algébrico nem sempre se dá de forma simples. Se uma função apresentar o grau do polinômio maior, podemos ter dificuldade em sua resolução, e o tempo até alcançar o resultado aumentaria.

\subsubsection{Regras Básicas da Diferenciação}

Nessa etapa do estudo, o objetivo foi mostrar para os alunos que, quando tratamos de derivadas, nem sempre se faz necessário o processo descrito na seção anterior. Para isso, existem as regras de derivação. Entretanto, não podemos desmerecer a importância dos cálculos realizados a partir da definição, pois com base neles desenvolvemos as regras apresentadas a seguir.

Estas regras de derivação foram introduzidas partindo-se de exemplos algébricos, e a única regra de derivação que demonstramos aos alunos foi a do produto, com a finalidade de que o grupo pudesse observar a importância do formalismo matemático.

\subsubsection{A Regra da Potência}

Para encontrar a derivada de uma função em forma de potência, por exemplo $y=x^{2}$, deve-se descer o expoente multiplicando-o pela função. Em seguida deve-se diminuir uma unidade no expoente, conforme esquematizado na Figura 1.24.

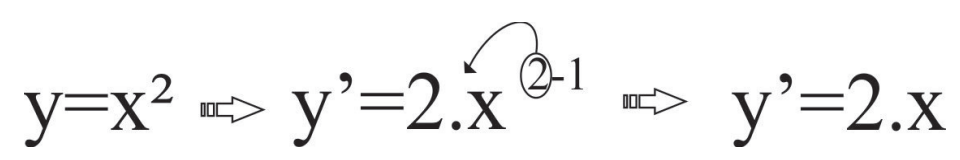

Figura 1.24: Derivada da função $y=x^{2}$.

Em seguida pediu-se que o grupo comparasse o resultado encontrado com o obtido no exemplo 1.3.4. Os alunos perceberam que os resultados foram iguais e assim puderam perceber a validade da regra apresentada. 
Logo após, o professor comentou que a regra geral para derivar a função $f(x)=x^{n}$ é $f^{\prime}(x)=$ $n . x^{n-1}$. Desenvolveu-se com os estudantes a demonstração da regra em questão a partir do conceito de limite. Não se obteve muito sucesso nessa demonstração, pois utilizou-se grande parte do tempo revisando conceitos algébricos, entre eles o binômio de Newton.

Fazendo uso da regra da potência, os alunos conseguiram calcular a derivada de várias funções polinomiais.

\subsubsection{A Derivada de Funções do $1^{\circ}$ Grau e Funções Constantes}

Nessa seção apresentamos uma interpretação geométrica para o cálculo de derivadas de funções do $1^{\circ}$ grau, com o intuito de reforçar aos alunos que a inclinação da reta secante em qualquer dois pontos de uma reta é igual a inclinação da reta tangente para qualquer ponto dessa reta, conforme vimos em itens anteriores.

Quanto ao cálculo da derivada de funções constantes, teve - se a preocupação de que os alunos observassem que a reta dessas funções são paralelas com o eixo $x$, sendo assim, pode se dizer que sua inclinação é nula.

Para discutir esses dois conceitos e interligá - los as regras de derivação desenvolveu - se o exemplo abaixo.

Exemplo 1.3.5 (Derivada de Funções do $1^{\circ}$ Grau e Funções Constantes). Introduziu-se esse exemplo apresentando novamente a função $f(p)=2 p$. Os alunos calcularam a derivada dessa função utilizando a regra da potência e obtiveram como resultado $f^{\prime}(p)=2$. De forma satisfatória, os alunos recordaram que não precisavam utilizar a regra da potência para o cálculo da derivada dessa função, pois o coeficiente angular da reta representa a sua derivada.

O professor apresentou várias outras funções do $1^{\circ}$ grau, e os integrantes do grupo perceberam que todas as situações eram análogas ao caso anterior.

Em seguida, pediu-se que o grupo calculasse a derivada da função constante $f(x)=5$. Como resposta, os alunos observaram que $f(x)$ poderia ser escrita como $f(x)=5 . x^{0}$ e assim, $f^{\prime}(x)=0$.

Para que os alunos notassem que não era necessário utilizar a regra da potência no cálculo da derivada de funções constantes, pediu-se que os mesmos atentassem novamente para o fato da relação existente entre derivada e inclinação de reta tangente. Para isto, solicitou-se que o grupo desenhasse o gráfico da função $f(x)=5$. Veja a Figura 1.25. 


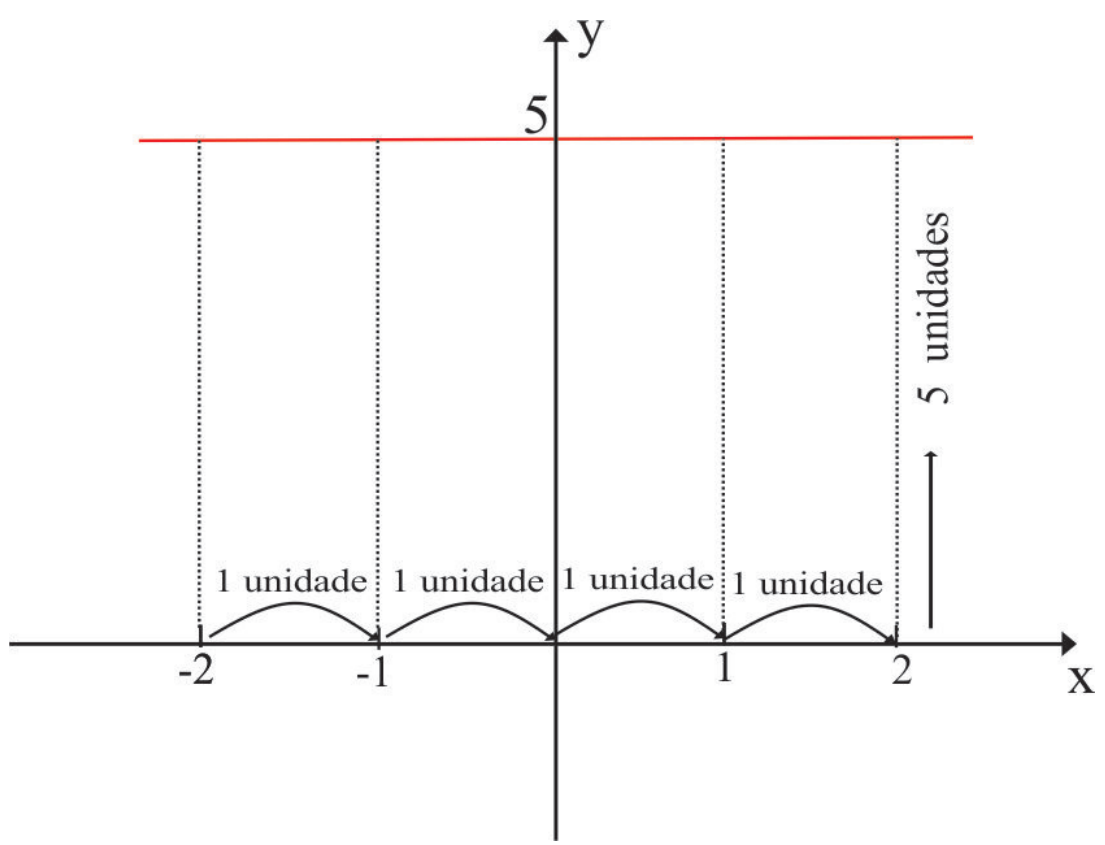

Figura 1.25: Gráfico de $f(x)=5$.

Ao realizar a análise, os alunos perceberam que, para qualquer ponto escolhido em $x$, a sua reta tangente é $f(x)=5$, e que essa reta tangente possui inclinação igual à zero.

Essas considerações foram relevantes no processo de formação do raciocínio de aprendizagem dos discentes. Por meio delas, os alunos conseguiram relacionar as regras de derivação com os estudos abordados em itens anteriores.

\subsubsection{A Regra da Soma}

De forma breve comentou-se com os alunos que quando se quer calcular a derivada da soma de funções ou da diferença de funções, basta encontrarmos a derivada de cada uma delas, separadamente, e somá-las. Assim, observa-se que os sinais de adição e subtração não são afetados pela diferenciação.

Por exemplo, para derivar a função $y=3 x^{5}-x^{4}-2 x^{3}+6 x^{2}+5$ podemos derivar separadamente cada parcela e somá-las, obtendo $y^{\prime}=15 x^{4}-4 x^{3}-6 x^{2}+12 x+5$.

Para fixar a compreensão desse tópico, apresentamos uma lista contendo 10 funções polinomiais, com a finalidade de que fossem derivadas. Os estudantes não apresentaram nenhuma dificuldade durante a resolução e compreenderam de forma satisfatória essa regra de derivação. 


\subsubsection{A Regra do Produto}

A regra do produto é usada quando temos uma função definida pelo produto de duas ou mais funções, por exemplo, $f(x)=(x+5) \cdot\left(x^{2}+2 x+1\right)$. Comentou-se com os alunos que podemos representar essa função na forma $f(x)=u$, onde $u=(x+5)$ e $v=\left(x^{2}+2 x+1\right)$. Diante do exemplo apresentado, os alunos foram desafiados a encontrarem uma alternativa para o cálculo de $f^{\prime}(x)$.

É interessante observar que, alguns alunos comentaram que para calcular a derivada da função $f(x)=u . v$ bastava derivar as funções $u$ e $v$, e em seguida realizar a multiplicação das derivadas.

É comum que a maioria dos alunos relacione a regra do produto com a regra da soma. Com a finalidade de desenvolver o raciocínio de maneira independente no grupo, desenvolvemos o exemplo abaixo.

Exemplo 1.3.6 (O Produto das Derivadas é a Derivada do Produto?). Solicitou-se aos alunos que calculassem a derivada da função $f(x)=(x+5) \cdot\left(x^{2}+2 x+1\right)$

Primeiramente, seguindo a sugestão dos alunos, calculou-se as derivadas das funções $u(x)=$ $(x+5)$ e $v(x)=\left(x^{2}+2 x+1\right)$ e em seguida multiplicou-se $u^{\prime}(x)$ e $v^{\prime}(x)$. Como $u^{\prime}(x)=1$ e $v^{\prime}(x)=2 x+2$, obtivemos $f^{\prime}(x)=u^{\prime}(x) \cdot v^{\prime}(x)=1 \cdot(2 x+2)=2 x+2$.

Em seguida, pediu-se que o grupo calculasse o produto dessas duas funções e logo após, calculassem a derivada da função obtida. Como solução, encontram

$$
f(x)=x^{3}+7 x^{2}+11 x+5 \rightarrow f^{\prime}(x)=3 x^{2}+14 x+11
$$

Como os resultados acima foram distintos, os alunos perceberam que, quando temos uma função definida por um produto, não podemos derivar cada um de seus fatores e multiplicá-los. Portanto, concluíram que o caminho mais seguro é desenvolver o produto, representando a função produto em uma função polinomial e, posteriormente, aplicar a derivada.

Entretanto, ressaltou-se aos alunos que nem sempre é simples calcular o produto entre duas funções, pois elas podem, por exemplo, estar elevadas a enormes potências, dificultando a multiplicação. Sendo assim, apresentamos ao grupo um caminho alternativo, conhecido como regra do produto.

Regra do produto: dada a função $f(x)=u(x) \cdot v(x)$, sua derivada é dada por $f^{\prime}(x)=u^{\prime}(x) \cdot v(x)+$ $u(x) \cdot v^{\prime}(x)$. 
Para "mostrar" que a regra do produto funciona, derivamos a função $f(x)=(x+5) \cdot\left(x^{2}+2 x+1\right)$ a partir da regra apresentada

$$
\begin{aligned}
f^{\prime}(x) & =(x+5)^{\prime} \cdot\left(x^{2}+2 x+1\right)+(x+5) \cdot\left(x^{2}+2 x+1\right)^{\prime} \\
& =1 \cdot\left(x^{2}+2 x+1\right)+(x+5) \cdot(2 x+2 \\
& =3 x^{2}+14 x+11 .
\end{aligned}
$$

Diante desse resultado os alunos perceberam que, desta vez, a regra parecia ser confiável.

Em seguida desenvolvemos a demonstração da regra do produto a partir da definição de derivada, para que os alunos pudessem perceber que as regras que estavam sendo apresentadas a eles são realmente válidas.

Demonstração da regra do produto.

Considere a função $f(x)=u(x) \cdot v(x)$. Sabemos que

$$
f^{\prime}(x)=\lim _{h \rightarrow 0} \frac{f(x+h)-f(x)}{h} .
$$

Observe que $f(x+h)=u(x+h) \cdot v(x+h)$. Logo,

$$
f^{\prime}(x)=\lim _{h \rightarrow 0} \frac{u(x+h) \cdot v(x+h)-u(x) \cdot v(x)}{h} .
$$

Antes de continuar, pedimos que os alunos observassem que, quando adicionamos e subtraímos uma mesma quantidade a uma determinada função ou expressão, o seu resultado não se altera. Em seguida, somamos e subtraimos

$$
\frac{u(x+h) \cdot v(x)}{h}
$$

na expressão de $f^{\prime}(x)$ e obtemos:

$$
\begin{aligned}
f^{\prime}(x) & =\lim _{h \rightarrow 0} \frac{u(x+h) \cdot v(x+h)-u(x) \cdot v(x)}{h}+\frac{u(x+h) \cdot v(x)}{h}-\frac{u(x+h) \cdot v(x)}{h} \\
& =\lim _{h \rightarrow 0} \frac{u(x+h) \cdot v(x+h)-u(x) \cdot v(x)+u(x+h) \cdot v(x)-u(x+h) \cdot v(x)}{h} \\
& =\lim _{h \rightarrow 0} \frac{u(x+h) \cdot v(x+h)-u(x+h) \cdot v(x)+u(x+h) \cdot v(x)-u(x) \cdot v(x)}{h} \\
& =\lim _{h \rightarrow 0} \frac{u(x+h) \cdot[v(x+h)-v(x)]+v(x)[u(x+h)-u(x)]}{h} \\
& =\lim _{h \rightarrow 0} u(x+h) \cdot \lim _{h \rightarrow 0} \frac{v(x+h)-v(x)}{h}+\lim _{h \rightarrow 0} v(x) \cdot \lim _{h \rightarrow 0} \frac{u(x+h)-u(x)}{h}
\end{aligned}
$$


Como $\lim _{h \rightarrow 0} u(x+h)=u(x)$ e $\lim _{h \rightarrow 0} v(x)=v(x)$, temos que,

$$
\begin{aligned}
f^{\prime}(x) & =u(x) \cdot \lim _{h \rightarrow 0} \frac{v(x+h)-v(x)}{h}+v(x) \cdot \lim _{h \rightarrow 0} \frac{u(x+h)-u(x)}{h} \\
& =u(x) \cdot v^{\prime}(x)+v(x) \cdot u^{\prime}(x)=u^{\prime}(x) \cdot v(x)+u(x) \cdot v^{\prime}(x)
\end{aligned}
$$

Os alunos ficaram surpresos com o final da demonstração, que provou a regra do produto partindo da definição de derivadas. Posteriormente, foi dito ao grupo que a demonstração acima só é possível desde que seus limites existam.

\subsubsection{A Regra do Quociente}

Como no caso do produto de duas funções, dada $f(x)=\frac{u(x)}{v(x)}$ definida pelo quociente de duas funções, não podemos derivar $u(x)$ e $v(x)$ e logo após realizar a divisão de $u^{\prime}(x)$ por $v^{\prime}(x)$. Para que os alunos não relacionassem a regra do quociente com a da soma desenvolvemos o exemplo abaixo.

Exemplo 1.3.7 (A Regra do Quociente). Neste exemplo retomou-se o gráfico das funções $f(x)=x+2$ e $g(x)=\frac{x^{2}-4}{x-2}$ exibidas pela Figura 1.12. Inicialmente, os alunos perceberam que estas duas funções são idênticas, com exceção do ponto $x=2$. Ao derivar a função $f(x)=x+2$, os alunos obtiveram como resultado $f^{\prime}(x)=1$. Sendo assim, ao derivarem $g(x)$ deveriam encontrar como solução $g^{\prime}(x)=1$, para $x \neq 2$.

Em seguida pediu-se que os alunos calculassem a derivada da função $g(x)$. Um dos alunos sugeriu que o grupo derivasse primeiramente $u(x)=x^{2}-4$ e depois $v(x)=x-2$. Obtiveram como solução $u^{\prime}(x)=2 x$ e $v^{\prime}(x)=1$, sendo assim, $g^{\prime}(x)=2 x$. Ao perceberem que $f^{\prime}(x) \neq g^{\prime}(x)$, o grupo constatou que na regra do quociente, não se pode calcular separadamente o numerador e o denominador e depois realizar o quociente. Sendo assim, o professor apresentou ao grupo a regra do quociente.

Regra do quociente: dada a função $g(x)=\frac{u(x)}{v(x)}$, sua derivada é dada por

$$
g^{\prime}(x)=\frac{u^{\prime}(x) \cdot v(x)-u(x) \cdot v^{\prime}(x)}{v(x)^{2}}
$$

Para "mostrar" que a regra do quociente funciona, derivamos a função

$$
g(x)=\frac{x^{2}-4}{x-2}
$$


a partir da regra apresentada.

$$
\begin{aligned}
g^{\prime}(x) & =\frac{\left(x^{2}-4\right)^{\prime} \cdot(x-2)-\left[\left(x^{2}-4\right)(x-2)^{\prime}\right]}{(x-2)^{2}} \\
& =\frac{2 x \cdot(x-2)-x^{2}+4}{x^{2}-4 x+4} \\
& =\frac{2 x^{2}-4 x-x^{2}+4}{x^{2}-4 x+4} \\
& =\frac{x^{2}-4 x+4}{x^{2}-4 x+4}=1 ; \text { com } x \neq 2 .
\end{aligned}
$$

Diante desse resultado os alunos notaram que $g^{\prime}(x)=f^{\prime}(x)$ e assim perceberam que a regra do quociente parecia ser confiável.

Para finalizar, propomos uma lista com dez funções em forma de produto e quociente a serem derivadas. Em geral, os alunos conseguiram aplicar facilmente a regra do produto e do quociente.

\subsubsection{Pontos Críticos de uma Função e Pontos de Máximo e Mínimo}

Os conceitos de pontos de máximo e de mínimo são fundamentais em muitas aplicações. Assim, antes de introduzir esses conceitos, debateu-se com o grupo a aplicabilidade desses termos em diversas situações do nosso cotidiano.

Sabe-se que algumas das aplicações mais importantes do cálculo diferencial e integral estão relacionadas aos problemas de otimização, em que o objetivo é encontrar o melhor caminho de se resolver uma determinada situação-problema. Como exemplo, podemos citar:

1) quais são as medidas de uma caixa que minimizam (ponto de mínimo) o custo de um manufaturado?;

2) qual é a aceleração máxima (ponto de máximo) de um ônibus espacial para que os astronautas suportem os efeitos dessa aceleração?;

3) qual deve ser o raio de uma traqueia (ponto de máximo) contraída para expelir mais rapidamente o ar durante uma tosse?;

4) sob que ângulo os vasos sanguíneos devem se ramificar de forma que minimizem (ponto de mínimo) o gasto de energia pelo coração no bombeamento do sangue? 
Os problemas apresentados acima podem ser reduzidos ao fato de encontrar os valores de máximo e mínimo de uma função, e discutir esses exemplos antes de introduzir definições e conceitos teóricos causou uma motivação no grupo.

Para introduzir a noção de pontos de máximo e mínimo, apresentou - se o seguinte exemplo:

Exemplo 1.3.8 (A Aplicação do Cálculo Através de uma Viagem de Carro). Solicitou-se que os alunos imaginassem uma viagem de carro em uma colina, com muitas montanhas e que o caminho dessa viagem fosse representado pela Figura 1.26.

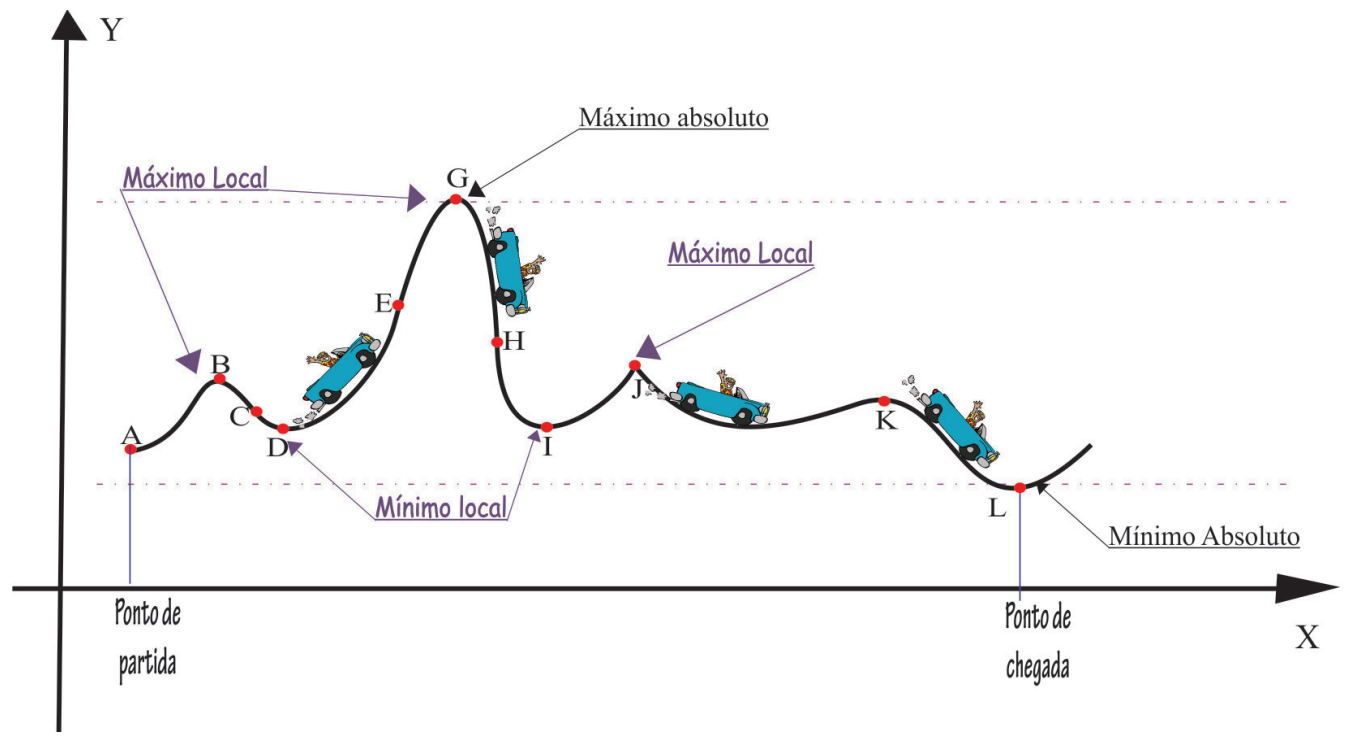

Figura 1.26: Viagem para uma colina, com diversos pontos a serem explorados.

Ao analisar a Figura 1.26, algumas observações foram feitas pelo professor e estão descritas abaixo.

1) Cada ponto da curva relaciona - se com a inclinação da estrada e, como já foi visto, inclinação e derivada são conceitos equivalentes;

2) do ponto A até o ponto B o motorista sobe, e cada reta tangente desenhada no trecho é crescente. Logo podemos dizer que sua derivada é positiva;

3) ao desenharmos a reta tangente no ponto B é possível observar que essa reta é paralela ao eixo $\mathrm{X}$, ou seja, a inclinação dessa reta é de zero . Logo, podemos dizer que a derivada da função nesse ponto é igual a zero; 
4) como do ponto B até o ponto D o motorista desce, cada reta tangente desenhada no trecho é decrescente. Logo podemos dizer que sua derivada é negativa.

A partir das observações acima, definiu-se o que é o ponto crítico de uma função. Um ponto crítico de uma função $f(x)$ é um ponto $x_{0}$ em que a inclinação da reta tangente ao gráfico de $f(x)$ em $\left(x_{0}, f\left(x_{0}\right)\right)$ é igual a zero. Esse ponto pode ser também onde existem infinitas retas tangentes. Nesse caso, dizemos que a sua derivada não existe. Em geral, $x_{0}$ é um ponto crítico de $f(x)$ se $f^{\prime}\left(x_{0}\right)=0$ ou $f^{\prime}\left(x_{0}\right)$ não existe.

Em seguida o professor desafiou os alunos a encontrarem outros pontos críticos no percurso descrito na Figura 1.26. De forma satisfatória, os mesmos comentaram que os pontos B, G, I, J e L são pontos críticos da função.

Diante das respostas apresentadas, o professor reforçou que os pontos B, G, I e L são pontos críticos da função e a sua derivada é igual a zero, pois ao desenharmos uma reta tangente em cada um desses pontos a sua inclinação é nula. Entretanto, o ponto J também é um ponto crítico, porém a sua derivada não existe. Para detalhar essa situação, comentou-se que o ponto J é um ponto que possui uma forma de bico (vértice). Logo, ao desenharmos uma reta tangente nesse ponto, podemos ter uma inclinação igual à zero, positiva ou negativa. Isto é, podemos ter infinitas retas tangentes, conforme mostra Figura 1.27.

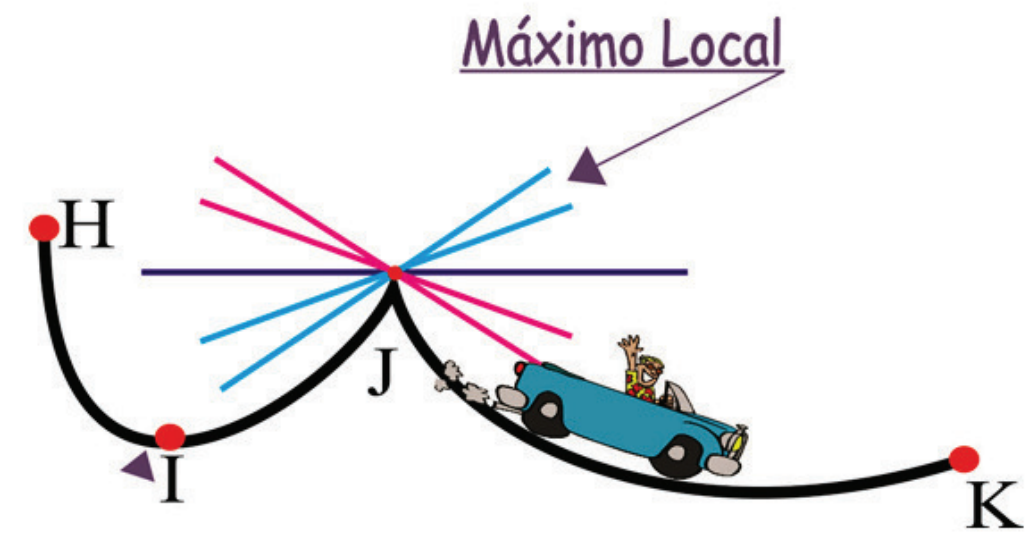

Figura 1.27: Um ponto crítico no qual a derivada não existe. 
Para introduzir os conceitos de máximo e mínimo através da trajetória da viagem, o professor fez alguns comentários:

1) Entre os pontos A e D, o ponto B é o mais alto, mas isso não acontece em todo o percurso;

2) entre dois pontos próximos de $\mathrm{D}$, percebe-se que o ponto $\mathrm{D}$ é o mais baixo, mas não é o mais baixo em todo o percurso;

3) matematicamente, dizemos que B é um ponto de máximo local e que D é um ponto de mínimo local;

4) se o motorista subir a colina até chegar ao ponto $\mathrm{G}$ e descer do carro para admirar a paisagem, com certeza terá uma visão de todo o trajeto. Assim, perceberá que o ponto G é o maior de toda a viagem;

5) matematicamente, dizemos que G é o ponto de máximo absoluto (ou global) da função cujo gráfico é dado pela trajetória da Figura 1.26;

6) o ponto L é o mais baixo de todo o percurso. Logo, dizemos que L é o ponto de mínimo absoluto (ou global) da função cujo gráfico é dado pela trajetória da Figura 1.26;

7) se a viagem não acabasse no ponto L poderíamos ter um novo ponto de máximo absoluto e o ponto $\mathrm{G}$ passaria a ser um ponto de máximo local. O mesmo vale para o ponto de mínimo absoluto.

Em seguida os alunos indicaram todos os pontos de máximos e mínimos locais que aparecem na Figura 1.26 .

O professor reforçou aos alunos o fato de que todos os pontos de máximos e mínimos locais devem ocorrer em pontos críticos, e mais ainda, ressaltou que um ponto de máximo local é um ponto no qual a inclinação das retas tangentes à curva muda o sinal de positivo para negativo, como mostra a Figura 1.28 (A). Raciocínio similar é válido para um ponto de mínimo local. Veja a Figura $1.28(\mathrm{~B})$ 


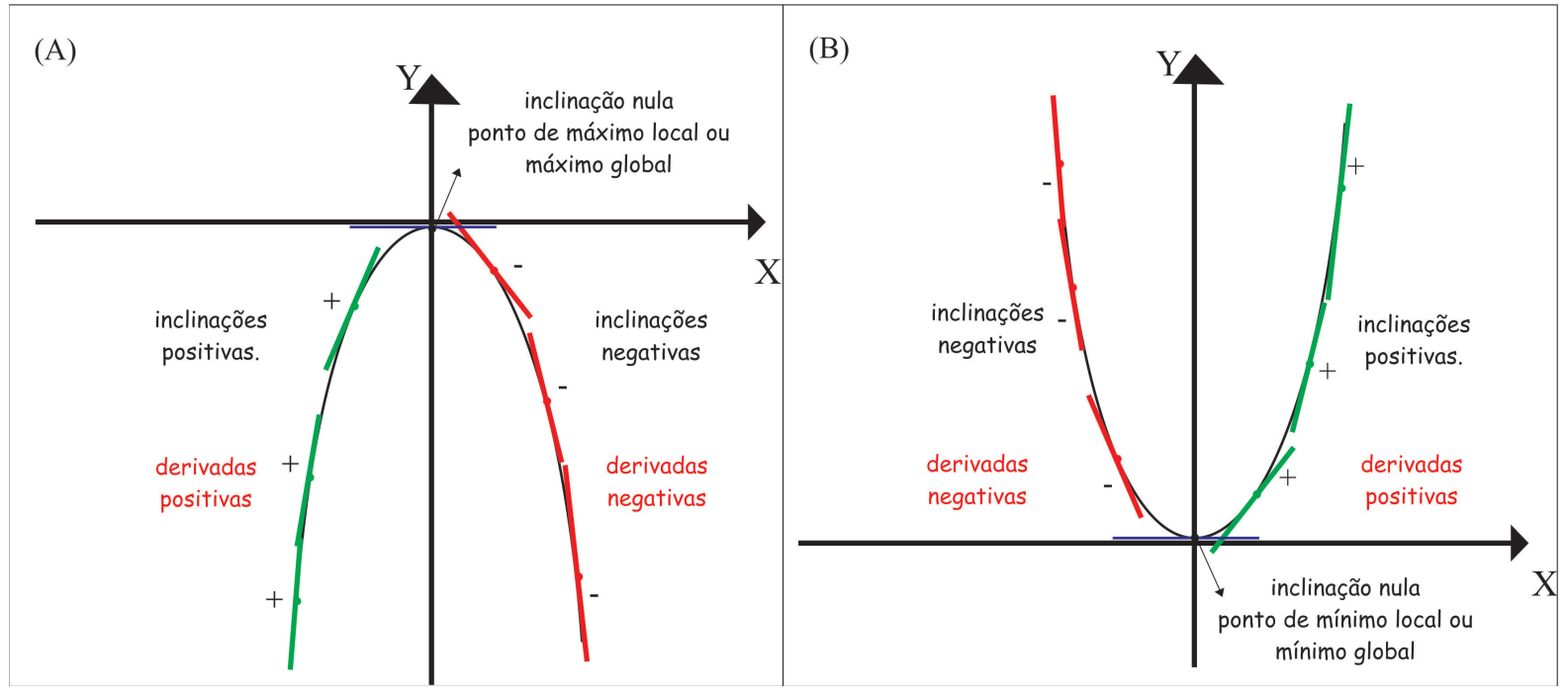

Figura 1.28: Interpretação geométrica para um ponto de máximo ou mínimo local.

É interessante notar que os alunos conseguiram entender com facilidade a interpretação geométrica apresentada acima.

Finalmente, enfatizou-se que os pontos de máximo e mínimo são importantes para a construção de gráficos de funções. Além disso, como apresentamos no início dessa seção, muitos problemas práticos requerem minimizar um custo, ou maximizar uma área, ou de alguma forma, encontrar a melhor saída de uma situação. Assim, descrevemos o procedimento utilizado para encontrar esses pontos, para uma dada função $f(x)$.

Para encontrarmos os pontos de máximo ou de mínimo de uma função $f(x)$ devemos derivar $f(x)$, encontrar os zeros dessa função e por último estudar o seu sinal. Nos pontos em que houver troca de sinal teremos um ponto de máximo ou de mínimo.

Esse procedimento foi apresentado ao grupo a partir de alguns exemplos numéricos. Mais adiante apresentaremos uma atividade em que os alunos terão que esboçar o gráfico de uma função polinomial, e assim, farão uso dos conceitos de máximo e mínimo, bem como de um novo assunto: ponto de inflexão.

\subsubsection{Pontos de Inflexão}

Inicialmente, apresentou - se ao aluno o que é um ponto de inflexão através de observações a Figura 1.26, no qual o professor enfatizou a noção sobre mudança de concavidade. Em seguida foi 
apresentado o procedimento algébrico para o cálculo do ponto de inflexão, no qual desenvolveu - se um exemplo com o intuito em justificar os passos utilizados para o cálculo do ponto de inflexão.

\subsubsection{Noção Intuitiva sobre o que é um Ponto de Inflexão}

O nosso objetivo nesta seção é de que o aluno seja capaz de localizar um ponto de inflexão. Para isso, solicitou-se que os mesmos retomassem a situação de aprendizagem desenvolvida no Exemplo 1.3.8. Em especial, pediu-se que observassem que, ao analisar o percurso descrito na viagem, outro ponto de interesse é o ponto C, conforme descrito na Figura 1.29.

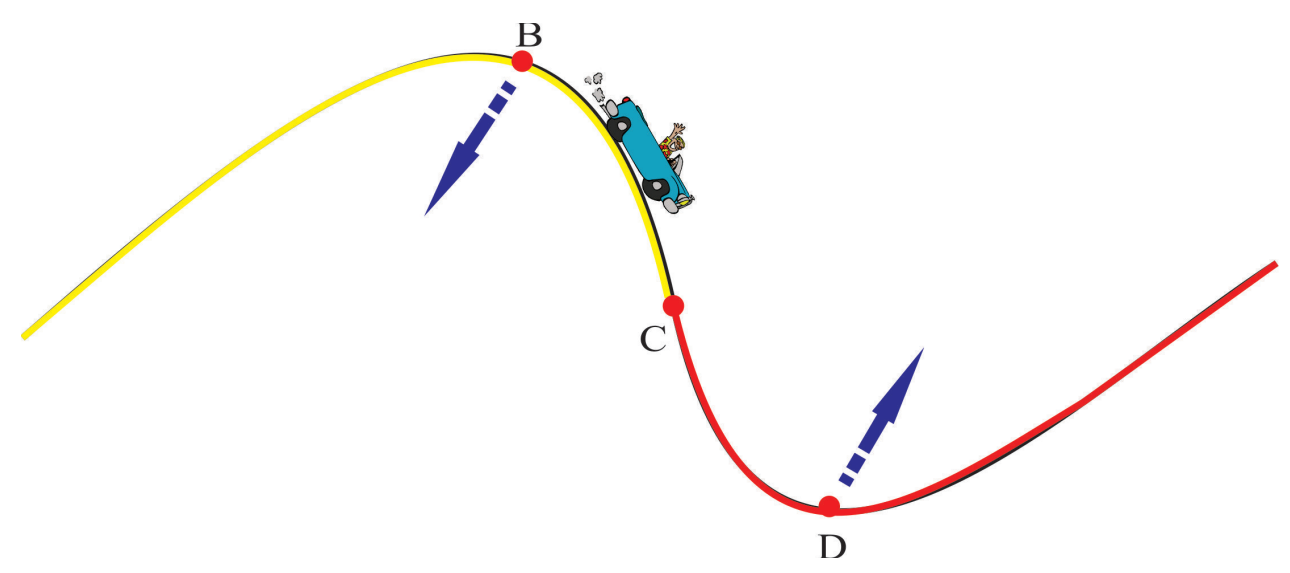

Figura 1.29: Problema de matemática regular.

Ao percorrer o trecho BD o motorista está apenas descendo a rampa, porém observa-se que no intervalo $\mathrm{BC}$ a inclinação da rampa é maior. Ao analisar esse intervalo, verifica-se que existe uma concavidade voltada para baixo. No trecho CD, o carro continua a descer, mas numa inclinação menor. Ao reparar esse trecho é possível perceber que existe uma concavidade voltada para cima. O professor pediu que os alunos atentassem ao fato de que, exatamente no ponto $\mathrm{C}$, existe uma troca de concavidade.

Diante disso, comentou-se com os alunos que, o ponto $\mathrm{C}$ é chamado de ponto de inflexão, e que esse ponto é sobre uma curva na qual existe uma troca de concavidade. O professor acrescentou ao grupo que esse ponto pode ocorrer em um trecho decrescente (trecho formado por inclinações de retas decrescentes), como no Exemplo 2.1.4, ou em um trecho crescente (trecho formado por inclinações de retas crescentes). 
Em seguida, pediu-se que o grupo descobrisse os pontos de inflexão que aparecem na Figura 1.26. Os alunos observaram e justificaram que além de $\mathrm{C}$, os pontos $\mathrm{E}, \mathrm{H}$ e $\mathrm{K}$ são pontos de inflexão. Como justificativa para o ponto E, comentaram que no trecho DG é visível uma subida (neste trecho todas as inclinações de retas tangentes são crescentes), logo é possível existir um ponto de inflexão.

Concluíram que o ponto E é um ponto de inflexão, pois no trecho DE a rampa é menos inclinada e apresenta uma concavidade voltada para cima, enquanto no trecho EG verifica-se uma rampa mais inclinada, com uma concavidade voltada para baixo, e exatamente no ponto E é possível observar uma troca de concavidade. As justificativas para os pontos H e K se apresentaram de forma análoga.

\subsubsection{Justificativa e Procedimento Algébrico para Encontrar o Ponto de Inflexão}

Inicialmente, o professor apresentou aos alunos o procedimento algébrico que deveriam realizar para encontrar e verificar se um ponto sobre a curva de uma função $f(x)$ é ou não um ponto de inflexão.

Dada uma função $f(x)$, para encontrarmos o(s) ponto(s) de inflexão da mesma, ao invés de derivar uma única vez a função, deve-se derivá-la duas vezes e em seguida estudar o sinal da segunda derivada.

Nos pontos em que existirem troca de sinal, teremos um ponto de inflexão, ou seja, existirá uma mudança de concavidade. Para que os alunos compreendessem os comentários transcritos acima, o professor apresentou uma função $f(x)$, a derivou duas vezes e estudou o sinal dessa função. Com o exemplo numérico percebeu - se que o grupo compreendeu de forma eficaz o processo álgebrico apresentado.

Com a finalidade de expor argumentos que justifiquem este procedimento apresentamos o exemplo abaixo.

Exemplo 1.3.9 (A Relação entre um ponto de Inflexão e a Segunda Derivada.). O objetivo principal nesse exemplo foi o de desenvolver uma situação de aprendizagem que justifique os procedimentos utilizados para o cálculo do ponto de inflexão.

Considerou-se a função $f(x)=-x^{3}+3 x^{2}-2$ e inicialmente pediu-se que os alunos encontrassem os pontos de máximo e de mínimo da função $f(x)$ e em seguida, com uso do software Geogebra, desenhassem o gráfico de $f(x)$, conforme mostra a Figura 1.30. 


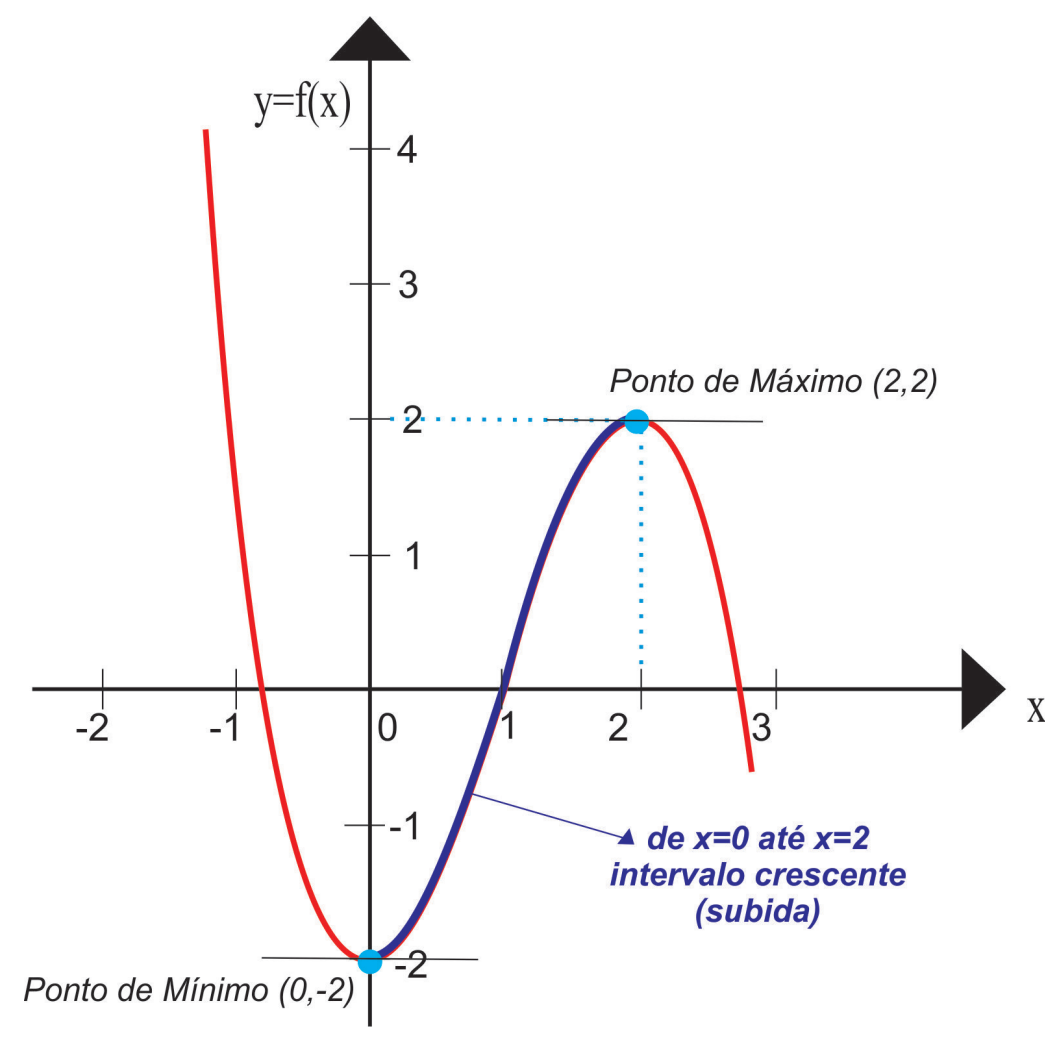

Figura 1.30: Gráfico da função $f(x)=-x^{3}+3 x^{2}-2$.

Ao analisarem a Figura 1.30, o professor acrescentou que entre o ponto mínimo e o ponto máximo de $f(x)$ poderá haver nenhum, um ou mais ponto(s) de inflexão e o nosso objetivo seria descobrir se este ponto existe, e se sim, indicar qual é esse ponto.

Para isso, recomendou-se que cada aluno seguisse os seguintes passos:

1) dividisse o intervalo $0 \leq x \leq 2$ de $f(x)$ em oito partes iguais e marcasse na curva as coordenadas do ponto $(x, y)$, correspondente a cada $x$ obtido;

2) desenhasse uma reta tangente a cada um desses pontos e, posteriormente, calculassem a derivada de cada uma dessas retas tangente. O resultado desses procedimentos foi apresentado na Figura 1.31 . 


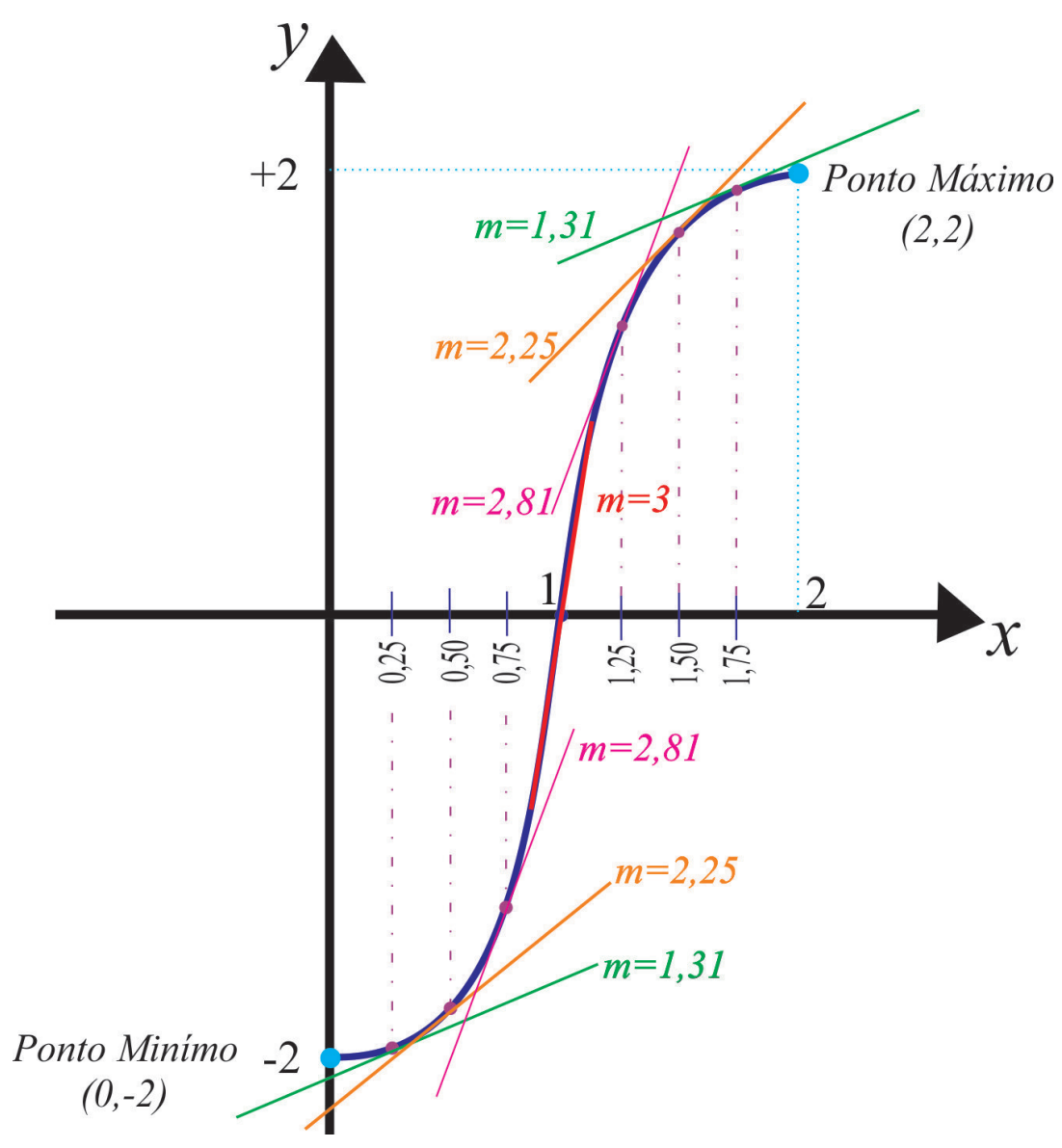

Figura 1.31: Retas tangentes desenhadas em $f(x)=-x^{3}+3 x^{2}-2$, com $0 \leq x \leq 2$.

Diante da Figura apresentada, o professor pediu que os alunos atentassem aos seguintes fatos:

1) no intervalo $0<x \leq 1$ as inclinações das retas tangentes estão aumentando. Esse aumento ocorre até $x=1$, no qual sua derivada é igual a três.

Dizemos que, quando as inclinações das retas tangentes, ou seja, o valor de suas derivadas está crescendo, ocorre o que chamamos de taxa de variação positiva.

2) No intervalo de $1<x<2$ as derivadas começam a diminuir até o ponto de máximo, isto é, $x=2$. Observa-se que as derivadas de cada reta nesse intervalo são positivas, porém estão diminuindo a cada instante. Neste caso, dizemos que a taxa de variação é negativa.

3) No ponto $x=1$ temos o instante exato em que as inclinações das retas tangentes, ou seja, as suas derivadas, deixam de aumentar e começam a diminuir. Neste caso dizemos que a taxa de 
variação é nula.

Com as observações acima os alunos já perceberam que $x=1$ ou o ponto $(1,0)$ era o único ponto de inflexão. Para mostrarmos o processo algébrico, o professor desenvolveu os seguintes passos com os alunos.

1) Para encontrar os pontos de inflexão de $f^{\prime}(x)$, devemos inicialmente encontrar $f^{\prime \prime}(x)$. Derivando $f(x)=-x^{3}+3 x^{2}-2$, o grupo encontrou como resposta $f^{\prime \prime}(x)=-6 x+6$.

2) Em seguida, é necessário encontrar os valores que satisfazem a equação $f^{\prime \prime}(x)=0$. Ao estudar o sinal de $f(x)$, se existir troca de sinal nesses pontos, pode-se afirmar que eles são pontos de inflexão.

O grupo verificou que $f^{\prime \prime}(x)=0 \Leftrightarrow-6 x+6=0 \Leftrightarrow x=1$. Logo, $x=1$ é o único candidato a ponto de inflexão. Em seguida, verificou-se que $f^{\prime \prime}(x)>0$ para todo $x<1$ e $f^{\prime \prime}(x)<0$ para todo $x>1$. Como houve troca de sinal em $x=1$ o grupo concluiu que $x=1$ é um ponto de inflexão.

Para finalizar expomos ao grupo uma "forma divertida" sobre a relação existente entre a concavidade e o sinal da segunda derivada. No intervalo em que o sinal da segunda derivada for negativo, temos uma concavidade voltada para baixo, e no intervalo com o sinal positivo, temos uma concavidade voltada para cima. Relacionamos os termos "negativo" e "positivo" com a ideia de "triste" e "feliz", respectivamente, conforme pode-se observar na Figura 1.32.

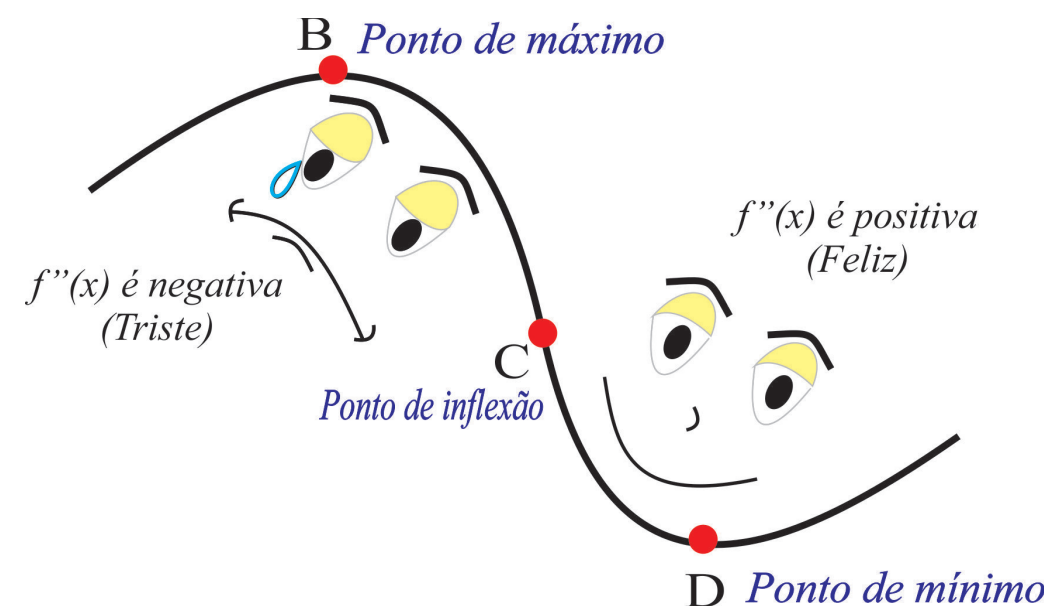

Figura 1.32: O sinal da segunda derivada e a sua relação com a mudança de concavidade. 
Essa abordagem metodológica apresentada pela figura acima tem o intuito de ajudar os alunos na construção do gráfico de uma função $f(x)$. Finalizando, percebeu-se que os alunos compreenderam o processo utilizado para encontrar os pontos de máximo e de mínimo e os pontos de inflexão, bem como a forma de justificar cada um desses procedimentos

\subsubsection{Usando as Ferramentas do Cálculo para Entender o Comportamento das Curvas}

O objetivo deste tópico é o de apresentar como as derivadas afetam o gráfico de uma função e, em particular, como nos ajudam a localizar os valores de máximo, mínimo e os pontos de inflexão de funções. Pretende-se ainda reforçar todo o aprendizado até aqui desenvolvido, conforme podemos observar no exemplo abaixo.

Exemplo 1.3.10 (A importância dos Pontos de Máximo e Mínimo e do Ponto de Inflexão para a Construção de Gráficos.). Introduzimos este exemplo apresentando ao grupo a função $p(t)=3 t^{5}-20 t^{3}$. Com a finalidade de apresentar um significado contextualizado à função $p(t)$, comentou-se que $p(t)$ representa a posição de um ciclista no tempo $t$.

O professor explicou aos alunos que desenhar a curva da função $p(t)=3 t^{5}-20 t^{3}$, permite descobrir a posição do ciclista em qualquer instante de tempo, além de encontrar qual foi o seu maior e menor deslocamento em relação a um referencial adotado.

Para entender e desenhar de forma precisa o gráfico dessa função devemos encontrar:

1) os pontos máximos e mínimos da função;

2) os pontos de inflexão.

Posteriormente, foi proposto que os alunos encontrassem os pontos de máximo e mínimo da função. Como já se sabia, esses pontos devem ter inclinações de retas tangentes iguais à zero, ou seja, $p^{\prime}(t)=15 t^{4}-60 t^{2}=0$, o que implica que $t=-2, t=0$ e $t=+2$.

Assim $t= \pm 2$ e $t=0$ são pontos críticos da função e são os candidatos a pontos de máximo ou de mínimo.

Os estudantes comentaram que, para verificar se esses pontos são pontos de máximo ou de mínimo, deve-se estudar o sinal de $p^{\prime}(t)$. Como $p^{\prime}(t)=15 t^{4}-60 t^{2}$ e pode ser escrito como $p^{\prime}(t)=$ $15 t^{2}\left(t^{2}-4\right)$, o professor acrescentou que poderiam estudar o sinal de cada um dos fatores. A partir 
desse estudo os alunos concluíram que $t=-2$ é um ponto de máximo e $t=2$ é um ponto de mínimo, conforme mostra a Figura 1.33.

\begin{tabular}{|c|c|c|c|c|}
\hline \multirow[b]{2}{*}{$p_{1}^{\prime}(t)=15 t$} & \multicolumn{2}{|c|}{-2} & \multicolumn{2}{|c|}{2} \\
\hline & - & - & + & + \\
\hline$p_{2}^{\prime}(t)=t^{2}-4$ & - & + & + & - \\
\hline$p^{\prime}(t)$ & + & & & \\
\hline
\end{tabular}

Figura 1.33: Estudo do sinal da função $p^{\prime}(t)=15 t^{4}-60 t^{2}$.

Ao estudarem o sinal da função descrito pela Figura 1.33, os alunos realizaram alguns comentários, nos quais merecem destaque:

1) quando $t<-2, p^{\prime}(t)$ possui valores positivos e quando $t>-2, p^{\prime}(t)$ possui valores negativos. Como existe uma troca de sinal, existe uma reta tangente com inclinação zero em $t=-2$. Como $p(-2)=64$, o ponto $(-2,64)$ é um ponto de máximo local;

2) tanto pela esquerda quanto pela direita de $t=0, p^{\prime}(t)$ assume valores negativos. Como não houve troca de sinal, as inclinações das retas tangentes são todas negativas nesse intervalo. Logo $p(0)=0$, ou seja, o ponto $(0,0)$ é um ponto crítico de $p(t)$, porém não representa nem um ponto máximo e nem de mínimo;

3) por fim, os alunos estabeleceram um raciocínio similar ao item 1 e concluíram que $t=2$, ou seja, o ponto $(2,-64)$ é um ponto de mínimo local.

Com as informações obtidas nos itens anteriores, os alunos se reuniram em grupo e desenharam o gráfico da função $p(t)$. Nesse primeiro instante fizeram um esboço gráfico da função indicando os intervalos em que $p(t)$ é crescente e decrescente e os pontos de máximo e mínimo. Posteriormente, o professor solicitou que os alunos plotassem o gráfico da função $p(t)$ com o auxílio do software gráfico Geogebra. Diante desses dois gráficos o professor pediu que a turma fizesse uma comparação, com o intuito de que percebessem a importância do ponto de inflexão no formato de uma curva. Conforme podemos observar a Figura 1.34A e a Figura 1.34 B 


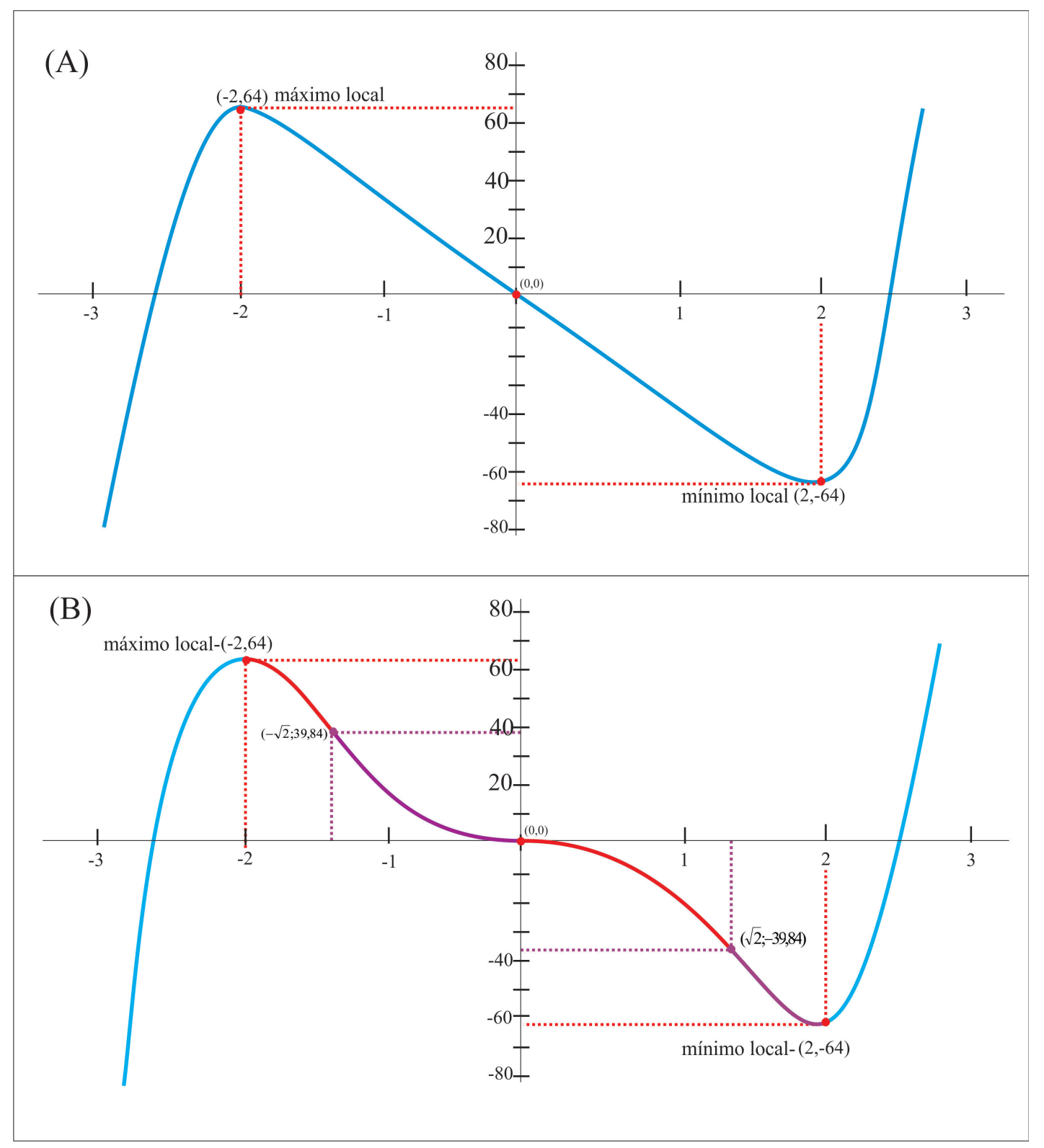

Figura 1.34: Comparação feita entre dois gráficos. Em 1.34(A) não se calculou os pontos de inflexão.

Comparando os dois gráficos, os alunos perceberam que no intervalo ]-2,2[ a curva exposta pela Figura 1.34(B) é decrescente, porém não de maneira suave como a representada na Figura 1.34 (A). Diante disso, perceberam a existência de mudanças de concavidade entre os pontos de máximo e de mínimo. Sendo assim, pediu-se que encontrassem quais seriam esses pontos, denominados pontos de inflexão. 
Com base nas explicações anteriores, os alunos calcularam $p^{\prime \prime}(t)$ e em seguida resolveram a equação $p^{\prime \prime}(t)=0$. Para finalizar, estudou-se o sinal da segunda derivada, conforme mostra a Figura 1.35 .

\begin{tabular}{l}
$p(t)=3 t^{5}-20 t^{2} \Rightarrow p^{\prime \prime}(t)=60 t^{3}-120 t \Rightarrow p^{\prime \prime}(t)=60 t .\left(t^{2}-2\right) \Rightarrow p^{\prime \prime}(t)=0 \Rightarrow t=-\sqrt{2}, 0, \sqrt{2}$ \\
\hline
\end{tabular}

Figura 1.35: Sinal da segunda derivada.

Com esse estudo verificou-se que os pontos $t=-\sqrt{2}, t=0$ e $t=+\sqrt{2}$ são pontos de inflexão, pois em ambos há troca de sinal de $p^{\prime \prime}(t)$. Com o uso de uma calculadora, os alunos encontraram os seguintes pontos:

$$
\begin{aligned}
& p(-\sqrt{2}) \approx 39,34 \Rightarrow A(-\sqrt{2} ; \approx 39,34) ; \\
& p(0)=0 \Rightarrow B(0,0) ; \\
& p(\sqrt{2}) \approx-39,34 \Rightarrow C(\sqrt{2} ; \approx-39,34)
\end{aligned}
$$

Assim, concluíram que, do ponto $(-2,64)$ até o ponto $A$, existe concavidade voltada para baixo, pois o sinal de $p^{\prime \prime}(t)$ neste intervalo é negativo. Do ponto $A$ até o ponto $B$, a função apresenta uma concavidade voltada para cima, pois o sinal da segunda derivada no intervalo é positivo. De forma análoga justificaram que os pontos $B$ e $C$, também são pontos de inflexão.

Em geral, os alunos conseguiram compreender e calcular o que é um ponto de máximo, mínimo e ponto de inflexão. Para finalizar, percebeu-se que os alunos conseguiram notar a importância desses pontos na construção de um gráfico.

\subsubsection{O Melhor do Cálculo: Algumas Aplicações}

O objetivo deste estudo foi apresentar aos alunos exemplos que mostrem como o cálculo pode ser aplicado na resolução de alguns problemas práticos. Especificamente, pretendeu-se que os alunos observassem a importância do estudo das derivadas e sua relação com outras disciplinas abordadas 
no ensino básico como, por exemplo, a Física. Aqui, optou-se em relacionar o estudo da derivada com os conceitos de velocidade e aceleração.

\subsubsection{Velocidade e Aceleração}

Com a finalidade de relacionar o estudo das derivadas com os conceitos de velocidade e aceleração, retomamos o Exemplo 1.3.10, visto que $p(t)$ neste exemplo descreve a posição de um ciclista em função do tempo.

O professor mostrou como calcular a velocidade e a aceleração desse atleta em um determinado tempo, a partir do conceito de derivada. Este processo está descrito no Exemplo 1.3.11.

Exemplo 1.3.11 (A derivada no Cálculo da Velocidade). Ao retomar o gráfico da função $p(t)$, o professor supôs que o ponto $(0,0)$ representasse o início do percurso. Os alunos foram desafiados a descobrirem a velocidade média do ciclista nas duas primeiras horas após sua partida, ou seja, de $t=0$ até $t=2$. Para auxiliá-los nesse desafio, destacou-se o gráfico de $p(t)$, no intervalo considerado.

Veja a Figura 1.36.

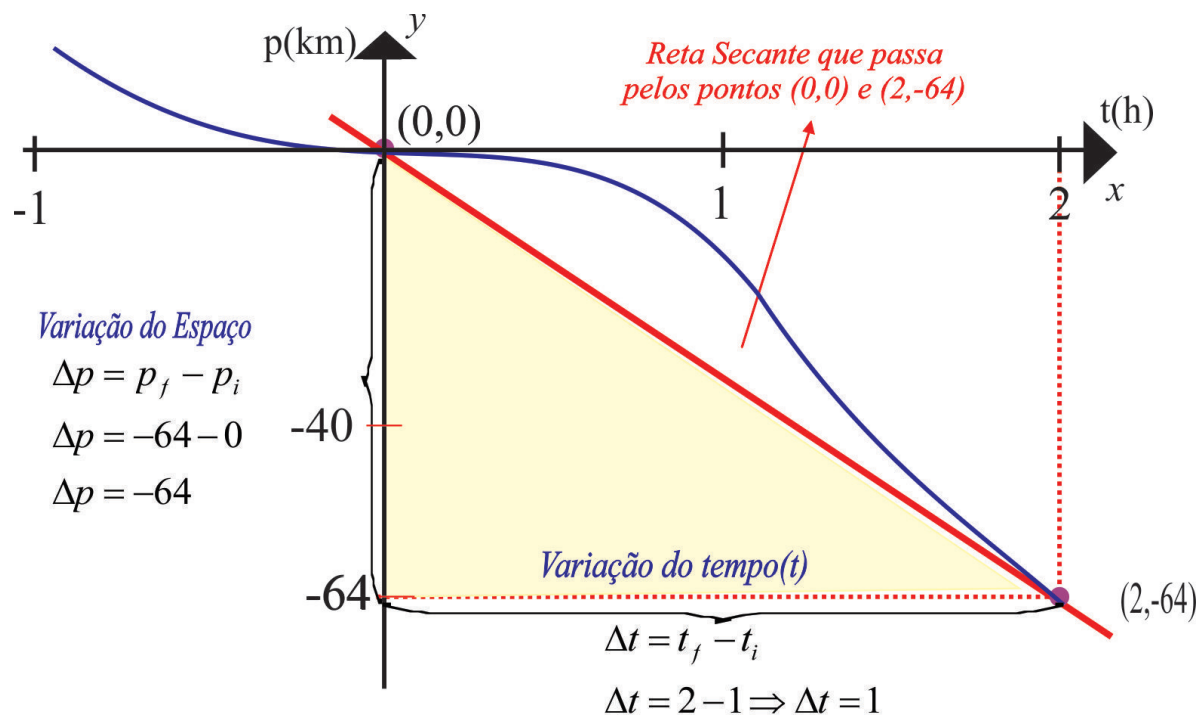

Figura 1.36: Cálculo da velocidade média nas duas primeiras horas do percurso.

Ao observar a Figura 1.36 os alunos conseguiram relacionar a inclinação da reta secante, que passa pelos pontos $(0,0)$ e $(2,-64)$, com a velocidade média do ciclista, ao comentarem que:

1) a derivada (coeficiente angular da reta) é dada por: $m=\frac{\Delta p}{\Delta t}=\frac{-64}{2}=-32 \mathrm{~km} / \mathrm{h}$; 
2) a velocidade média é a razão entre a variação do espaço pela variação do tempo, sendo assim, $V_{m}=\frac{\Delta p}{\Delta t}=\frac{-64}{2}=-32 \mathrm{~km} / \mathrm{h}$.

Diante das considerações feitas pelos alunos, o professor ressaltou que:

1) a velocidade média nesse intervalo de tempo foi negativa, pois o ciclista está se movimentando em sentido contrário ao referencial adotado;

2) a velocidade média é igual à inclinação da reta secante.

A seguir, o professor questionou se os alunos sabiam o que é uma velocidade instantânea. Em geral, responderam que é a velocidade em um exato momento. Diante dessa resposta, foi proposto que descobrissem a velocidade exata do ciclista no instante $t=1,5 h$.

Notou-se que os alunos não sabiam como encontrar essa velocidade. Sendo assim, o professor sugeriu que observassem que, no instante $t=1,5 \mathrm{~h}$ tem-se que $p(1,5)=-44,71 \mathrm{~km}$. Em seguida, a Figura 1.37 foi exposta, com a intenção de que os alunos relacionassem o conceito de inclinação de reta tangente em um ponto com o conceito de velocidade instantânea.

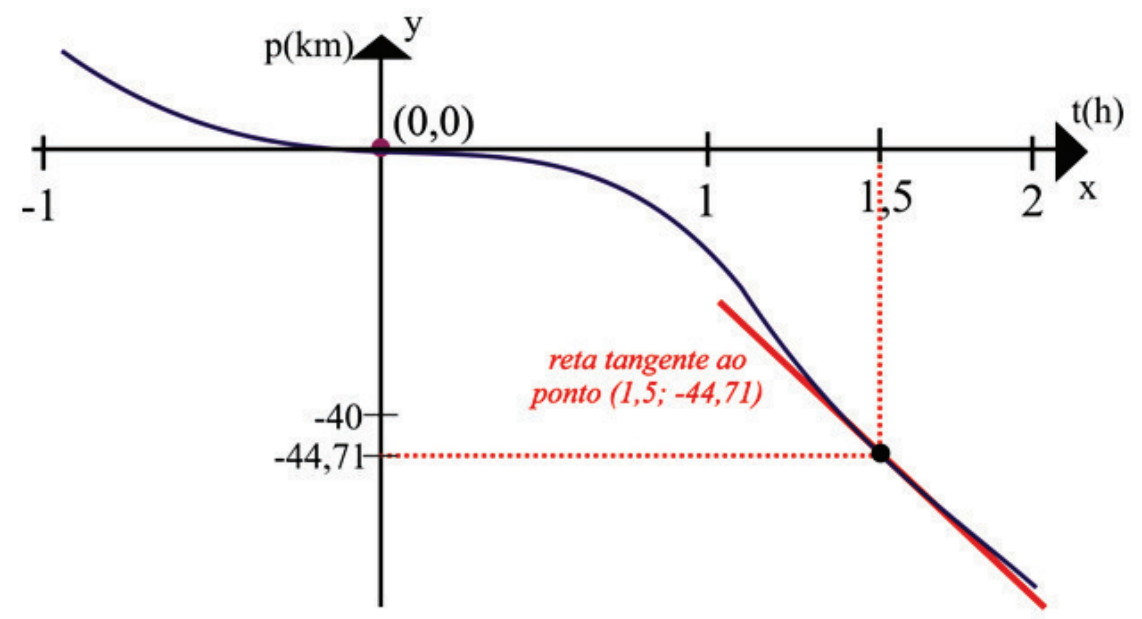

Figura 1.37: Cálculo da velocidade instantânea em $t=1,5 h$.

Os alunos mostraram-se entusiasmados, pois perceberam a relação entre a inclinação da reta secante da Figura 1.36 (que representa a velocidade média do ciclista em um dado intervalo de tempo), e a inclinação da reta tangente da Figura 1.37 (que representa a velocidade do ciclista em um exato momento - velocidade instantânea). 
Logo, o grupo conseguiu perceber que, se tivermos uma expressão que descreve a posição ou o espaço percorrido por um móvel em função do tempo, é possível encontrarmos a velocidade desse móvel em um exato momento. Basta que essa função seja derivada uma única vez, caso sua derivada exista, que encontraremos a expressão que descreve a velocidade instantânea em função do tempo.

No nosso caso, a função $v(t)=p^{\prime}(t)=15 t^{4}-60 t^{2}$ fornece a velocidade do ciclista em qualquer instante de tempo $t$. Em particular, em $t=1,5$ a sua velocidade é de $v(1,5)=p^{\prime}(1,5) \approx-59,06 \mathrm{~km} / \mathrm{h}$.

Os alunos observaram que a velocidade média do ciclista no intervalo de $0 \leq t \leq 2$ foi de $-32 \mathrm{~km} / \mathrm{h}$, enquanto que a velocidade no instante $t=1,5$ foi de $-59,06 \mathrm{~km} / \mathrm{h}$. Com isso, o grupo pode concluir que a velocidade não se manteve sempre constante a $-32 \mathrm{~km} / \mathrm{h}$ e que essa velocidade representa apenas uma média de todas as velocidades. Visto que os alunos compreenderam de maneira satisfatória os conceitos de velocidade média e instantânea, introduziu - se a noção de aceleração média e instantânea, conforme podemos observar no exemplo abaixo.

Exemplo 1.3.12 (A Derivada no Cálculo da Aceleração). O professor comentou com os alunos que o quanto variamos uma determinada distância em um intervalo de tempo resulta no que chamamos de velocidade, porém, o quanto variamos a velocidade de um objeto em um intervalo de tempo é o que chamamos de aceleração. Para que o aluno pudesse ter uma noção mais contextualizada sobre aceleração foi pedido que imaginassem uma pessoa "pisando"no acelerador de um carro e questionou - se ao grupo o que aconteceria. Os alunos responderam que a velocidade do carro iria aumentar à medida que o tempo fosse passando. Em resumo, no intervalo de tempo ao qual pisamos no acelerador, estará ocorrendo uma variação na velocidade do carro e é isto que de forma intuitiva denominamos aceleração.

Para estudar a aceleração média e instantânea, retomou - se a função $p(t)$ do Exemplo 1.3.10, que descreve a posição do ciclista em função do tempo. Pediu - se que os alunos atentassem ao fato de que $p^{\prime}(t)=15 t^{4}-60 t^{2}$ expressa a variação da velocidade em função do tempo. Sendo assim, o grupo foi solicitado a desentar o gráfico da função $p^{\prime}(t)$ e, posteriormente, pediu - se que calculassem a aceleração média desenvolvida pelo ciclista no intervalo de $t=1,5$ até $t=1,9$; ilustrado pela Figura 1.38 . 


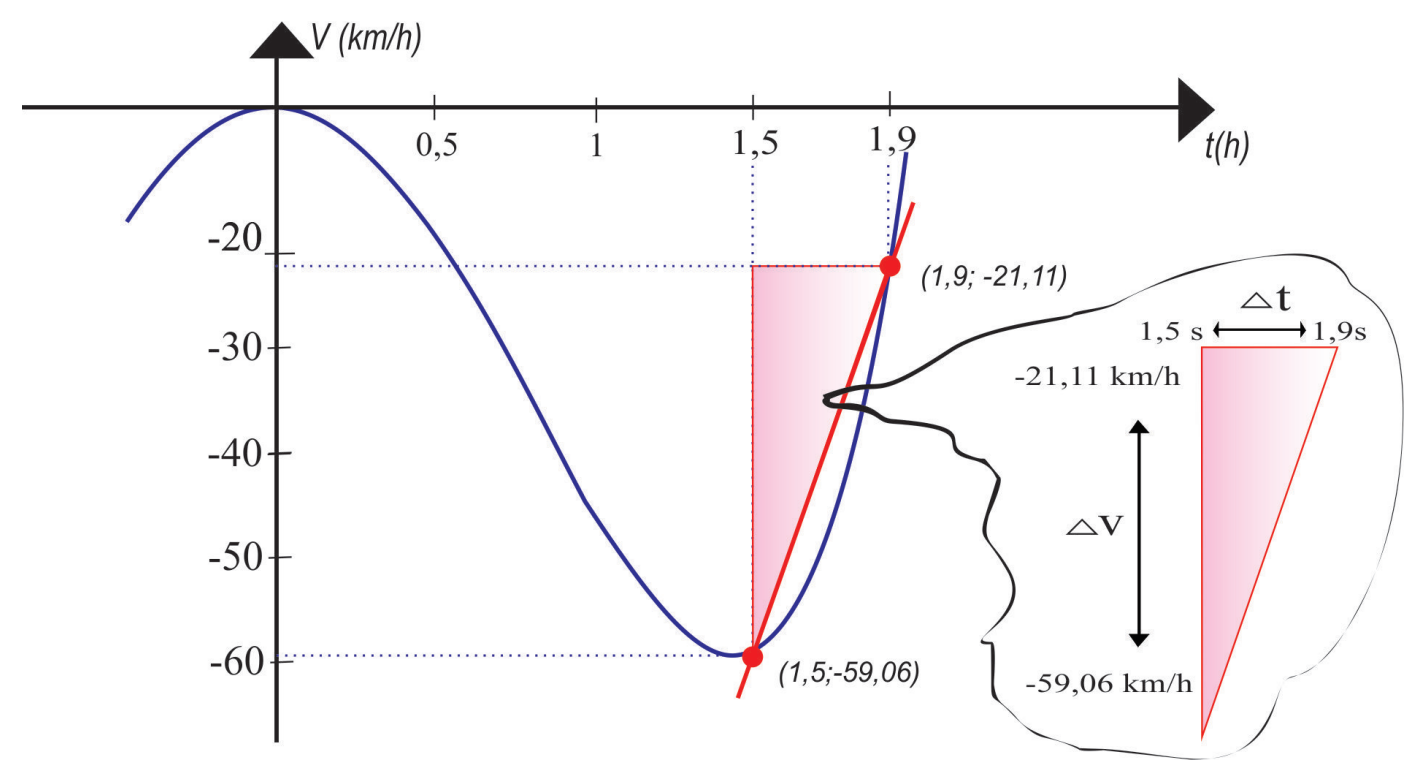

Figura 1.38: Cálculo da aceleração média no intervalo de $t=1,5$ até $t=1,9$.

Ao observar a Figura 1.38, os alunos conseguiram relacionar a inclinação da reta secante, que passa pelos pontos $(1,5 ;-59,06)$ e $(1,9 ;-21,11)$, com a aceleração média do ciclista. Diante disso, conseguiram calcular a aceleração média que é de $+94,87 \mathrm{~km} / \mathrm{h}^{2}$

A seguir, o professor desafiou a turma a calcular a aceleração do ciclista no instante $t=1,7$, e como forma de ajudar aos alunos, apresentou o seguinte gráfico, expresso pela Figura 1.39.

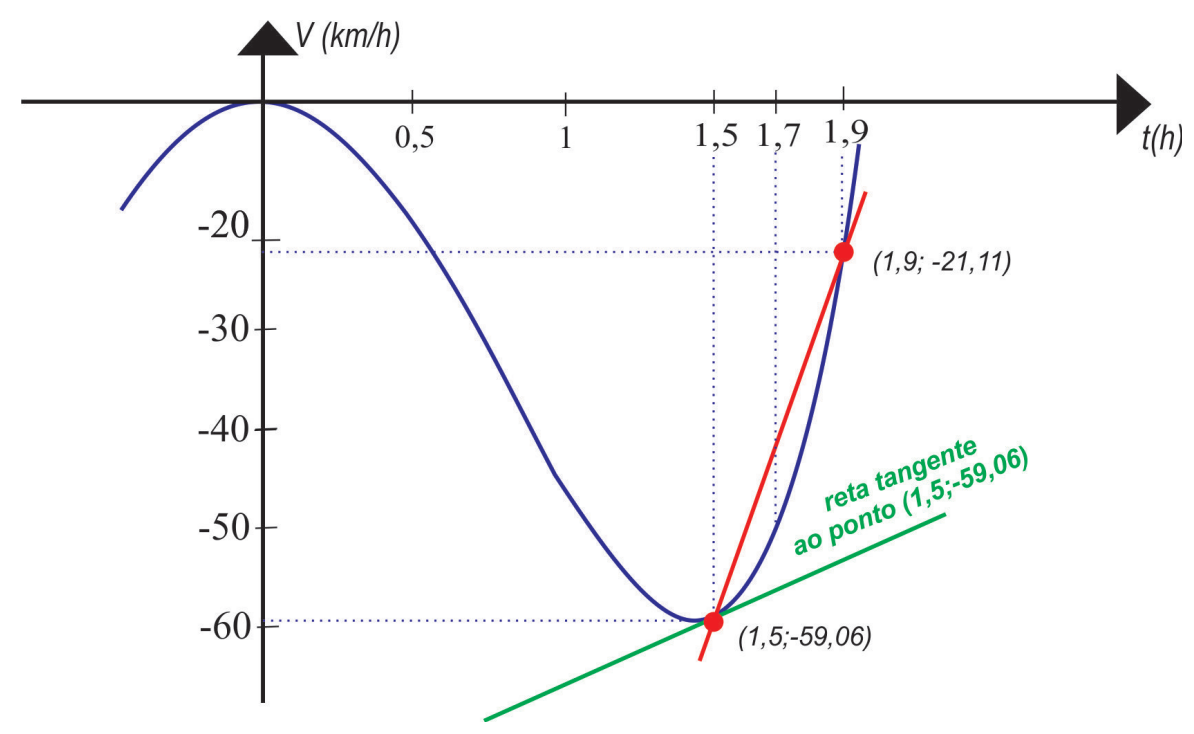

Figura 1.39: Cálculo da aceleração instantânea no ponto $(1,5 ;-59,06)$. 
Após exibir a Figura 1.39, notou-se que alguns alunos sabiam como encontrar a aceleração instantânea ao comentarem que, para o cálculo da mesma, deveriam derivar a função velocidade, e assim, caso a derivada exista, encontrariam a função que descreve a variação da velocidade em função do tempo. Os alunos apresentaram como solução o seguinte raciocínio:

$$
a(t)=p^{\prime \prime}(t)=60 t^{3}-120 t \Rightarrow p^{\prime \prime}(1,5)=22,5 k m / h^{2} .
$$

Para finalizar, o professor complementou dizendo que a aceleração instantânea é o limite da aceleração média quando o intervalo de tempo tende a zero, ou seja,

$$
a=\lim _{\Delta t \rightarrow 0} \frac{\Delta v}{\Delta t} .
$$

Esse capítulo desenvolveu com o grupo 1 dois dos principais assuntos do cálculo diferencial e integral: o estudo de limites e derivadas. Durante as atividades realizadas nesse caso, enfatizouse a aplicação, a intuição e a visualização dos conceitos e, apesar das dificuldades apresentadas, percebeu-se que a forma como as situações de aprendizagem foram abordadas, pode ser considerada muito positiva.

Percebeu-se que o grupo compreendeu a noção intuitiva de limites, e a sua importância para o conceito de derivadas. A aplicação de limites como forma de estudar o comportamento de uma função ajudou de forma motivadora para o desenvolvimento desse trabalho, pois os alunos conseguiram observar essa importância na construção de gráficos.

No decorrer das aulas, foi possível observar que os alunos compreenderam o conceito de derivada de uma função em um ponto, a partir da noção de inclinação de reta tangente. Além disso, o significado de ponto de mínimo, máximo e ponto de inflexão, e a sua relação com os conceitos de velocidade e aceleração média e instantânea, foram assuntos motivadores aos estudantes. 


\title{
Capítulo 2
}

\section{Metodologia Aplicada ao Grupo 2}

\author{
Resumo \\ Neste capítulo apresentamos o estudo realizado com os alunos do segundo grupo. Assim \\ como no caso do grupo 1, dentre os conceitos abordados, apresentaremos os de limite e \\ derivada. \\ Como referências para o desenvolvimento desse estudo, utilizou-se a seguinte bibliografia: \\ 1) Um curso de Cálculo: Hamiltom Luiz Guidorizzi. Volume 1. Rio de Janeiro: LTC, 2008; \\ 2) Cálculo com Geometria Analítica: Earl W. Swokowski. Volume 1. São Paulo: Makron, \\ 1999 \\ 3) Cálculo: James Stewart. Volume 1. São Paulo: Trilha, 2013. \\ Especificamente com esse grupo, fez-se uso de uma metodologia tradicional, baseada na \\ abordagem adotada pelos autores citados acima. Entretanto, não seguimos na integra todo \\ o formalismo matemático, em especial o utilizado em demonstrações, essencialmente por dois \\ motivos:
}

1) os participantes eram alunos de ensino médio e não estavam acostumados com a linguagem algébrica apresentada por esses livros, além de não estarem aptos a lidar com demonstrações de teoremas;

2) não desmotivar ou desinteressar o grupo para o estudo proposto.

Por se tratar de um estudo tradicional, não apresentando grandes novidades na forma de abordagem, as demonstrações e atividades realizadas pelos alunos serão relatadas de forma geral, através dos pontos de maior importância dentro dos temas. 


\subsection{Noções de Limite}

Nesta seção apresentaremos os principais conceitos sobre limites, estudados com os alunos do grupo 2. Inicialmente, elaboramos atividades que abordam a noção intuitiva de limites, a partir do uso de gráficos e tabelas. Em seguida, como realizou-se com o primeiro grupo, abordamos os conceitos de limites laterais, as propriedades dos limites, limites no infinito, limites infinitos e suas relações com as assíntotas horizontais e assíntotas verticais. Finalmente, discutimos a noção intuitiva e a definição formal sobre continuidade.

\subsubsection{Noção Intuitiva de Limites}

Para apresentar uma noção intuitiva sobre os limites, desenvolveu-se o seguinte exemplo.

Exemplo 2.1.1. Neste exemplo consideramos as funções $f(x)=x^{2}+1$ e $g(x)=\frac{x^{2}-1}{x-1}$, e solicitou-se aos alunos que estudassem o comportamento das mesmas nas proximidades do ponto $x=1$.

Para isto, pediu-se inicialmente que os alunos desenhassem o gráfico da função $f(x)=x^{2}+1$ e, com o auxílio do software Excel, estudassem o comportamento dessa função nas proximidades do ponto $x=1$, tanto pela esquerda quanto pela direita, conforme ilustrado na Figura 2.1.

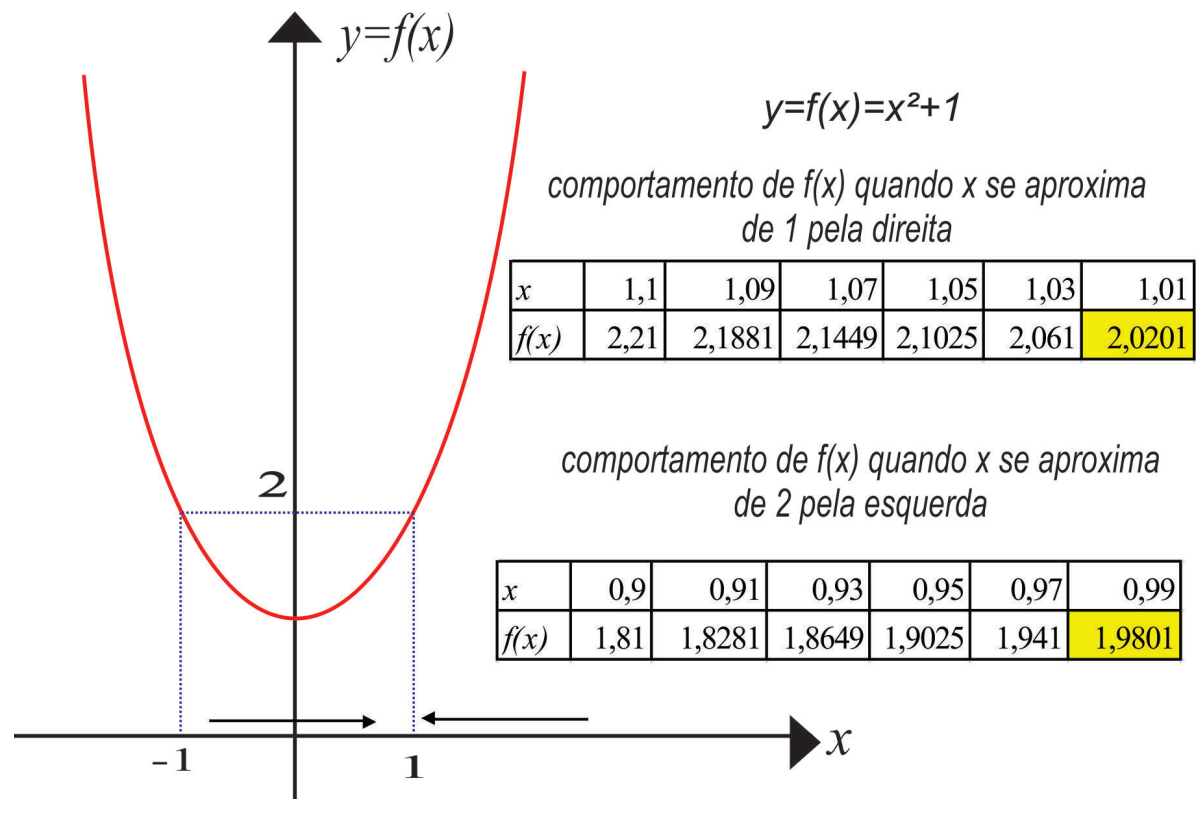

Figura 2.1: Gráfico de $f(x)=x^{2}+1$. 
Ao observarem a Figura 2.1 os alunos constataram que, quando $x$ estiver próximo de 1 (de qualquer lado de 1), $f(x)$ aproxima de 2. Em seguida, o professor comentou que:

1) podemos tornar os valores de $f(x)=x^{2}+1$ tão próximos de 2 quanto quisermos, ao tornar $x$ suficientemente próximo de 1. Expressamos isto dizendo que "o limite de $f(x)$ quando $x$ tende a 1 é igual a 2". Matematicamente, usamos a notação: $\lim _{x \rightarrow 1} x^{2}+1=2$ ou $\lim _{x \rightarrow 1} f(x)=2$;

2) a função $f(x)=x^{2}+1$ está definida em $x=1$, ou seja, $f(1)=2$. Entretanto, ao calcular o limite de $f(x)$ quando $x$ tende a 1 , nunca consideramos $x=1$. O importante é analisar como se comporta $f(x)$ quando $x$ está próximo de 1.

Com o objetivo de explorar os comentários citados no item (2), solicitamos que os alunos estudassem o comportamento da função

$$
g(x)=\frac{x^{2}-1}{x-1}
$$

conforme apresentado na Tabela 2.1 e 2.2 .

Tabela 2.1: Comportamento de $g(x)$, quando $x$ está tende a 1 pela esquerda

\begin{tabular}{llllll}
$x$ & 0,5 & 0,75 & 0,875 & 0,9375 & 0,9685 \\
\hline$g(x)$ & 1,5 & 1,75 & 1,875 & 1,9375 & 1,9685 \\
\hline
\end{tabular}

Tabela 2.2: Comportamento de $g(x)$, quando $x$ está tende a 1 pela direita

\begin{tabular}{llllll}
$x$ & 1,5 & 1,25 & 1,125 & 1,0625 & 1,03125 \\
\hline$g(x)$ & 2,5 & 2,25 & 2,125 & 2,0625 & 2,03125 \\
\hline
\end{tabular}

Ao observar a função $g(x)$ os alunos perceberam que não poderiam estabelecer uma imagem para $g(x)$ quando $x=1$, pois se isso fosse possível teríamos

$$
g(1)=\frac{0^{2}-1}{0-1}=\frac{0}{0}
$$

Isto significa que $g(x)$ está definida para qualquer $x \in \mathbb{R}-\{1\}$. No entanto, perceberam também que quando $x$ se aproxima de 1 por ambos os lados, $g(x)$ se aproxima de 2 . Ou seja, $\lim _{x \rightarrow 1} g(x)=2$.

Em complemento à observação dos alunos, o professor reforçou que, ao estudar o limite de uma função, estamos interessados em analisar o seu comportamento nas proximidades de um ponto, nesse caso, $x=1$, mesmo que a função não esteja definida neste ponto. 
Diante das observações feitas no exemplo acima, apresentamos a seguinte definição.

Definição 2.1.2. Seja $f(x)$ uma função definida num intervalo aberto que contenha $a$, exceto possivelmente no próprio $a$. Dizemos que $\lim _{x \rightarrow a} f(x)=L$, se pudermos tornar os valores de $f(x)$ arbitrariamente próximos de $L$, tornando $x$ suficientemente próximo de $a$ (por ambos os lados de a), mas não igual a $a$.

\subsubsection{Limites Laterais}

Para introduzir os estudos de limites laterais, retomou-se a função $g(x)$ desenvolvida no Exemplo 2.1.1. Pediu-se que os alunos observassem a Tabela 2.1 e 2.2, e alguns comentários foram feitos pelo professor. Dentre eles merecem destaque:

1) quando $x$ tende a 1 , por valores menores do que 1 , dizemos que $x$ tende a 1 pela esquerda e escrevemos $x \rightarrow 1^{-}$. Logo, $\lim _{x \rightarrow 1^{-}} g(x)=2$. Chamamos este limite de limite lateral esquerdo;

2) quando $x$ tende a 1 , por valores maiores do que 1 , dizemos que $x$ tende a 1 pela direita $\mathrm{e}$ escrevemos $x \rightarrow 1^{+}$. Logo, $\lim _{x \rightarrow 1^{+}} g(x)=2$. Chamamos este limite de limite lateral direito;

3) como $\lim _{x \rightarrow 1^{-}} g(x)=2=\lim _{x \rightarrow 1^{+}} g(x)=2$, podemos concluir que $\lim _{x \rightarrow 1} g(x)=2$, pois independentemente de como nos aproximamos de $x=1, g(x)$ se aproxima de 2;

4) se $g(x)$ se aproximasse de valores distintos, quando $x$ se aproximasse de 1 pela esquerda e pela direita, respectivamente, então diríamos que o limite da função $g(x)$ não existiria nesse ponto.

A partir dos comentários acima, apresentou-se, o Teorema abaixo.

Teorema 2.1.3. $\lim _{x \rightarrow a} g(x)=L$ se, e somente se, $\lim _{x \rightarrow a^{-}} g(x)=\lim _{x \rightarrow a^{+}} g(x)$.

O Teorema 2.1.3 nos diz que o limite de $g(x)$, quando $x$ se aproxima de $a$, existe se, e somente se, ambos os limites laterais, direito e esquerdo, existem e são iguais. Este Teorema foi apenas citado aos alunos, não foi feita uma demonstração.

Com o objetivo de oferecer aos alunos uma melhor compreensão sobre limites laterais, desenvolvemos o próximo exemplo.

Exemplo 2.1.4. Considere a função $h(x)=\left\{\begin{array}{ll}x^{2} & , x<2 \\ x & , x \geq 2\end{array}\right.$. Calcule $\lim _{x \rightarrow 2} h(x)$. 
Para que os alunos notassem o que ocorre com a função $h(x)$ quando nos aproximamos de $x=2$, elaborou-se, com o auxílio do software Excel, as Tabelas 2.3 e 2.4.

Tabela 2.3: Comportamento de $h(x)$, quando $x$ está tende a 2 pela esquerda

\begin{tabular}{llllll}
$x$ & 1,5 & 1,75 & 1,875 & 1,9375 & 1,9685 \\
\hline$h(x)=x^{2}$ & 2,25 & 3,0625 & 3,515 & 3,754 & 3,875 \\
\hline
\end{tabular}

Tabela 2.4: Comportamento de $h(x)$, quando $x$ está tende a 2 pela direita

\begin{tabular}{llllll}
\hline$x$ & 2,5 & 2,25 & 2,125 & 2,0625 & 2,03125 \\
$h(x)=x$ & 2,5 & 2,25 & 2,125 & 2,0625 & 2,03125 \\
\hline
\end{tabular}

Os alunos constataram que à medida que $x$ se aproxima de 2 pela esquerda, $h(x)$ se aproxima de 4. Por outro lado, à medida que $x$ se aproxima de 2 pela direita, $h(x)$ se aproxima 2. Assim, concluíram que os limites laterais de $h(x)$ são diferentes, portanto $\lim _{x \rightarrow 2} h(x)$ não existe.

Para que os alunos pudessem observar geometricamente esta situação, esboçamos o gráfico de $h(x)$, conforme mostra a Figura 2.2.

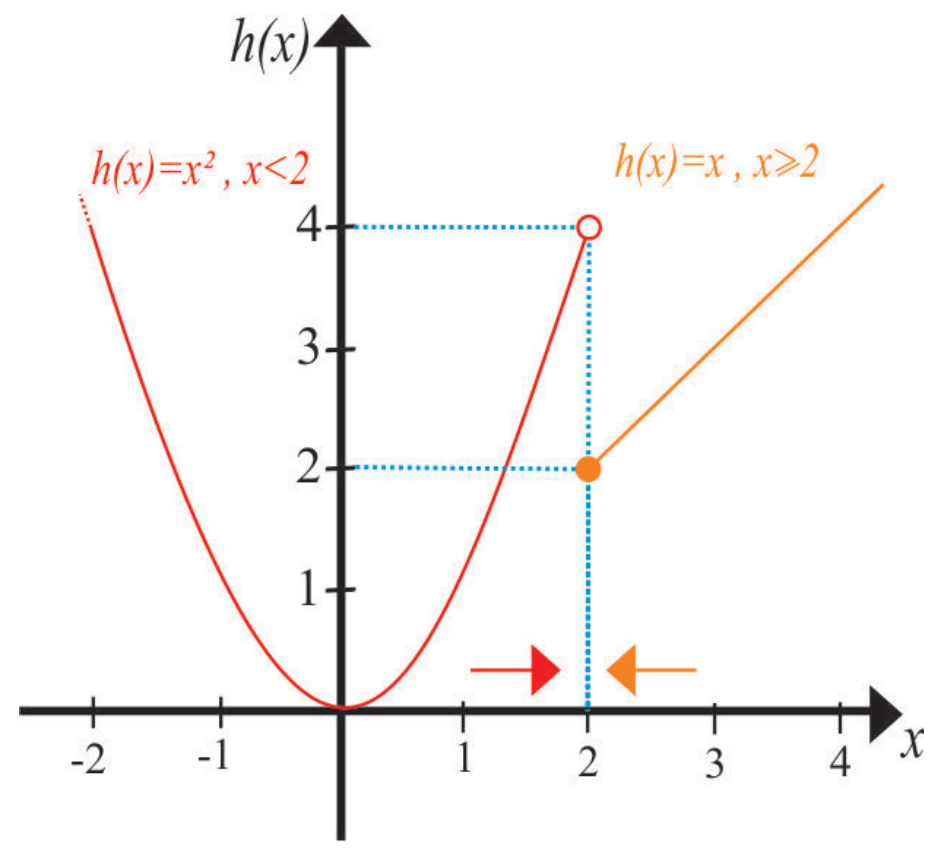

Figura 2.2: Gráfico da função $h(x)$. 
Ao finalizar esta atividade alguns alunos questionaram se seria necessário sempre construirmos uma tabela de aproximações para determinarmos se o limite de uma função existe. Como resposta, o professor explicou que existem métodos algébricos para o cálculo de limites, bem como a existência de algumas propriedades que irão nos auxiliar nessa resolução.

\subsubsection{Propriedade dos Limites}

O professor apresentou as principais propriedades dos limites, enfatizando que elas podem ser demonstradas, porém essas demonstrações seriam desenvolvidas no ensino superior.

Se os limites $\lim _{x \rightarrow a} f(x)$ e $\lim _{x \rightarrow a} g(x)$ existirem e $k$ for um número real qualquer, então valem as seguintes propriedades:

1) se $f(x)=k, \forall x \in \mathbb{R}$, então $\lim _{x \rightarrow a} f(x)=\lim _{x \rightarrow a} k=k$;

2) $\lim _{x \rightarrow a}[f(x) \pm g(x)]=\lim _{x \rightarrow a} f(x) \pm \lim _{x \rightarrow a} g(x)$;

3) $\lim _{x \rightarrow a}[k \cdot f(x)]=k \cdot \lim _{x \rightarrow a} f(x)$;

4) $\lim _{x \rightarrow a}[f(x) g(x)]=\lim _{x \rightarrow a} f(x) . \lim _{x \rightarrow a} g(x)$;

5) $\lim _{x \rightarrow a} \frac{f(x)}{g(x)}=\frac{\lim _{x \rightarrow a} f(x)}{\lim _{x \rightarrow a} g(x)}$, desde que $\lim _{x \rightarrow a} g(x) \neq 0$.

Para a aplicação destas propriedades desenvolveu-se o seguinte exemplo.

Exemplo 2.1.5 (Cálculo dos Limites, Envolvendo suas Propriedades). Para aplicar as propriedades apresentadas, o professor retomou os limites abordados no Exemplo 2.1.1, como segue:

1) calcule o $\lim _{x \rightarrow 1}\left(x^{2}+1\right)$, utilizando as propriedades de limites.

Resolução: Das propriedades vistas acima, temos que:

$$
\lim _{x \rightarrow 1}\left(x^{2}+1\right)=\lim _{x \rightarrow 1} x^{2}+\lim _{x \rightarrow 1} 1=1^{2}+1=2 .
$$

2) calcule o $\lim _{x \rightarrow 1} \frac{x^{2}-1}{x-1}$

Resolução: seja $g(x)=\frac{x^{2}-1}{x-1}$, solicitou-se que os alunos observassem que não podemos utilizar a propriedade do quociente, pois $\lim _{x \rightarrow 1}(x-1)=0$. Então, para resolver esse limite é necessário fazer algumas operações algébricas para simplificar $g(x)$. 
Fatorando o numerador de $g(x)$ como diferença de quadrados temos que para $x \neq 1$,

$$
\frac{x^{2}-1}{x-1}=\frac{(x+1)(x-1)}{(x-1)}=x+1 .
$$

Logo,

$$
\lim _{x \rightarrow 1}\left(\frac{x^{2}-1}{x-1}\right)=\lim _{x \rightarrow 1}(x+1)=2 .
$$

O professor transmitiu aos alunos que é possível calcular esse limite, pois conseguimos substituir a função

$$
g(x)=\frac{x^{2}-1}{x-1}
$$

por outra mais simples,

$$
g_{1}(x)=x+1,
$$

e reforçou que isso é válido, pois quando calculamos o limite com $x \rightarrow 1$, estamos interessado em valores de $x$ muito próximos de 1 , mas $x \neq 1$.

Para finalizar, concluímos que, se $g(x)=g_{1}(x)$ quando $x \neq a$, então $\lim _{x \rightarrow a} g(x)=\lim _{x \rightarrow a} g_{1}(x)$, desde que o limite exista.

Para fixar o conteúdo aqui apresentado, solicitou-se que o grupo resolvesse uma lista envolvendo uma série de exercícios. O professor auxiliou os alunos durante a realização das atividades. Ainda assim, ao fazer a correção dos exercícios percebeu-se algumas dificuldades, em especial, nas questões envolvendo fatoração.

\subsubsection{Limites Infinitos}

Introduzimos a abordagem sobre limites envolvendo infinito apresentando a função

$$
f(x)=\frac{1}{(x-1)^{2}} .
$$

Inicialmente os alunos verificaram que $f(x)$ está definida para todo $x \in \mathbb{R}-\{1\}$. Em seguida, com o auxílio do gráfico e do software Excel, solicitou-se que estudassem o comportamento de $f(x)$ nas proximidades de $x=1$. Veja a Figura 2.3. 


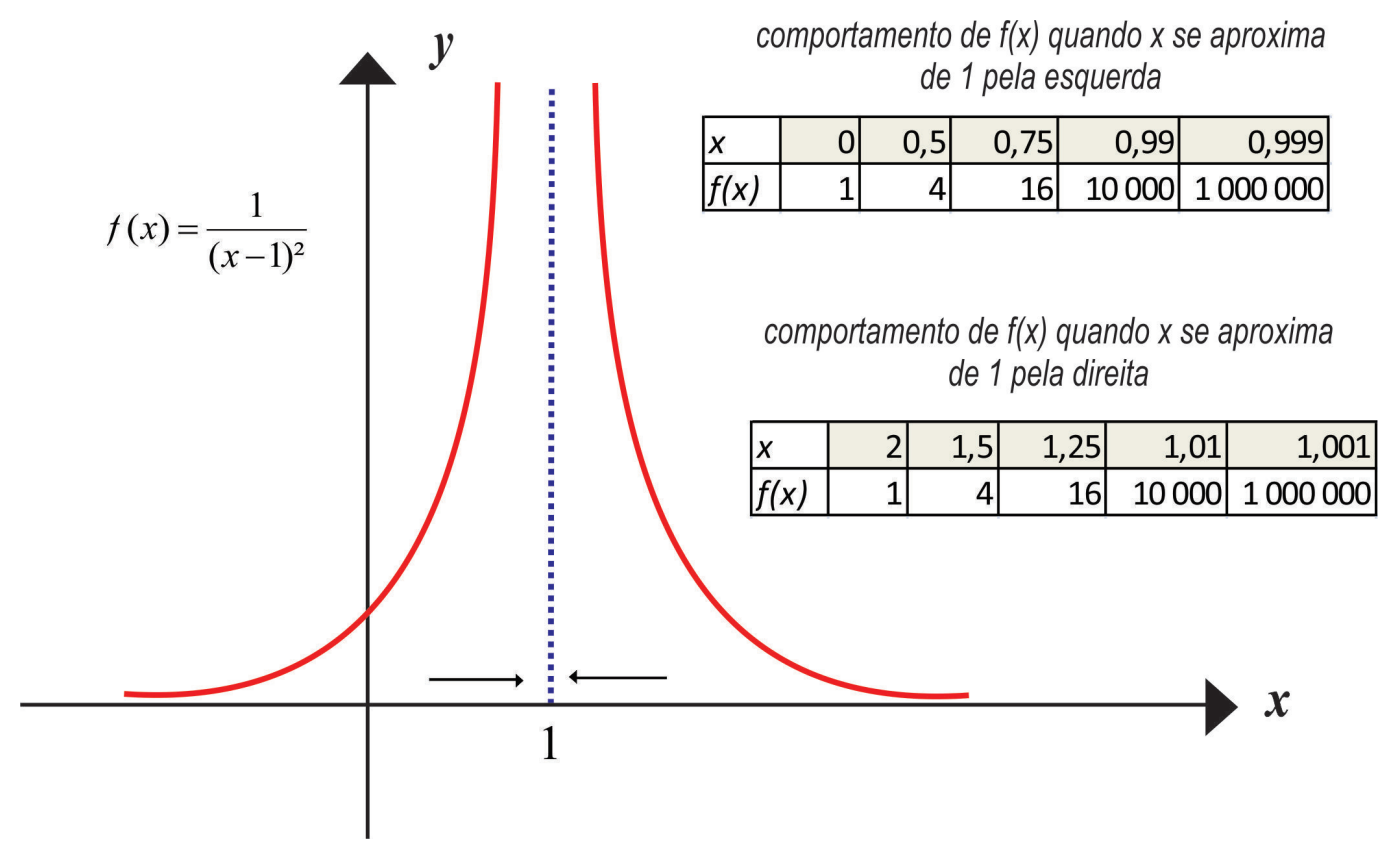

Figura 2.3: Gráfico de $f(x)=\frac{1}{(x-1)^{2}}$.

Ao analisarem a Figura 2.3, o professor solicitou aos alunos para observarem que os valores da função são cada vez maiores à medida que $x$ se aproxima de 1 pela esquerda e pela direita. Em outras palavras, podemos tornar $f(x)$ tão grande quanto se deseja, isto é, maior que qualquer número positivo, tomando valores de $x$ bastante próximos de 1 . Matematicamente, escrevemos essa situação como: $\lim _{x \rightarrow 1} f(x)=+\infty$. Ressaltou-se que o símbolo $\infty$ (infinito) não representa um número real. É apenas uma notação que usamos para dizer que os valores de uma função crescem indefinidamente.

Em seguida, o professor apresentou a função

$$
g(x)=\frac{-1}{(x-1)^{2}}
$$

e solicitou aos alunos que, com o uso do Excel e do software Geogebra, fizessem uma análise do comportamento da função $g(x)$ nas proximidades de $x=1$. De maneira análoga ao caso anterior, os alunos chegaram à conclusão que

$$
\lim _{x \rightarrow 1} \frac{-1}{(x-1)^{2}}=-\infty
$$

isto é,

$$
\lim _{x \rightarrow 1} g(x)=-\infty
$$


Como antes, o professor comentou que podemos tornar os valores de $g(x)$ menores quanto desejarmos, isto é, menores que qualquer número negativo, tomando valores de $x$ bastante próximos de 1.

Os alunos perceberam que os valores das funções $f(x)$ e $g(x)$ acima, crescem ou decrescem indefinidamente quando $x$ se aproxima de 1. Para que o grupo chegasse à essa mesma conclusão, sem a necessidade de construir tabelas ou gráficos da função, apresentou-se o seguinte Teorema.

Teorema 2.1.6. Sejam $f(x)$ e $g(x)$ funções tais que $\lim _{x \rightarrow a} f(x)=c \neq 0$ e $\lim _{x \rightarrow a} g(x)=0$. Então:

1) $\lim _{x \rightarrow a} \frac{f(x)}{g(x)}=+\infty$, se $\frac{f(x)}{g(x)}>0$ quando $x$ está próximo de $a$.

2) $\lim _{x \rightarrow a} \frac{f(x)}{g(x)}=-\infty$, se $\frac{f(x)}{g(x)}<0$ quando $x$ está próximo de $a$.

Para abordar a aplicabilidade do Teorema 2.1.6, elaborou-se o exemplo abaixo.

Exemplo 2.1.7. Calcular $\lim _{x \rightarrow 1} \frac{2 x+1}{x-1}$

Inicialmente, chamou - se de $f(x)$ o polinômio $2 x+1$ e de $g(x)$ o polinômio $x-1$. Sendo assim, os alunos substituíram $x=1$ na função $\frac{f(x)}{g(x)}$ e obtiveram como resultado $\frac{f(1)}{g(1)}=\frac{3}{0}$. De acordo com o Teorema 2.1.6, comentaram que esse limite terá como resultado $+\infty$ ou $-\infty$. O professor complementou que, para obterem a resposta correta deveriam estudar o sinal de $\frac{f(x)}{g(x)}$.

O grupo apresentou certa dificuldade em estudar o sinal da função racional, entretanto, com o auxílio do professor, esse objetivo foi concretizado, conforme pode-se observar na Figura 2.4.

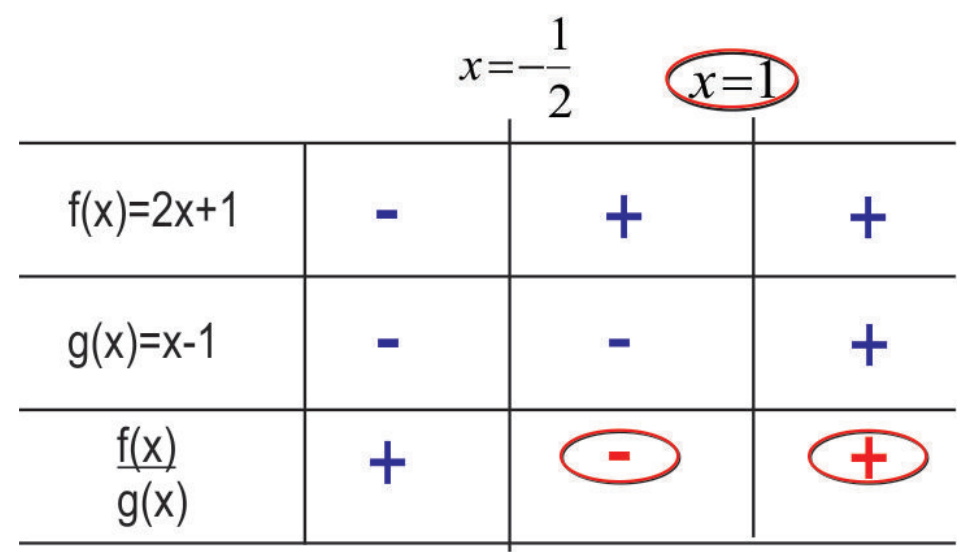

Figura 2.4: Estudo do sinal de $\frac{f(x)}{g(x)}$. 
Após o estudo do sinal, os alunos constataram que $\frac{f(x)}{g(x)}<0$ quando $x \rightarrow 1^{-}$e através do Teorema 2.1.6 concluíram que $\lim _{x \rightarrow 1^{-}} \frac{2 x+1}{x-1}=-\infty$. De forma semelhante observaram que $\lim _{x \rightarrow 1^{+}} \frac{2 x+1}{x-1}=+\infty$.

O professor comentou que, neste caso, o $\lim _{x \rightarrow 1} \frac{2 x+1}{x-1}$ não existe, ou seja, não podemos dizer que seu resultado é $-\infty$ e nem que é $+\infty$. Neste instante, observou-se que os alunos fizeram uma analogia com a atividade desenvolvida no Exemplo 2.1.4 que trata sobre a existência ou não de limites finitos.

Com o uso do software Geogebra, expôs-se ao grupo o gráfico da função $\frac{f(x)}{g(x)}$, conforme mostra a Figura 2.5.

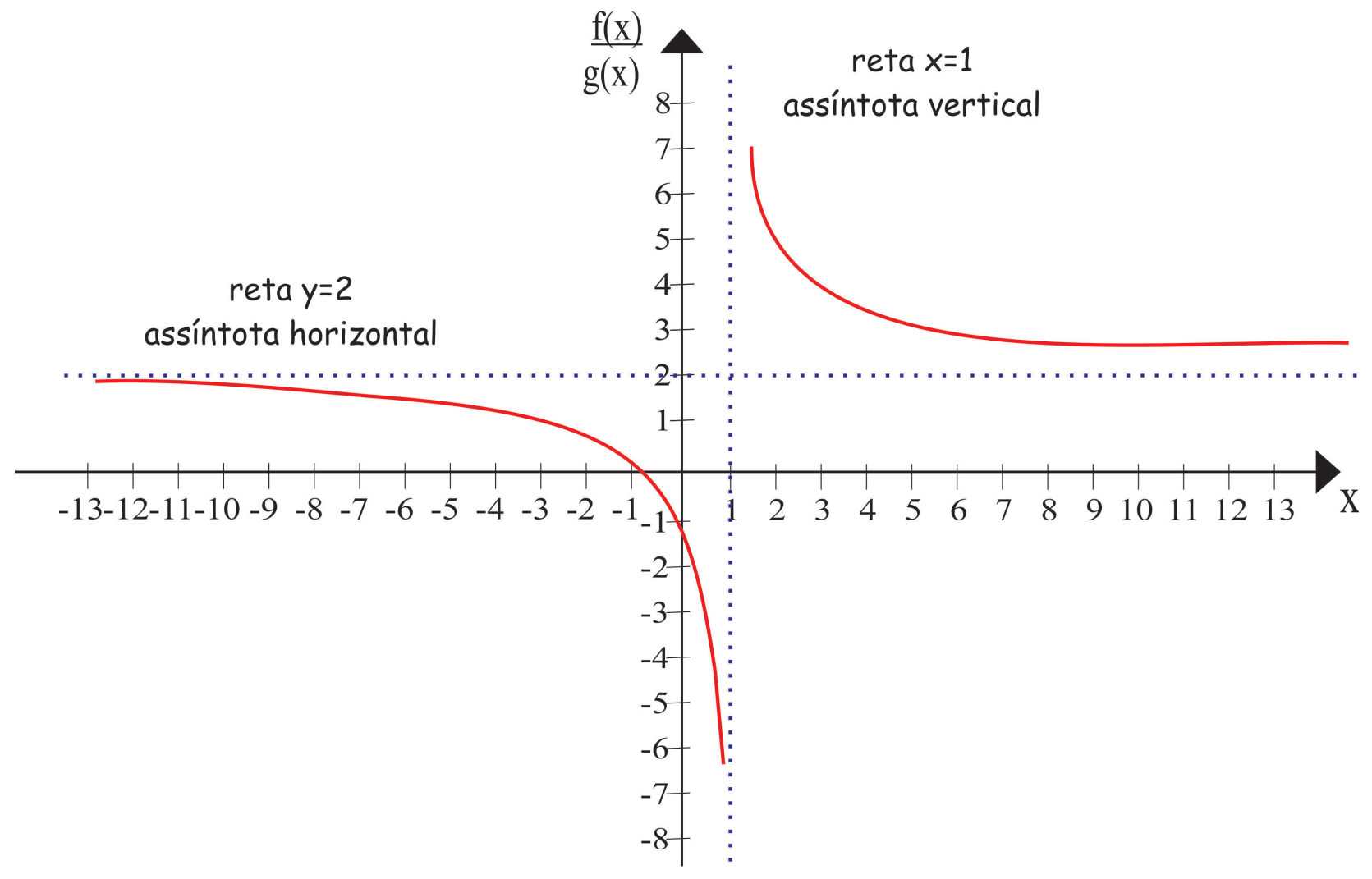

Figura 2.5: Gráfico da função $\frac{f(x)}{g(x)}$, onde $f(x)=2 x+1$ e $g(x)=x-1$

A partir da Figura 2.5, o professor comentou com o grupo que a reta $x=1$ é chamada de assíntota vertical da curva $\frac{f(x)}{g(x)}$. Resumidamente, enfatizou-se que quando temos uma função $h(x)$ e $\lim _{x \rightarrow a} h(x)= \pm \infty, \lim _{x \rightarrow a^{-}} h(x)= \pm \infty$ ou $\lim _{x \rightarrow a^{+}} h(x)= \pm \infty$ a reta $x=a$ é chamada assíntota vertical.

O professor aproveitou o gráfico expresso pela Figura 2.5 para explicar o que é uma assíntota 
horizontal, pedindo que os alunos observassem a reta $y=2$.

Diante do exemplo proposto, verificou-se que a turma compreendeu o significado de limites infinitos. Porém, a aula se apresentou mais expositiva do que participativa, isto é, os alunos não conseguiam concluir as ideias sem que houvesse um auxílio oferecido pelo professor.

\subsubsection{Limites no Infinito}

Nesta seção estávamos interessados em estudar o comportamento de uma função $f(x)$ quando a variável $x$ cresce ou decresce indefinidamente e introduziu-se as notações $x \rightarrow+\infty$ e $x \rightarrow-\infty$, respectivamente.

Quando $x \rightarrow \infty$, a função pode se aproximar de um valor, crescer ou decrescer indefinidamente, conforme ilustra a Figura 2.6.

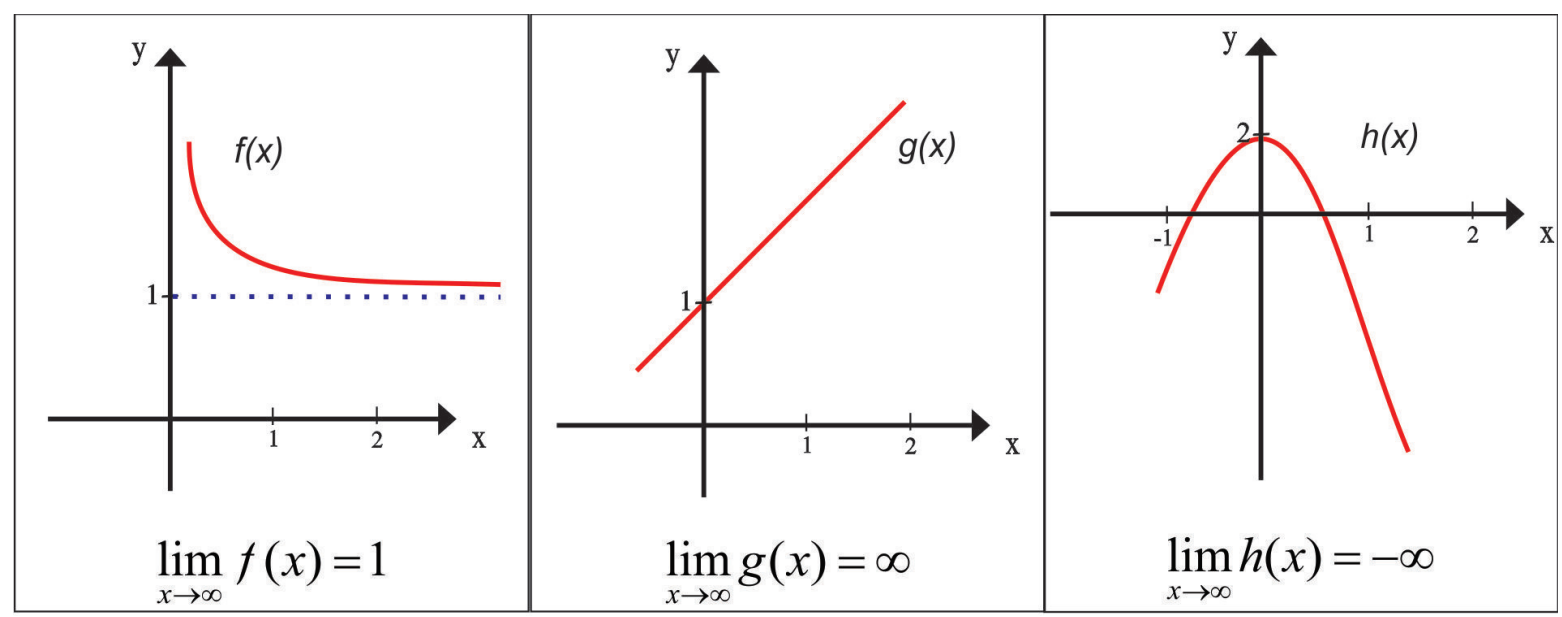

Figura 2.6: Comportamento de algumas funções quando $(x \rightarrow \infty)$.

Ressaltou-se aos alunos que situações análogas podem ocorrer quando $x \rightarrow-\infty$. Após introduzir o significado e a notação de $\lim _{x \rightarrow \pm \infty} f(x)$, foi desenvolvido o seguinte exemplo.

Exemplo 2.1.8 (O Comportamento de $f(x)=\frac{1}{x}$ quando $x \rightarrow \pm \infty$ ). Para que fosse feita uma análise do comportamento da função $f(x)=\frac{1}{x}$ à medida que $x$ cresce ou decresce indefinidamente, atribuímos valores cada vez maiores e menores a $x$. Em seguida, foi feita uma comparação entre os resultados obtidos e o esboço gráfico da função, conforme mostra a Figura 2.7. 


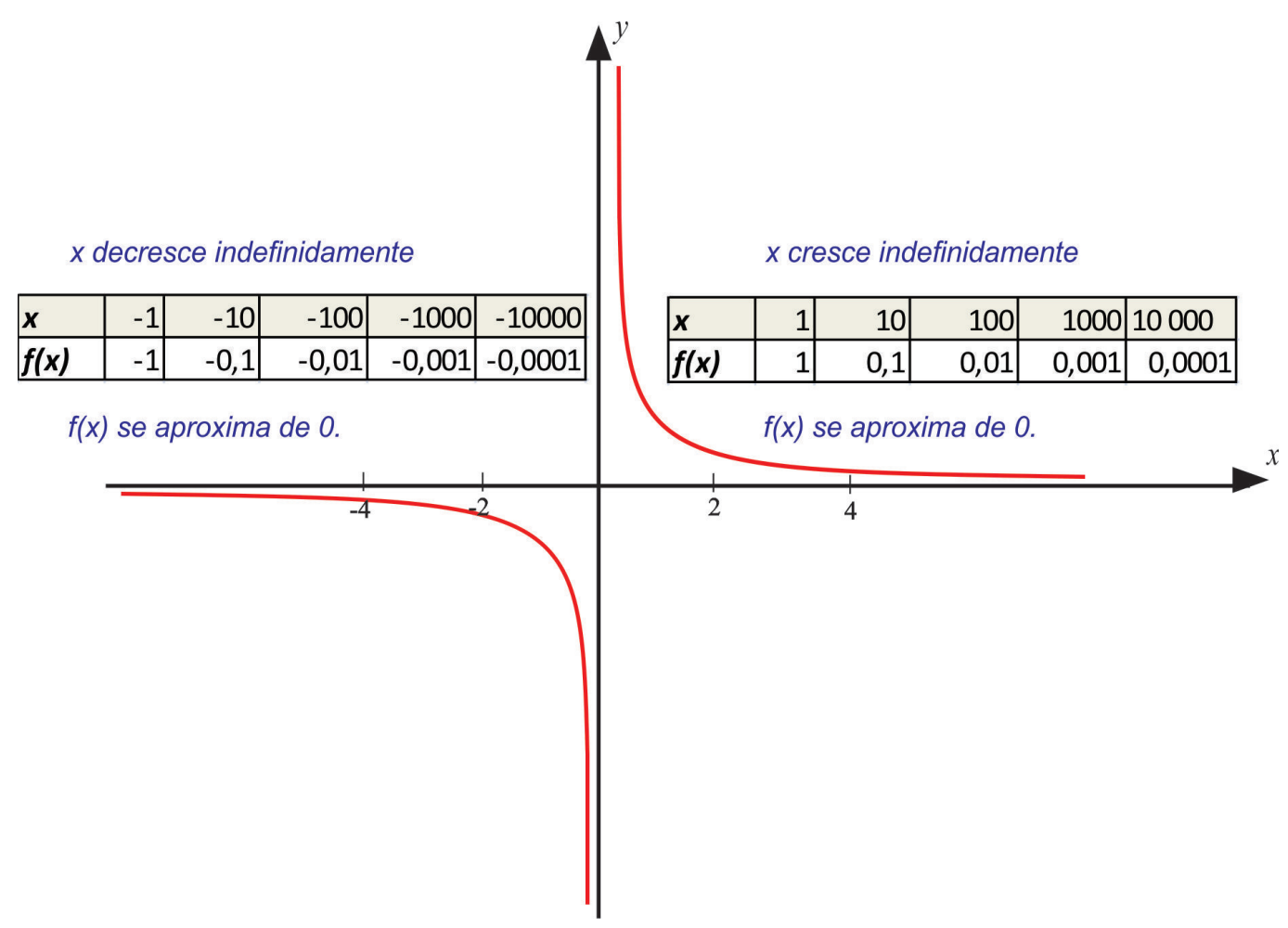

Figura 2.7: Comportamento da função: $f(x)=\frac{1}{x}$.

A partir das informações descritas pela Figura 2.7, os alunos concluíram que $\lim _{x \rightarrow+\infty} \frac{1}{x}=0$ e $\lim _{x \rightarrow-\infty} \frac{1}{x}=0$. Ao analisarem o gráfico, constataram ainda que à medida que $x$ fica cada vez mais próximo de zero pela direita, $f(x)$ cresce indefinidamente, ou seja, $\lim _{x \rightarrow 0^{+}} \frac{1}{x}=+\infty$. De forma análoga concluíram que $\lim _{x \rightarrow 0^{-}} \frac{1}{x}=-\infty$

Até esse momento, para concluir algo em relação ao comportamento da função quando $x$ cresce ou decresce ilimitadamente, construímos uma tabela de valores de $x$ e $f(x)$ e observamos o gráfico da função. Para chegar à mesma conclusão, sem a necessidade de tabelas e gráficos, apresentamos aos alunos alguns teoremas, como segue abaixo:

Teorema 2.1.9. Se $c \in \mathbb{R}$, então $\lim _{x \rightarrow+\infty} c=c=\lim _{x \rightarrow-\infty} c$.

Teorema 2.1.10. Se $n$ é um número natural, então teremos:

1) $\lim _{x \rightarrow+\infty} x^{n}=+\infty$ 
2) $\lim _{x \rightarrow-\infty} x^{n}= \begin{cases}+\infty & \text { se } n \text { é par } \\ -\infty & \text { se } n \text { é ímpar. }\end{cases}$

Teorema 2.1.11. Se $n$ é um número natural, então:

1) $\lim _{x \rightarrow+\infty} \frac{1}{x^{n}}=0$

2) $\lim _{x \rightarrow-\infty} \frac{1}{x^{n}}=0$

Teorema 2.1.12. Se $f(x)=a_{0}+a_{1} x+a_{2} x^{2}+\ldots+a_{n} x^{n} \operatorname{com} a_{n} \neq 0$, então $\lim _{x \rightarrow+\infty} f(x)=\lim _{x \rightarrow+\infty}\left(a_{n} x^{n}\right)$ e $\lim _{x \rightarrow-\infty} f(x)=\lim _{x \rightarrow-\infty}\left(a_{n} x^{n}\right)$.

Teorema 2.1.13. Se $f(x)=a_{0}+a_{1} x+a_{2} x^{2}+\ldots+a_{n} x^{n}$ com $a_{n} \neq 0$, e $g(x)=b_{0}+b_{1} x+b_{2} x^{2}+$ $\ldots+b_{m} x^{m} \operatorname{com} b_{m} \neq 0$, então $\lim _{x \rightarrow \pm \infty} \frac{f(x)}{g(x)}=\lim _{x \rightarrow \pm \infty}\left(\frac{a_{n}}{b_{m}} x^{n-m}\right)$.

Os Teoremas 2.1 .12 e 2.1 .13 foram demonstrados utilizando-se apenas conceitos algébricos. Ainda assim, a maioria dos alunos apresentou dificuldades de compreensão, alegando um uso excessivo de variáveis.

Para apresentar algumas aplicações dos Teoremas 2.1.9 ao 2.1.13, elaborou-se o seguinte exemplo.

Exemplo 2.1.14 (Cálculo de limites no infinito). Solicitou-se que os alunos se organizassem em grupos e que tentassem calcular os limites apresentados abaixo.

1) $\lim _{x \rightarrow+\infty}\left(4 x^{2}-7 x+3\right)$

2) $\lim _{x \rightarrow+\infty} \frac{3 x+2}{5 x-1}$

3) $\lim _{x \rightarrow-\infty} \frac{4 x-1}{3 x^{2}+5 x-2}$

4) $\lim _{x \rightarrow+\infty} \frac{5 x^{2}-4 x+3}{3 x+2}$

Com a explicação e a abordagem dos Teoremas 2.1.9-2.1.13 apresentadas até esse instante, os alunos não conseguiram desenvolver o cálculo dos limites. Após a explicação de como proceder em cada caso, compreenderam como calcular cada limite. Em seguida, com uso do software Geogebra, fizemos o esboço das funções dadas com a finalidade de que os alunos interpretassem geometricamente os resultados obtidos. 
A partir de uma análise detalhada do gráfico, o professor retomou o conceito de assíntota horizontal. O grupo percebeu a importância do cálculo de limites no infinito para a representação gráfica.

Em resumo, os alunos conseguiram perceber o processo algébrico para o cálculo de limites no infinito, porém comentaram que o assunto parecia complexo.

\subsubsection{Continuidade}

Para introduzir o estudo de continuidade, inicialmente apresentamos o gráfico da função $f(x)=$ $4 x^{2}-7 x+3$. Os alunos perceberam que o gráfico dessa função é uma curva sem interrupções. Diante disso, o professor explicou que funções com essa propriedade são chamadas de funções contínuas. A partir desse exemplo introduziu-se a definição formal de continuidade.

Definição 2.1.15. Uma função $f(x)$ é contínua em $c \in \mathbb{R}$ se:

1) $f(c)$ está definida;

2) $\lim _{x \rightarrow c} f(x)$ existe;

3) $\lim _{x \rightarrow c} f(x)=f(c)$.

Em outras palavras, a definição diz que $f(x)$ é contínua em $c$ se $f(x)$ tende a $f(c)$ quando $x$ tende a $c$. Se $f(x)$ não é contínua em $c$, dizemos que há uma descontinuidade nesse ponto.

Em seguida, comentou-se com os alunos sobre as propriedades das funções contínuas, alegando que existem alguns casos em que o conhecimento sobre essas propriedades nos ajuda a verificar se uma função é ou não contínua, em um determinado ponto.

\subsubsection{Propriedades das Funções Contínuas}

Se $f(x)$ e $g(x)$ forem contínuas em $c$, e se $k$ for uma constante, então as funções:

$f(x)+g(x) ; f(x)-g(x) ; k f(x) ; f(x) \cdot g(x)$ e $\frac{f(x)}{g(x)}$ se $g(c) \neq 0$ também serão contínuas em $c$.

Das propriedades acima, demonstrou-se a propriedade da soma de funções contínuas. Para auxiliar os alunos na compreensão das condições de continuidade na Definição 2.1.15 e as suas propriedades, elaborou-se o exemplo abaixo.

Exemplo 2.1.16. Solicitou-se aos alunos que verificassem se as funções $f(x), g(x)$ e $h(x)$ abaixo são contínuas no ponto $x=1$. 
1) $f(x)=2 x+1$

Os alunos verificaram que $f(1)=3$ e $\lim _{x \rightarrow 1}(2 x+1)=3$. Logo, constataram que $\lim _{x \rightarrow 1} f(x)=$ $f(1)$, e concluíram que $f(x)$ é contínua em $x=1$. O professor complementou pedindo que o grupo desenhasse o gráfico de $f(x)$ e notasse que essa função é contínua em todo o seu domínio, conforme mostra a Figura 2.8.

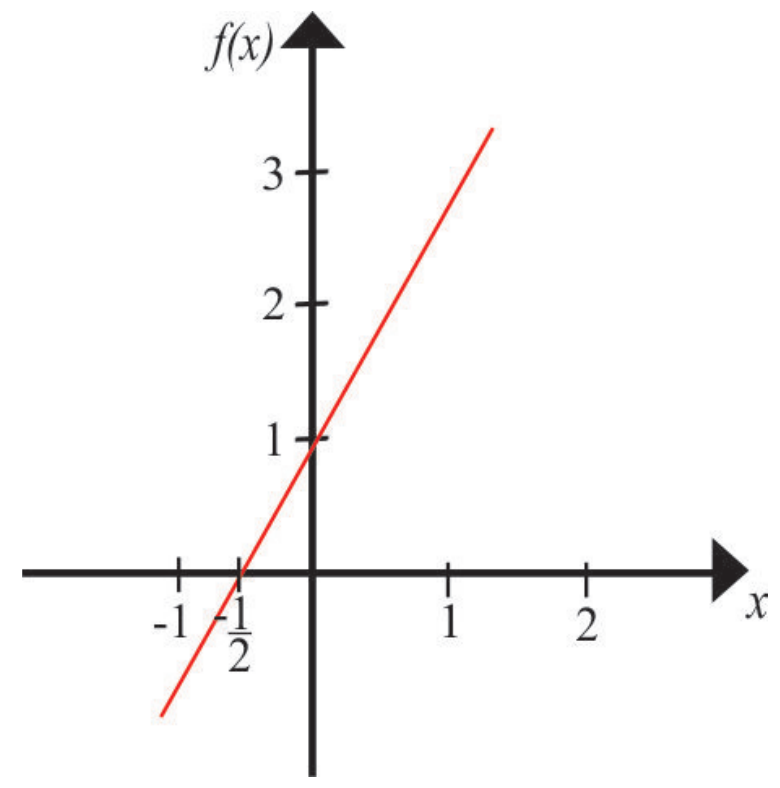

Figura 2.8: : $f(x)=2 x+1$.

Por fim, o professor explicou e demonstrou que qualquer polinômio é contínuo em todo o seu domínio. Ao observarem o gráfico da Figura acima, os alunos conseguiram perceber que $f(x)$ é contínua para qualquer $c \in \mathbb{R}$, pois $\lim _{x \rightarrow c}(2 x+1)=2 c+1+f(c)$. Entretanto, ao apresentar a demonstração de que todo polinômio é contínuo em $\mathbb{R}$ os alunos não compreenderam bem a demonstração, além do mais, o professor percebeu que estavam dispersos.

2) $g(x)= \begin{cases}2 x+1 & , x \neq 1 \\ 4 & , x=1\end{cases}$

O grupo verificou que $g(1)=4$ e $\lim _{x \rightarrow 1} g(x)=\lim _{x \rightarrow 1}(2 x+1)=3$. Logo, perceberam que $\lim _{x \rightarrow 1} g(x) \neq$ $g(1)$. Pela definição, pode-se afirmar que a função $g(x)$ é descontinua no ponto $x=1$. Para que os alunos observassem a descontinuidade ocorrida nesse ponto, apresentamos o gráfico da função $g(x)$. Veja a Figura 2.9. 


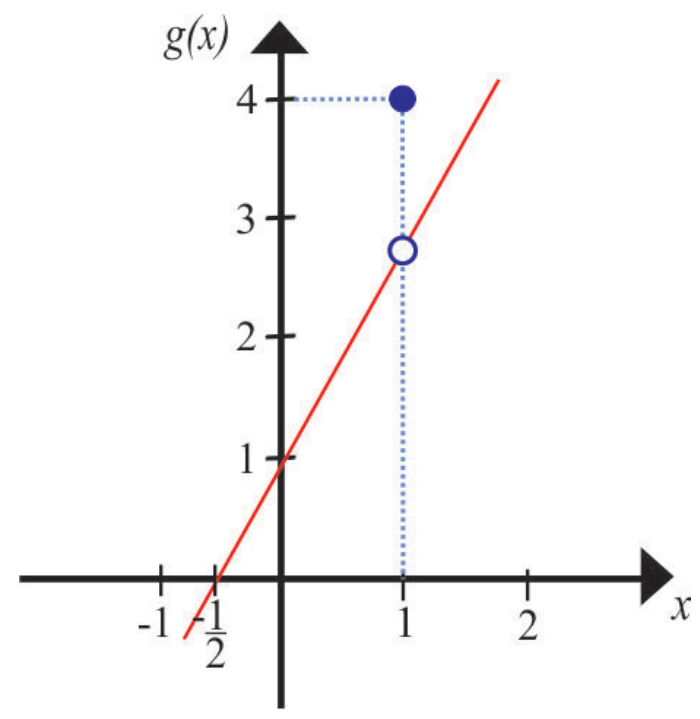

Figura 2.9: Gráfico da função: $g(x)$.

3) $h(x)=\frac{x^{2}-1}{x-1}$

Inicialmente, os alunos verificaram que $h(x)$ está definida em $\mathbb{R}-\{1\}$. Assim, o ponto $x=1$ não pertence ao domínio da função, ou seja, $h(1)$ não está definida. Logo, concluíram que $h(x)$ não é contínua em $x=1$. O professor comentou que, para todos os demais pontos $h(x)$ é contínua. De fato, a função $h(x)$ é uma função racional da forma $h(x)=\frac{p(x)}{q(x)}$, onde $p(x)$ e $q(x)$ são polinômios. O domínio de $h(x)$ é $D=\{x \in \mathbb{R} / q(x) \neq 0\}$. Sabemos do item 1 , desse exemplo, que $p(x)$ e $q(x)$ são contínuas em todo o seu domínio. Assim, pela propriedade 5 de continuidade, $h(x)$ é contínua em todo o seu domínio.

Por fim, o professor esclareceu aos alunos que qualquer função racional é contínua em seu domínio.

\subsection{Derivadas}

Introduziu-se o estudo das derivadas a partir da noção de reta secante entre dois pontos. Através desse conceito, definimos o que é uma reta tangente, enfatizando que as mesmas são definidas por um tipo especial de limite. Com esses conceitos bem assimilados, definimos de maneira formal o que é derivada. 
Apresentamos uma seção na qual discutimos as principais regras de derivação. Com o auxílio dessas regras, discutiu-se como as derivadas afetam o formato do gráfico de uma função e, em particular, como nos ajudam a localizar os valores de máximo e mínimo. Comentamos também, sobre o que é um ponto de inflexão.

Para finalizar, complementou-se o estudo das derivadas, relacionando-o à noção de taxa de variação instantânea de uma função, à qual está presente no cotidiano das pessoas, através por exemplo, da determinação da taxa de crescimento de certa população, taxa de crescimento econômico de um país, taxa de variação de velocidade e de aceleração. Dentre essas aplicações optamos em comentar com os alunos sobre a taxa de variação da velocidade e da aceleração.

\subsubsection{A Reta Tangente e a Derivada}

Muitos problemas de cálculo envolvem a determinação da reta tangente a uma curva dada, em um determinado ponto dessa curva. Para que fosse possível definir reta tangente, debateu-se com os alunos alguns conceitos sobre reta secante.

Se uma curva $C$ apresentar uma equação $y=f(x)$ e quisermos encontrar a reta tangente a $C$ em um ponto $A=\left(x_{0}, f\left(x_{0}\right)\right)$, consideramos inicialmente um ponto próximo $B(x, f(x))$, como na Figura 2.10.

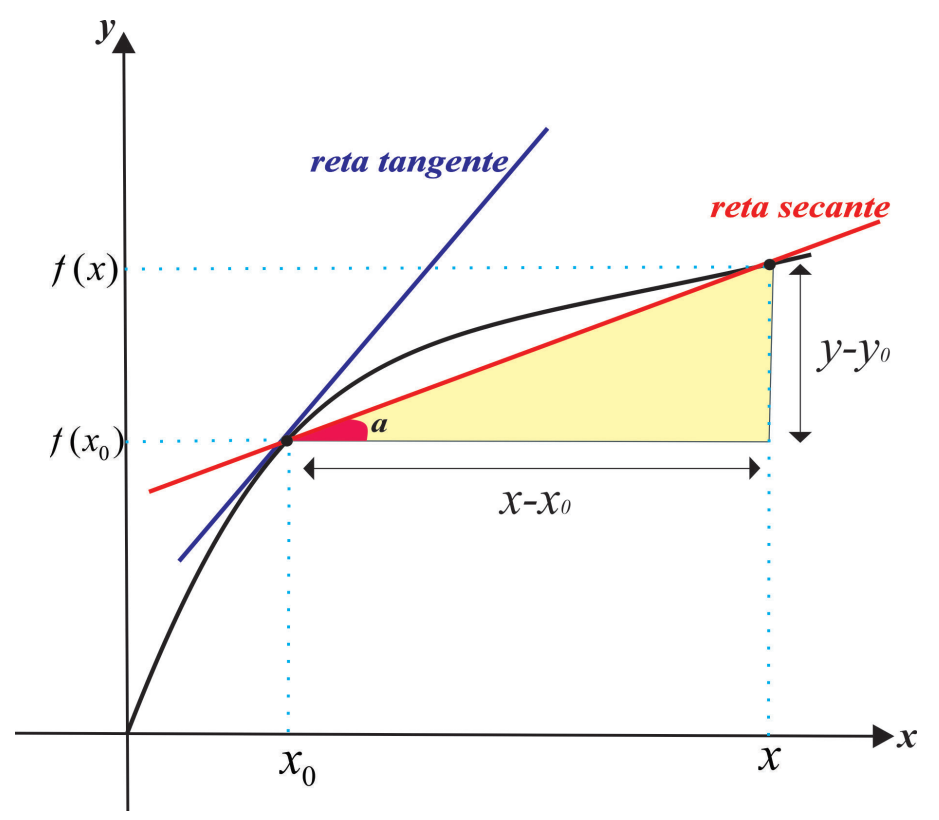

Figura 2.10: Reta secante e reta tangente a uma curva. 
Ao analisar a Figura 2.10, os alunos calcularam a inclinação da reta secante $A B$, dada por

$$
m_{A B}=\frac{f(x)-f\left(x_{0}\right)}{x-x_{0}} .
$$

Em seguida, o professor questionou se algum aluno saberia o procedimento para encontrar a inclinação da reta tangente ao ponto $A$.

Como nenhum aluno indicou uma alternativa, o professor explicou que, para encontrarmos a inclinação da reta tangente ao ponto $A$ fazemos o ponto $B$ se aproximar de $A$ ao longo da curva $C$. Dessa forma, $x$ tende a $x_{0}$. Se a inclinação da reta secante $\left(m_{A B}\right)$ tender a um número $m$, dizemos que $m$ representa a inclinação da reta tangente ao ponto $A$. Diante desses comentários definimos de uma maneira formal o conceito de reta tangente.

Definição 2.2.1. A reta tangente à curva $y=f(x)$ em um ponto $A=\left(x_{0}, f\left(x_{0}\right)\right)$ é a reta que passa por $A$ com a inclinação $m=\lim _{x \rightarrow x_{0}} \frac{f(x)-f\left(x_{0}\right)}{x-x_{0}}$, desde que o limite exista.

Acrescentou-se ao grupo que existe outra expressão para a inclinação da reta tangente. Se $h=x-x_{0}$, então $x=x_{0}+h$. Como $x \rightarrow x_{0}$, podemos dizer que $h \rightarrow 0$.

Assim, a expressão para a inclinação da reta tangente na Definição 2.2.1 pode ser representada por: $m=\lim _{h \rightarrow 0} \frac{f(x+h)-f\left(x_{0}\right)}{h}$.

Para que os alunos pudessem compreender de maneira eficaz a Definição 2.2.1, desenvolveu-se o exemplo abaixo.

Exemplo 2.2.2. Solicitou-se que os alunos encontrassem a inclinação da reta tangente à parábola $f(x)=x^{2}+1$ no ponto $A=(2,5)$.

Nesse exemplo os estudantes necessitaram do auxílio do professor indicando como deveriam proceder.

O professor explicou que, como estamos interessados em encontrar a inclinação da reta tangente, devemos usar o limite

$$
\lim _{h \rightarrow 0} \frac{f(x+h)-f\left(x_{0}\right)}{h} .
$$

Os alunos tiveram dificuldade em interpretar quem seria o $x_{0}$. Diante disso, o professor esclareceu que $x_{0}=2$ e $f\left(x_{0}\right)=5$. Em seguida, detalhou a resolução, como segue abaixo

$$
\lim _{h \rightarrow 0} \frac{(2+h)^{2}+1-5}{h}=\lim _{h \rightarrow 0} \frac{4+4 h+h^{2}-4}{h}=\lim _{h \rightarrow 0} \frac{4 h+h^{2}}{h}=\lim _{h \rightarrow 0} 4+h=4 .
$$


Por fim, comentou-se que neste exemplo estávamos interessados em encontrar a inclinação da reta tangente em um ponto específico, no caso $A=(2,5)$, porém para um ponto genérico $A^{\prime}=$ $(x, y)$, podemos dizer que a derivada de uma função $f(x)$ é a função $f^{\prime}(x)$ definida por $f^{\prime}(x)=$ $\lim _{h \rightarrow 0} \frac{f(x+h)-f(x)}{h}$, desde que o limite exista.

Para exemplificar a definição de derivada, elaborou-se o seguinte exemplo.

Exemplo 2.2.3. (a) Calcular a derivada de $f(x)=x^{2}+x$.

(b) Encontre a equação da reta tangente a $y=f(x)$ no ponto $(1,2)$.

Para o item (a) os alunos conseguiram perceber que, para calcular a derivada da função $f(x)$, deveriam utilizar a expressão

$$
f^{\prime}(x)=\lim _{h \rightarrow 0} \frac{f(x+h)-f(x)}{h} .
$$

Ao observarem $f^{\prime}(x)$, não sabiam como encontrar o $f(x+h)$. Para auxiliar o grupo, o professor comentou que se $f(x)=x^{2}+x$ então $f(x+h)=(x+h)^{2}+(x+h)$. Logo após, os estudantes obtiveram:

$$
f^{\prime}(x)=\lim _{h \rightarrow 0} \frac{h^{2}+2 x h+h}{h}=\lim _{h \rightarrow 0} \frac{h(h+2 x+1)}{h}=\lim _{h \rightarrow 0}(h+2 x+1)=2 x+1 .
$$

Portanto, $f^{\prime}(x)=2 x+1$.

Os alunos tiveram dificuldade para a realização do item (b). Logo, foi necessário que o professor apresentasse a resolução desse exercício de forma detalhada, argumentando que para encontrem a equação da reta tangente ao ponto $(1,2)$ deveriam, inicialmente, encontrar a inclinação da reta tangente ao ponto $(1,2)$ em $f(x)$. Do item anterior temos que $f^{\prime}(x)=2 x+1$ e, portanto, $f^{\prime}(1)=3$.

Foi feita uma revisão com o grupo sobre as equações gerais e reduzidas da reta, assuntos desenvolvidos no ensino médio. Ao utilizarem a fórmula $y-y_{0}=m\left(x-x_{0}\right)$, onde $\left(x_{0}, y_{0}\right)$ é um ponto que pertence à reta tangente, os alunos concluíram que a equação da reta tangente à $f(x)$ que passa por $(1,2)$ é $y=3 x-1$.

\subsubsection{Regras de Derivação}

Na seção anterior vimos que as derivadas são interpretadas como inclinações de retas tangentes. Usamos um limite para calcular a derivada de funções, seja para um ponto especifico $x_{0}$ ou em qualquer ponto. Mas seria cansativo e não muito prático se sempre usássemos essa definição. 
Diante disso, apresentou-se aos alunos as regras de derivação, que nos permitem calcular com relativa facilidade as derivadas de polinômios, funções racionais, funções algébricas, além de outras funções que não serão exploradas neste trabalho.

Optou-se por demonstrar algumas das regras de derivação. A necessidade de se apresentar essas demonstrações deu-se pelos seguintes fatos:

1) conscientizar os alunos sobre a importância da definição de limite;

2) desenvolver nos alunos a habilidade de trabalharem algebricamente;

3) mostrar aos alunos a importância das demonstrações matemáticas, que têm como objetivo principal validar um resultado.

Proposição 2.2.4 (Derivada da Função Constante). Se $k$ é uma constante e $f(x)=k, \forall x \in \mathbb{R}$, então $f^{\prime}(x)=0$.

Demonstração. Se $f^{\prime}(x)$ existe, então:

$$
f^{\prime}(x)=\lim _{h \rightarrow 0} \frac{f(x+h)-f(x)}{h}=\lim _{h \rightarrow 0} \frac{k-k}{h}=\lim _{h \rightarrow 0} 0=0 .
$$

Proposição 2.2.5 (Derivada da Função Potência). Se $f(x)=x^{n}$, com $n \in \mathbb{N} \neq-1$, então $f^{\prime}(x)=n \cdot x^{n-1}$.

Demonstração. Se $f^{\prime}(x)$ existe, então:

$$
\begin{aligned}
f^{\prime}(x) & =\lim _{h \rightarrow 0} \frac{f(x+h)-f(x)}{h} \\
& =\lim _{h \rightarrow 0} \frac{(x+h)^{n}-x^{n}}{h} \\
& =\lim _{x \rightarrow 0} \frac{\left[\left(\begin{array}{c}
n \\
0
\end{array}\right) x^{0} h^{n}+\left(\begin{array}{l}
n \\
1
\end{array}\right) x^{1} h^{n-1}+\ldots+\left(\begin{array}{c}
n \\
n-1
\end{array}\right) x^{n-1} h^{1}+\left(\begin{array}{c}
n \\
n
\end{array}\right) x^{n} h^{0}\right]-x^{n}}{h} \\
& =\lim _{x \rightarrow 0} \frac{\left[h^{n}+n x h^{n-1}+\ldots+n x^{n-1} h+x^{n}\right]-x^{n}}{h} \\
& =\lim _{x \rightarrow 0} \frac{h\left(h^{n-1}+n x h^{n-2}+\ldots+\frac{n(n-1)}{2} x^{n-2} h^{2}+n x^{n-1}\right)+x^{n}-x^{n}}{h} \\
& =\lim _{x \rightarrow 0} h^{n-1}+n x h^{n-2}+\ldots+\frac{n(n-1)}{2} x^{n-2} h+n x^{n-1} \\
& =0^{n-1}+n x 0^{n-2}+\ldots+\frac{n(n-1)}{2} x^{n-2} 0+n x^{n-1} \\
& =n x^{n-1} .
\end{aligned}
$$


Proposição 2.2.6 (A Regra da Multiplicação por Constante). Se $g(x)=k \cdot f(x)$, onde $k$ é uma constante e $f(x)$ é derivável, então $g^{\prime}(x)=k \cdot f^{\prime}(x)$.

Proposição 2.2.7 (A Regra da Soma). Sejam $u(x)$ e $v(x)$ duas funções, tais que $u^{\prime}(x)$ e $v^{\prime}(x)$ existam.

Se $f(x)=u(x) \pm v(x)$, então $f^{\prime}(x)=u^{\prime}(x) \pm v^{\prime}(x)$.

Proposição 2.2.8 (A regra do Produto). Se $f(x)=u(x) v(x)$, com $u(x)$ e $v(x)$ deriváveis, então

$$
f^{\prime}(x)=u^{\prime}(x) v(x)+u(x) v^{\prime}(x) .
$$

Proposição 2.2.9 (A Regra da Quociente). Se $f(x)=\frac{u(x)}{v(x)} ; v(x) \neq 0$ com $u(x)$ e $v(x)$ deriváveis então

$$
f^{\prime}(x)=\frac{u^{\prime}(x) v(x)-u(x) v^{\prime}(x)}{v(x)^{2}} .
$$

Dentre as Proposições 2.2.6 - 2.2.9 também foi demonstrada a Proposição 2.2.8. Observou-se que a demonstração da Proposição 2.2.5, além de ajudar os alunos na compreensão sobre demonstrações, fez com que percebessem que vários conceitos abordados no ensino básico, como o de binômio de Newton, são fundamentais para o desenvolvimento de conteúdos estudados no ensino superior.

Para cada uma das proposições acima foram apresentados três exemplos, para que os alunos pudessem compreender melhor e aplicar cada regra de derivação. Nessa fase da pesquisa percebeuse que os alunos assimilaram como utilizar as regras apresentadas. Entretanto, os mesmos apresentaram muita dificuldade em compreender as demonstrações.

\subsubsection{Aplicações de Derivada}

Nesta seção abordamos as definições e aplicações de ponto crítico, pontos mínimo e máximo e ponto de inflexão de uma função. Iniciou-se este estudo comentando que os pontos de máximo e de mínimo estão presentes em diversas situações do cotidiano como por exemplo, para minimizar o custo de um produto, maximizar certa área, etc. Complementou-se, destacando que esses conceitos são fundamentais para a construção de gráficos de funções.

\subsubsection{Pontos Críticos de uma Função e Pontos de Máximo e Mínimo}

Inicialmente, apresentou-se aos alunos uma noção sobre o valor máximo ou mínimo de uma função. Para isto, o professor apresentou o gráfico de uma certa função $f(x)$ através da Figura 2.11. 


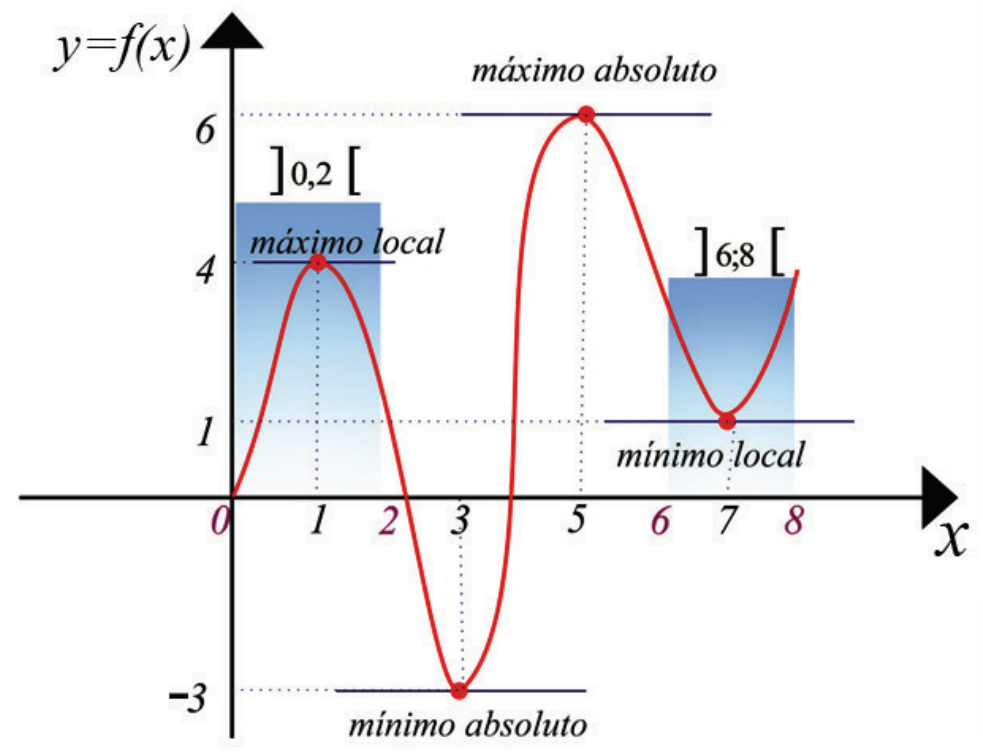

Figura 2.11: Noção de pontos de máximo e mínimo.

Ao observar a figura acima, os alunos notaram que o maior valor de $f(x)$ é $f(5)=6$ e que seu menor valor é $f(3)=3$. O professor comentou que, neste caso, dizemos que $f(5)=6$ é o máximo absoluto de $f(x)$ e $f(3)=-3$ é o mínimo absoluto. Entretanto, se restringirmos a nossa atenção ao intervalo $] 0,2[$, constatamos que o ponto mais alto será $f(1)=4$. Esse ponto é denominado ponto de máximo local, pois não é o maior ponto de toda a função. O mesmo raciocínio pode ser feito se restringirmos a nossa atenção ao intervalo ]6,8[. É fácil perceber que neste intervalo o ponto mais baixo será $f(7)=1$. Esse ponto é denominado ponto de mínimo local. Em geral, usamos as seguintes definições.

Definição 2.2.10. Seja $c$ um ponto no domínio $D$ de uma função $f(x)$. Então $f(c)$ é:

1) o máximo absoluto de $f(x)$ em $D$ se $f(x) \leq f(c)$ para qualquer que seja $x$ em $D$;

2) o mínimo absoluto de $f(x)$ em $D$ se $f(x) \geq f(c)$ para qualquer que seja $x$ em $D$.

Definição 2.2.11. Seja $c$ um ponto no domínio $D$ de uma função $f(x)$. Então $f(c)$ é:

1) um valor de máximo local em $c$ se $f(x) \leq f(c)$ para qualquer $x$ em um intervalo aberto que contenha $c$; 
2) um valor de mínimo local em $c$ se $f(x) \geq f(c)$ para qualquer $x$ em um intervalo aberto que contenha $c$.

Em seguida, com o auxílio do software Geogebra, desenhamos os gráficos de algumas funções e o professor pediu que os alunos analisassem a existência e pontos de máximo e mínimo absoluto e local. Através dessa atividade o grupo reforçou a ideia desses conceitos, chamados de valores extremos de $f(x)$.

Logo após, solicitou-se que os alunos observassem que, na Figura 2.11 os pontos da curva em que a função atingiu valores de máximo e de mínimo, possuem retas tangentes horizontais e, portanto, cada uma dessas retas possui inclinação igual a zero. Assim, como a derivada é a inclinação da reta tangente, devemos ter $f^{\prime}(1)=f^{\prime}(3)=f^{\prime}(5)=f^{\prime}(7)=0$. O teorema a seguir afirma que isso é sempre verdadeiro para as funções deriváveis.

Teorema 2.2.12. Se $f(x)$ tiver um máximo ou mínimo local em $c$ e se $f^{\prime}(c)$ existir, então $f^{\prime}(c)=0$. A seguir duas observações importantes sobre o teorema acima foram feitas.

1) A recíproca do Teorema 2.2.12 não é verdadeira. Ou seja, se $f^{\prime}(c)=0$ existir, pode não existir um máximo ou um mínimo em $c$.

2) Uma função $f(x)$ pode assumir um valor máximo ou mínimo em um ponto $c$ e $f^{\prime}(c) \neq 0$.

Para que os alunos entendessem melhor o teorema acima, o professor apresentou os dois exemplos que seguem.

Exemplo 2.2.13. Considere a função $f(x)=x^{3}$. Ao derivar $f(x)=x^{3}$ obtemos $f^{\prime}(x)=3 x^{2}$. O grupo observou que $f^{\prime}(x)=0$ para $x=0$, porém o ponto $(0,0)$ não é um ponto de máximo e nem de mínimo da função $f(x)$.

Em seguida o professor pediu que os alunos esboçassem o gráfico da função $f(x)=x^{3}$, para que pudessem comprovar a inexistência de um ponto de máximo e de mínimo, conforme mostra a Figura 2.12. 


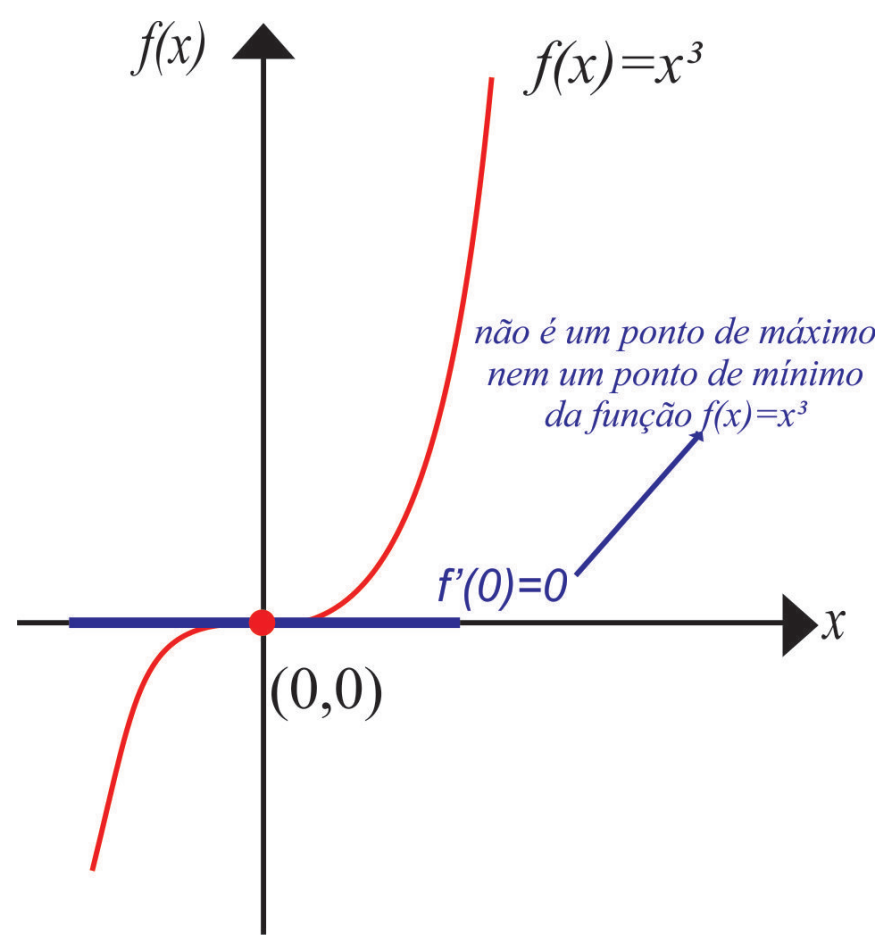

Figura 2.12: Gráfico da função $f(x)=x^{3}$.

Exemplo 2.2.14. Considere a função $g(x)=|x|$. Inicialmente, pedimos que os alunos esboçassem o gráfico da função $g(x)$. Veja a Figura 2.13.

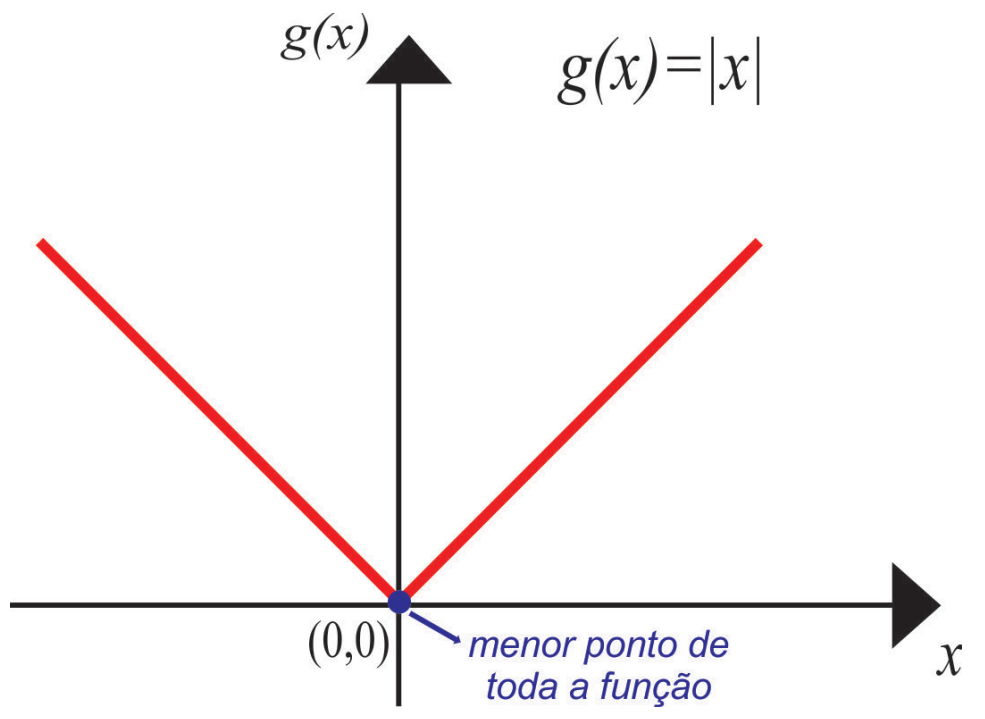

Figura 2.13: Gráfico da função $g(x)=|x|$. 
Ao observar o gráfico da Figura 2.13 os alunos perceberam que o ponto $(0,0)$ é um ponto de mínimo local e absoluto.

Em seguida mostrou-se, utilizando a definição de derivadas, que $f^{\prime}(0)$ não existe e o professor notou dificuldade de compreensão e falta de motivação dos alunos.

A partir do Teorema 2.2.12 e das observações feitas para este teorema, pode-se perceber que os pontos $c$ onde $f^{\prime}(c)=0$ ou onde $f^{\prime}(c)$ não existem, são candidatos para os valores de máximo ou de mínimo de uma função. Assim damos um nome especial para estes pontos.

Definição 2.2.15. Um número $c$ no domínio de uma função $f(x)$ é chamado ponto crítico de $f(x)$ se $f^{\prime}(c)=0$ ou $f^{\prime}(c)$ não existe.

A partir da definição acima, comentou-se com os alunos que o zero é um ponto crítico tanto para a função $f(x)=x^{3}$ quanto para $f(x)=|x|$, pois como vimos nos Exemplos 2.2.13 e 2.2.14, para a primeira função $f^{\prime}(0)=0$ e para a segunda $f^{\prime}(0)$ não existe.

Em seguida, o professor reforçou que os valores de máximo e mínimo são às vezes chamados valores extremos, ou apenas extremos de uma função e apresentou o seguinte teorema.

Teorema 2.2.16. Se uma função $f(x)$ é contínua em um intervalo fechado $[a, b]$, então $f(x)$ toma seu valor máximo e seu mínimo ao menos uma vez em $[a, b]$.

A demonstração do teorema acima não foi realizada com os alunos, entretanto o grupo conseguiu compreender o teorema de forma intuitiva.

Para reforçar a teoria apresentada até este momento, desenvolvemos o seguinte exemplo.

Exemplo 2.2.17. Encontre os pontos críticos da função $f(x)=x^{3}-12 x$ e em seguida calcule os pontos de máximo e mínimo no intervalo $[-3,5]$.

Os alunos comentaram que os pontos críticos de $f(x)$ ocorrem onde $f^{\prime}(x)=0$ ou $f^{\prime}(x)$ não existe. Ao derivarem $f(x)=x^{3}-12 x$ obtiveram $f^{\prime}(x)=3(x+2)(x-2)$, como a derivada existe para todo $x$, os únicos pontos críticos são aqueles em que a derivada é zero, isto é, $f^{\prime}(x)=3(x+2)(x-2)=$ $0 \Rightarrow x=-2$ e $x=2$.

Em seguida, o professor pediu que os alunos observassem que $f(x)$ é contínua em todo o seu intervalo por ser uma função polinomial, logo é continua em $[-3,5]$. De acordo com o Teorema 2.2.16, segue que os valores de máximo e mínimo estão entre os números $f(-3), f(-2), f(2)$ e $f(5)$. Calculando esses valores o grupo desenvolveu a tabela abaixo. 
Tabela 2.5: Extremos da função $f(x)=x^{3}-12 x$ no intervalo $[-3,5]$

\begin{tabular}{cll} 
Valor de $x$ & Classificação de $x$ & Valor de $f(x)$ \\
\hline-3 & Extremo de $[-3,5]$ & $f(-3)=9$ \\
5 & Extremo de $[-3,5]$ & $f(5)=65$ \\
-2 & Ponto crítico de $f(x)$ & $f(-2)=16$ \\
2 & Ponto crítico de $f(x)$ & $f(2)=16$ \\
\hline
\end{tabular}

Ao observarem a Tabela 2.5, o grupo percebeu que o valor mínimo de $f(x)$ em $[3,5]$ é -16 e o valor máximo é o ponto extremo $f(5)=65$. Pediu-se que o grupo observasse que no ponto $(-2,16)$ é possível desenhar uma reta tangente com inclinação zero, logo $f(2)=-16$ é um ponto de mínimo local de $f(x)$. Para finalizar, o professor fez um esboço gráfico da função $f(x)$, com escalas diferentes para os eixos $x$ e $y$. Assim, os alunos poderiam interpretar melhor os resultados obtidos. Veja a Figura 2.14.

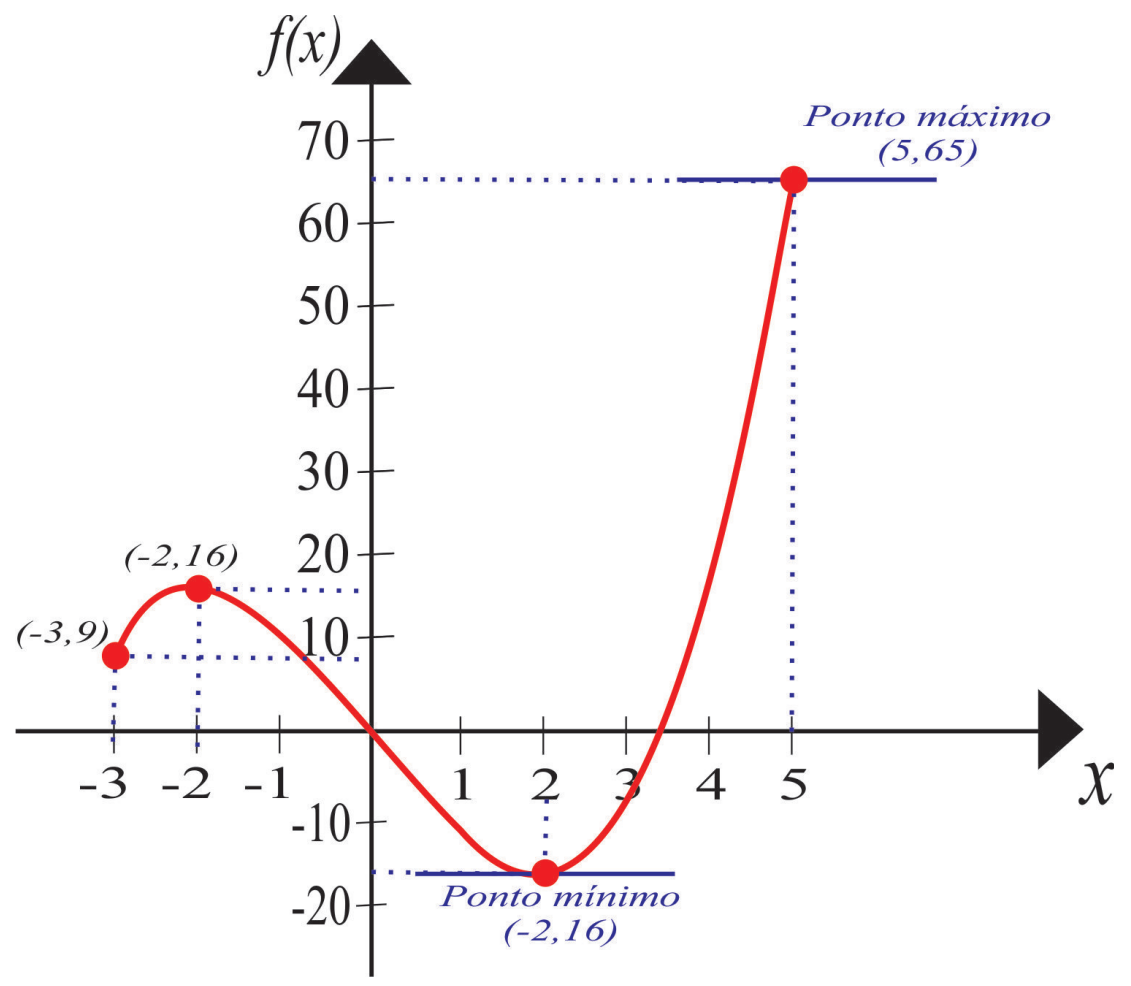

Figura 2.14: Gráfico da função $f(x)=x^{3}-12 x$ no intervalo $[-3,5]$. 


\subsubsection{O Teste da Primeira Derivada}

Nesta seção mostrou-se aos alunos como o sinal da derivada $f^{\prime}(x)$ pode ser usado para determinar onde uma função $f(x)$ é crescente e decrescente. O professor comentou que estas informações permitem que classifiquemos os extremos locais dessa função.

Vimos que a derivada de uma função $f(x)$ representa a inclinação da curva $y=f(x)$ no ponto $(x, f(x))$. Além disso, pode nos dizer onde uma função é crescente ou decrescente. Veja Figura 2.15.

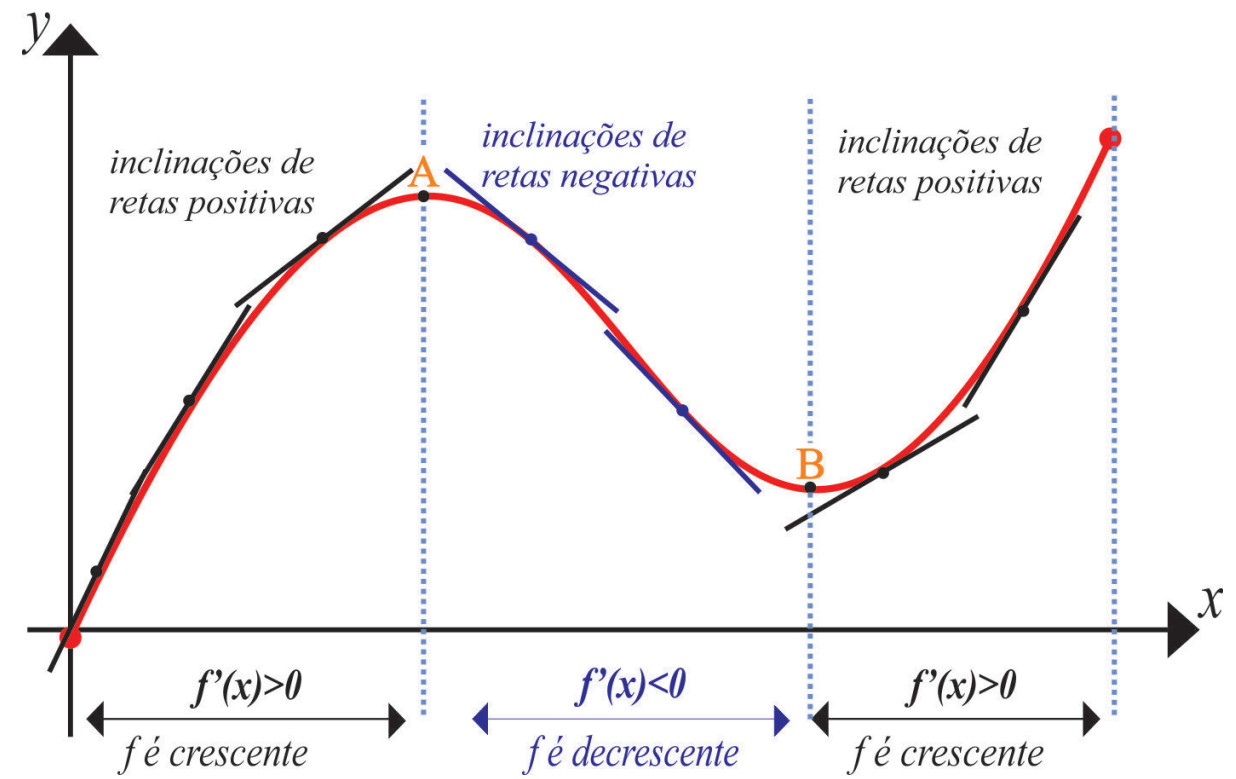

Figura 2.15: Inclinações de retas crescentes e decrescentes.

Debateu-se com os alunos os conceitos de intervalos crescentes e decrescentes, com base nas informações contidas na Figura 2.15. O fato de essas observações intuitivas serem verdadeiras, é uma consequência do seguinte teorema:(A demonstração desse teorema não foi realizada).

Teorema 2.2.18. Seja $f(x)$ contínua em $[a, b]$ e derivável em $(a, b)$.

1) Se $f^{\prime}(x)>0$ para todo $x$ em $(a, b)$, então $f$ é crescente em $[a, b]$.

2) Se $f^{\prime}(x)<0$ para todo $x$ em $(a, b)$, então $f$ é decrescente em $[a, b]$.

Para reforçar o aprendizado sobre o Teorema 2.2.18, introduziu-se o seguinte exemplo.

Exemplo 2.2.19. Determinar os intervalos em que a função $f(x)=x^{3}-9 x^{2}+15 x-5$ é crescente e os intervalos em que é decrescente. 
Inicialmente, os alunos comentaram que deveriam calcular $f^{\prime}(x)$, e obtiveram como solução $f^{\prime}(x)=3 x^{2}-18 x+15$. Entretanto, nenhum aluno conseguiu responder qual procedimento deveria ser seguido para encontrarem os intervalos crescentes e decrescentes da função $f(x)$. O professor sugeriu que estudassem o sinal da função $f^{\prime}(x)$. Diante disso, os alunos concluíram que $f^{\prime}(x)>0$ para $x<1$ e $x>5$ e que $f^{\prime}(x)<0$ para $1<x<5$, conforme mostra a Figura 2.16.

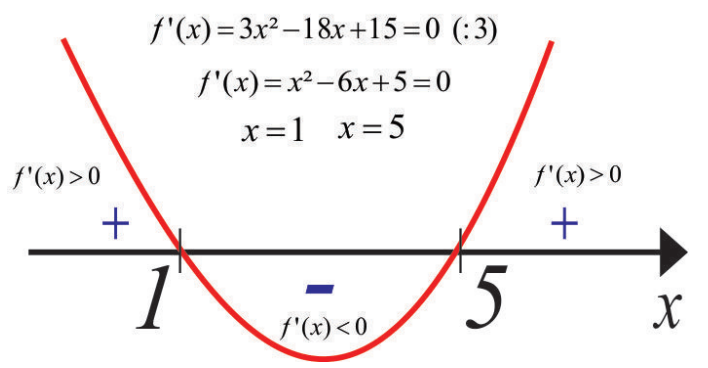

Figura 2.16: Estudo do sinal de $f^{\prime}(x)$.

Logo, concluíram que $f(x)$ é crescente para $x<1$ e $x>5$ e decrescente para $1<x<5$.

Por fim, o professor fez um esboço gráfico da função $f(x)$, com escalas diferentes para os eixos $x$ e $y$, conforme esquematizado pela Figura 2.17.

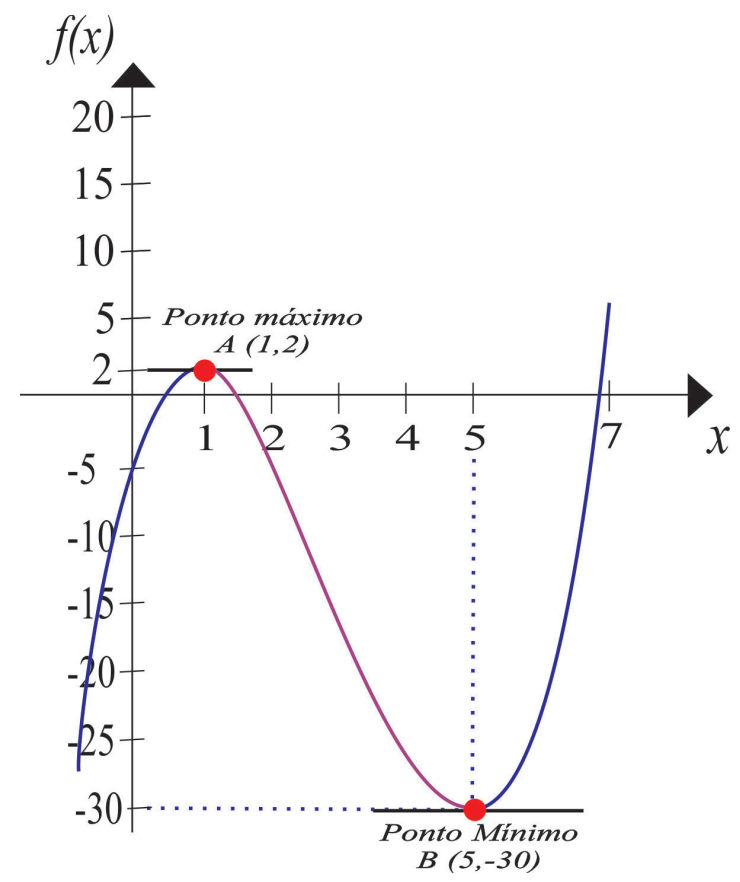

Figura 2.17: Gráfico da função $f(x)=x^{3}-9 x^{2}+15 x-5$. 
Ao analisar a Figura 2.17 os alunos perceberam que qualquer reta tangente desenhada sobre a curva da função $f(x)$, nos intervalos $x<1$ e $x>5$, possui inclinação positiva, ou seja, $f^{\prime}(x)>0$, constatando a veracidade desse fato através da observação da Figura 2.16. De forma semelhante, concluíram que qualquer reta tangente desenhada sobre a curva de $f(x)$, em $1<x<5$ tem inclinação negativa, ou seja, $f^{\prime}(x)<0$.

Em seguida, o professor pediu aos alunos que observassem que, na situação descrita pela Figura 2.17, as retas tangentes trocam de sentidos nos pontos $A$ e $B$ indicados.

Visto que os alunos compreenderam o exemplo acima, o professor enunciou o teste da primeira derivada e comentou que esse teste é de grande importância para encontrarmos os pontos de máximo ou mínimo de uma função.

Teste da primeira derivada. Suponha que $c$ seja o ponto crítico de uma função contínua $f(x)$.

1) Se o sinal da primeira derivada mudar de positivo para negativo em $c$, então $f(x)$ tem um máximo local em $c$.

2) Se o sinal da primeira derivada mudar de negativo para positivo em $c$, então $f(x)$ tem um mínimo local em $c$.

3) Se o sinal da primeira derivada não mudar em $c$, então $f(x)$ não tem máximo ou mínimo local em $c$.

Em seguida, o professor retomou o Exemplo 2.2.19, e pediu que os alunos aplicassem o teste da primeira derivada para analisarem os pontos de máximo e mínimo locais. Satisfatoriamente, os alunos comentaram que:

1) $x=1$ representa um ponto de máximo local, pois existe uma troca de sinal de positivo para negativo;

2) $x=5$ representa um ponto de mínimo local, pois existe uma troca de sinal de negativa para positiva.

\subsubsection{Concavidades e Pontos de Inflexão}

Para introduzir a definição de ponto de inflexão, apresentou-se a relação existente entre retas tangentes e concavidade voltada para cima ou para baixo. Para isto apresentou-se a Figura 2.18. 


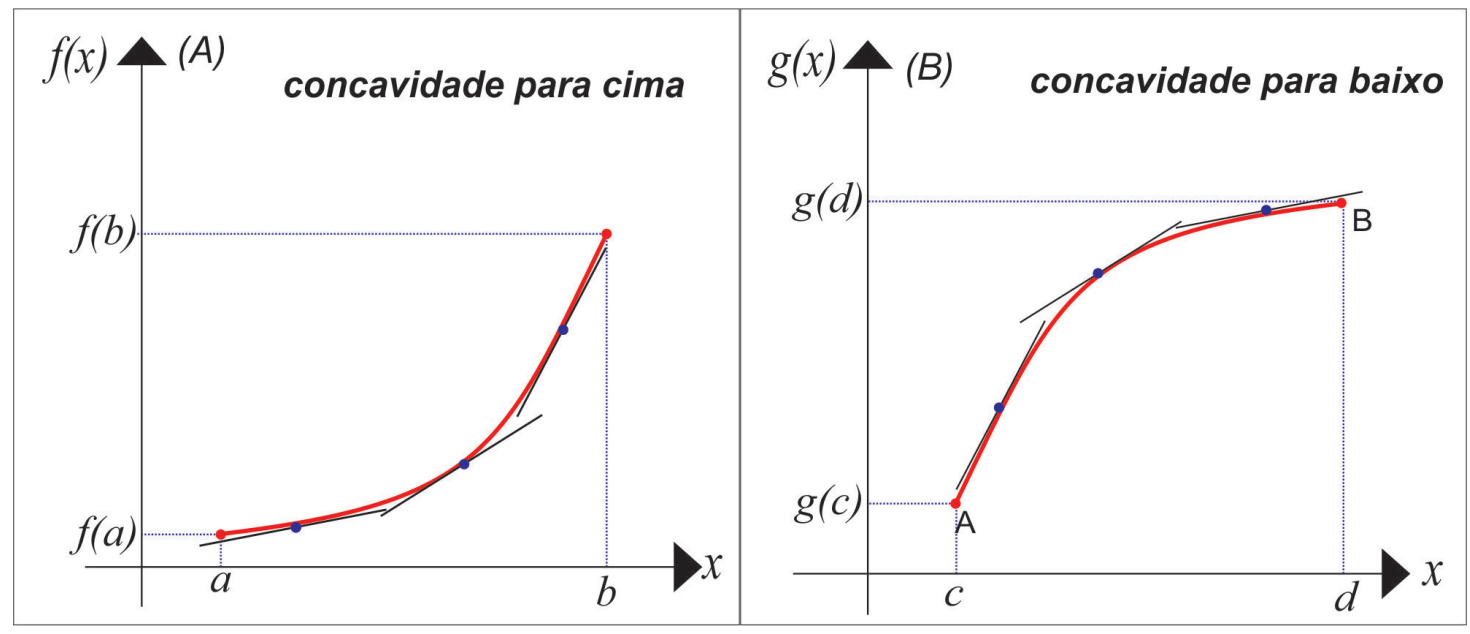

Figura 2.18: Relacionando retas tangentes à concavidade de uma função.

Pediu-se que os alunos observassem que as duas funções descritas pela Figura 2.18 (A) e (B) são crescentes conforme $x$ aumenta, mas que as retas tangentes desenhadas nos intervalos $[a, b]$ e $[c, d]$ se curvam de maneiras distintas. Observando as retas tangentes da Figura 2.18 (A) vemos que a inclinação $f^{\prime}(x)$ da curva aumenta no intervalo $[a, b]$, e ao observar as retas tangentes da Figuras 2.18 (B) vemos que a inclinação $g^{\prime}(x)$ diminui no intervalo $[c, d]$. A curva $f(x)$ é côncava para cima em $[a, b]$ e a curva $g(x)$ é côncava para baixo em $[c, d]$. Diante disso, o professor complementou, esclarecendo que a curva se situa acima de suas tangentes quando é côncava para cima (Figura 2.18(A)) e abaixo destas quando é côncava para baixo (Figura 2.18(B)).

Dos comentários acima, apresentou -se ao grupo o teste de concavidade.

Teste da segunda derivada para concavidade. Se $f(x)$ é uma função derivável até segunda ordem, em um intervalo $I$, então:

1) se $f^{\prime \prime}(x)>0$, então o gráfico de $f(x)$ é côncavo para cima;

2) se $f^{\prime \prime}(x)<0$, então o gráfico de $f(x)$ é côncavo para baixo.

Em seguida, definiu-se o que é um ponto de inflexão.

Definição 2.2.20 (Ponto de Inflexão). Um ponto onde o gráfico de uma função possui uma reta tangente e onde há mudança de concavidade, é um ponto de inflexão.

O professor acrescentou que, um ponto em curva no qual $f^{\prime \prime}(x)$ é positiva de um lado e negativa do outro, é um ponto de inflexão. Nesse ponto, $f^{\prime \prime}(x)$ é zero. Por fim, apresentamos a Figura 2.19. 


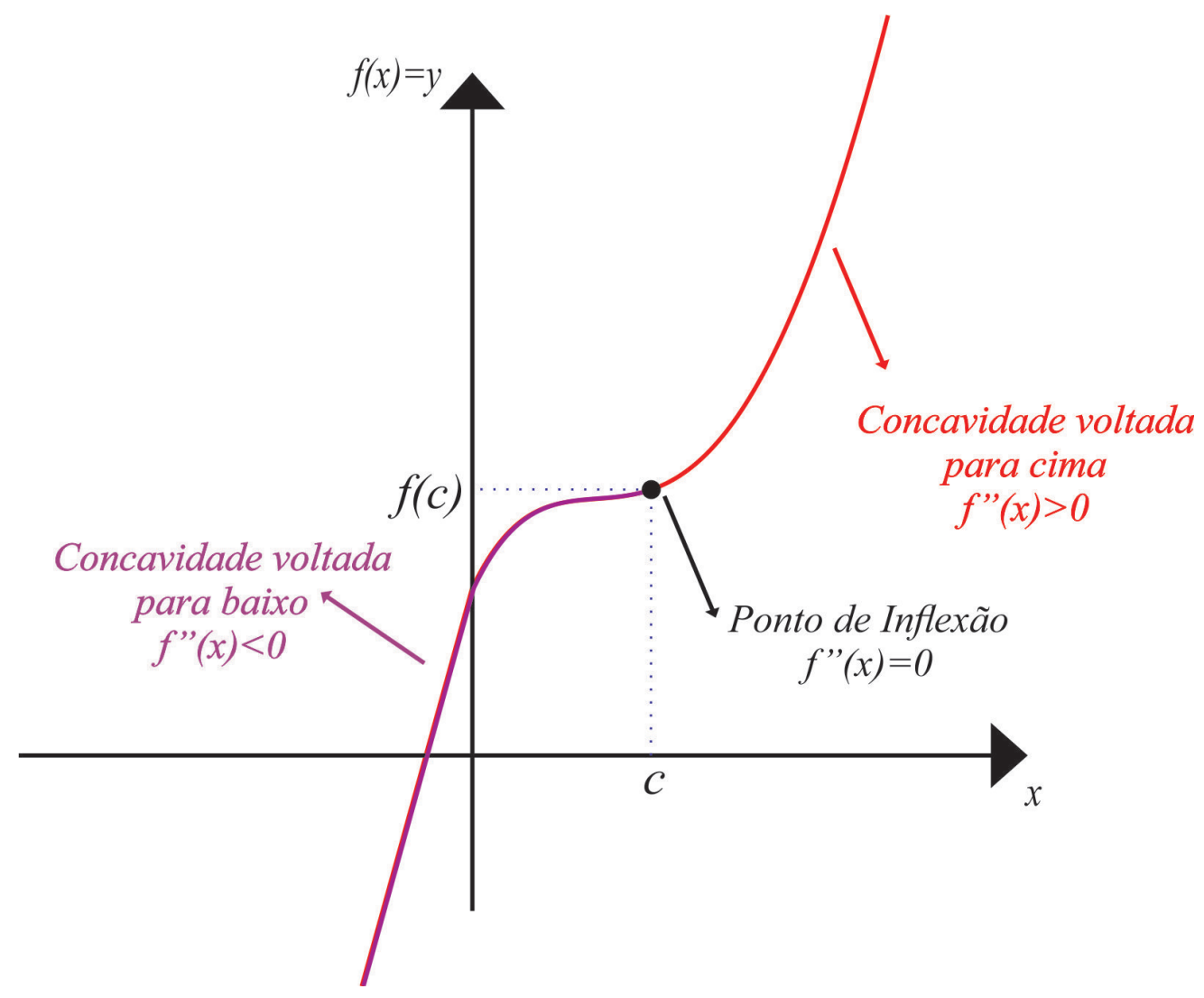

Figura 2.19: Interpretação geométrica sobre ponto de inflexão.

Com o objetivo de apresentar um contexto e aplicar os conceitos de pontos de máximo, mínimo e inflexão, elaborou-se o seguinte exemplo.

Exemplo 2.2.21. Estude o gráfico de $f(x)=-x^{4}+2 x^{2}+12$ com relação à concavidade, aos pontos de inflexão, mínimo e máximo locais. Use essas informações para esboçar o gráfico.

Inicialmente, o professor auxiliou os alunos a encontrarem os pontos críticos de $f(x)$. Para isso, fizeram $f^{\prime}(x)=0$, ou seja, $-4 x^{3}+4 x=4 x\left(1-x^{2}\right)=0$. Logo, encontraram $x=-1, x=0$ e $x=1$.

O grupo não conseguiu encontrar os pontos de máximo e mínimo da função. Para ajudá-los, o professor sugeriu que os alunos estudassem o sinal da derivada e aplicassem o teste da primeira derivada. Ao estudarem o sinal de $f^{\prime}(x)$ concluíram que:

1) para $x<-1, f^{\prime}(x)$ é positiva e para $-1<x<0, f^{\prime}(x)$ é negativa. Pelo teste da primeira derivada, concluíram que $x=-1$ é um ponto de máximo local; 
2) como, para $-1<x<0, f^{\prime}(x)$ é negativa e, para $0<x<1, f^{\prime}(x)$ é positiva. Pelo teste da primeira derivada, concluíram que $x=0$ é um ponto de mínimo local;

3) como, para $0<x<1, f^{\prime}(x)$ é positiva e, para $x>1$ é negativa. Pelo teste da primeira derivada, concluíram que $x=1$ é um ponto de máximo local.

Logo depois, o professor auxiliou os estudantes a encontrarem o(s) ponto(s) de inflexão. Derivando $f(x)$ duas vezes, obtiveram $f^{\prime \prime}(x)=-12 x^{2}+4$. Ao calcularem os zeros de $f^{\prime \prime}(x)$ encontraram $x= \pm \frac{\sqrt{3}}{3}$. Em seguida, constataram que $f^{\prime \prime}(x)$ é positiva para $\frac{-\sqrt{3}}{3}<x<\frac{\sqrt{3}}{3} \mathrm{e}$ negativa para $x<\frac{-\sqrt{3}}{3}$ e $x>\frac{\sqrt{3}}{3}$.

Juntamente com o professor, os alunos perceberam $x=\frac{-\sqrt{3}}{3}$ é um ponto de inflexão, uma vez que a curva muda de côncava para cima para côncava para baixo. O ponto $x=\frac{\sqrt{3}}{3}$ também é um ponto de inflexão, uma vez que é ali que a curva muda de côncava para baixo para cima.

O grupo apresentou dificuldades em desenhar o gráfico da função a partir das informações obtidas. Com a ajuda do professor o esboço gráfico foi realizado, conforme detalha a Figura 2.20.

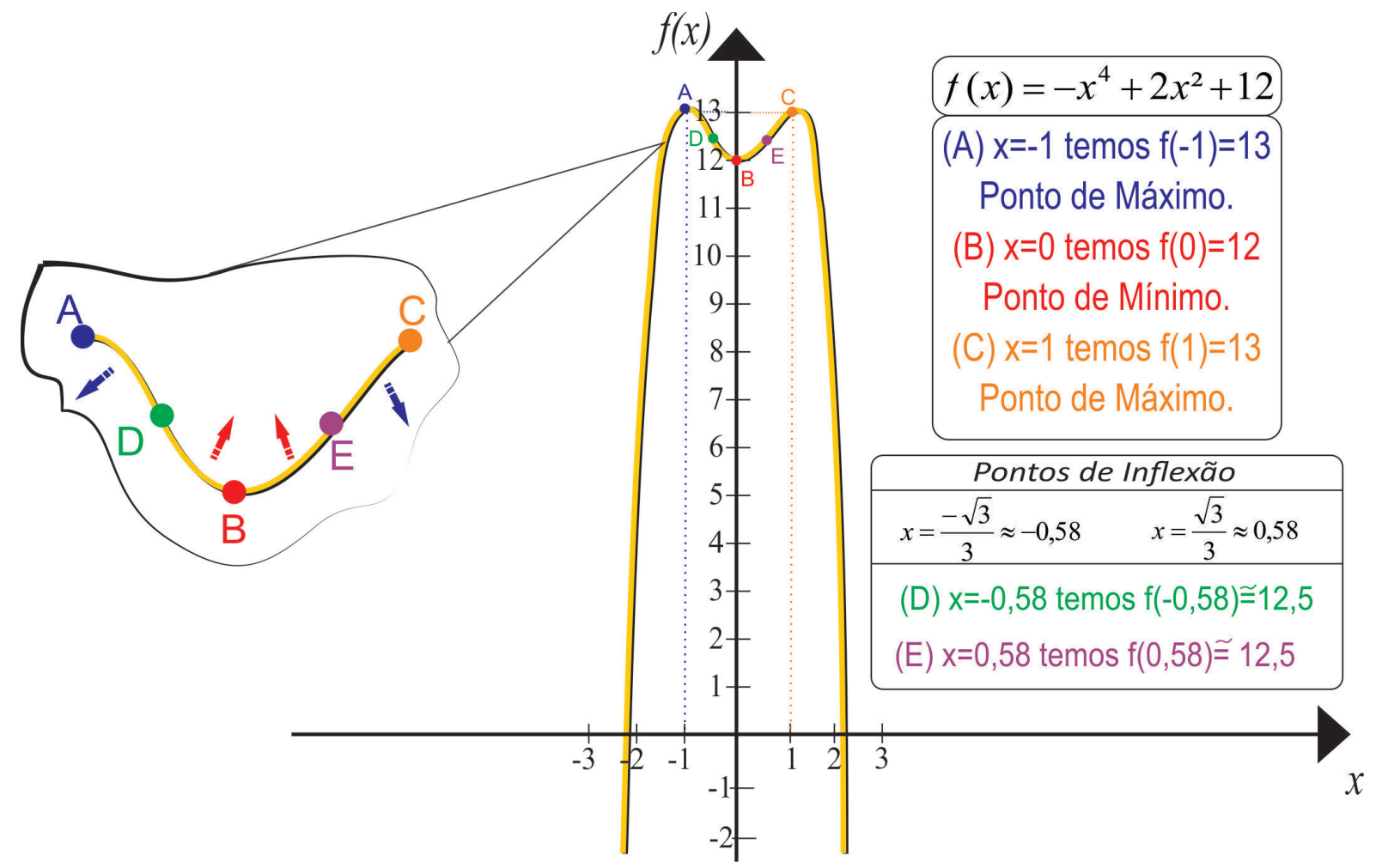

Figura 2.20: Gráfico da função $f(x)=-x^{4}+2 x^{2}+12$. 


\subsubsection{Algumas Aplicações do Cálculo: Velocidade e Aceleração}

Desenvolvemos esta seção para que os alunos pudessem relacionar o estudo da derivada com os conceitos de velocidade e aceleração, assunto abordado na disciplina de Física no primeiro ano do ensino médio.

\subsubsection{A Velocidade Instantânea e sua Relação com a Primeira Derivada}

Para mostrar a relação entre a primeira derivada e o conceito de velocidade, recordamos que a velocidade média é a razão da variação do espaço $(\Delta s)$ percorrido por um objeto pela variação do tempo $(\Delta t)$, ou seja, $v_{m}=\frac{\Delta s}{\Delta t}$.

O professor pediu que o grupo imaginasse que esse objeto se move sobre uma reta definida pela equação $s=s(t)$, na qual $s(t)$ é o deslocamento do objeto a partir da origem no instante $t$. A função $s$ que descreve o movimento é chamada de função posição do objeto. No intervalo de tempo entre $t=x_{0}$ e $t=x_{0}+h$, a variação na posição será $s\left(x_{0}+h\right)-s\left(x_{0}\right)$. Sendo assim, podemos dizer que a velocidade média pode ser representada pela equação

$$
v_{m}=\frac{s\left(x_{0}+h\right)-s\left(x_{0}\right)}{h}
$$

(que é também a da inclinação da reta secante passando pelos dois pontos $\left(x_{0}, s\left(x_{0}\right)\right)$ e $\left(x_{0}+h, s\left(x_{0}+\right.\right.$ $h))$.

A velocidade média nada nos diz sobre a velocidade em um dado instante, por exemplo, a velocidade média não nos informa qual a velocidade do objeto no instante $t=x_{0}$. Sendo assim, introduzimos o conceito de velocidade instantânea: se quisermos que a velocidade média seja calculada em intervalos cada vez menores, na verdade estamos fazendo $h \rightarrow 0$. Diante desse contexto, definimos velocidade instantânea no instante $t=x_{0}$ por

$$
v\left(x_{0}\right)=\lim _{h \rightarrow 0} \frac{s\left(x_{0}+h\right)-s\left(x_{0}\right)}{h} .
$$

A partir da expressão acima, solicitou-se que os alunos observassem que a velocidade instantânea em $t=x_{0}$, nada mais é do que a derivada da função $s(t)$ em $t=x_{0}$, ou seja, $v\left(x_{0}\right)=s^{\prime}\left(x_{0}\right)$.

\subsubsection{A Aceleração Instantânea e sua Relação com a Segunda Derivada}

Para exibir a relação entre a segunda derivada e o conceito de aceleração, recordamos que aceleração média é a razão da variação da velocidade pela variação do tempo, ou seja, $a_{m}=\frac{\Delta v}{\Delta t}$. 
Considerando agora $v=v(t)$ como sendo a função que nos fornece a velocidade de um objeto em cada instante $t$, como no caso anterior, vemos que no intervalo de tempo $\left[x_{0}, x_{0}+h\right]$, a aceleração média é

$$
a_{m}=\frac{v\left(x_{0}+h\right)-v\left(x_{0}\right)}{h} .
$$

Entretanto, se quisermos a aceleração instantânea em $t=x_{0}$, será dada por

$$
a\left(x_{0}\right)=\lim _{h \rightarrow 0} \frac{v\left(x_{0}+h\right)-v\left(x_{0}\right)}{h}=v^{\prime}\left(x_{0}\right)=s^{\prime \prime}\left(x_{0}\right)
$$

Ou seja, a aceleração instantânea em $t=x_{0}$ nada mais é do que a segunda derivada da função posição em $t=x_{0}$.

Por fim, elaboramos o exemplo abaixo, com a finalidade de ilustrar os conceitos de velocidade e aceleração instantânea.

Exemplo 2.2.22. Um projétil é lançado verticalmente para cima com uma velocidade de $120 \mathrm{~m} / \mathrm{s}$. Sabe-se que, a sua distância acima do solo após $t$ segundos é $s(t)=-4,9 t^{2}+120 t$, conforme expresso pela Figura 2.21.

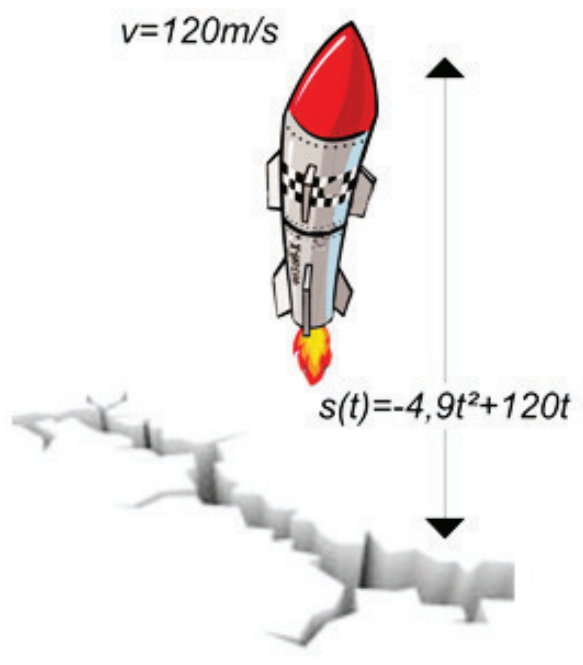

Figura 2.21: Lançamento de um projétil.

(a) Determine o instante e com que velocidade o projétil atinge o solo.

(b) Determine a aceleração em um instante arbitrário 
O grupo não conseguiu interpretar de maneira adequada o exemplo, sendo necessário o auxílio do professor.

(a) Explicou-se que, como a expressão $s(t)=-4,9 t^{2}+120 t$ representa a distância acima do solo após $t$ segundo, para descobrirmos o instante em que o projétil atinge o solo é natural que essa distância seja igual à zero, ou seja, $s(t)=0$. Ao resolver a equação $-4,9 t^{2}+120 t=0$, encontramos como solução $t=0$ e $t=24,5$.

Em seguida, pediu-se que os alunos encontrassem qual a velocidade do projétil no instante $t=24,5$. Como não houve resposta por partes dos alunos, o professor explicou que deveríamos encontrar a expressão que nos fornece a velocidade instantânea, ou seja, deveríamos derivar a expressão do espaço em função do tempo. Logo, obtiveram $s^{\prime}(t)=v(t)=-9,8 t+120$. Em particular, $v(24,5)=-120,1 \mathrm{~m} / \mathrm{s}$. O professor complementou, esclarecendo que a velocidade negativa significa que o projétil está se movendo no sentido contrário ao referencial (para baixo).

(b) Para o cálculo da aceleração, comentamos que a partir da expressão da velocidade instantânea, é possível encontrar a aceleração instantânea. Para isso, basta que se derive duas vezes $s(t)$, ou simplesmente uma vez $v(t)$. Diante dos comentários feitos, o grupo constatou que $a(t)=$ $s^{\prime \prime}(t)=-9,8 \mathrm{~m} / \mathrm{s}^{2}$. Comentamos que essa aceleração é constante e é a força da gravidade.

Neste capítulo, desenvolvemos com o segundo grupo dois dos principais tópicos do cálculo diferencial e integral: o de limites e o de derivadas. Durante as atividades realizadas com esse grupo, foram apresentados os principais conceitos, proposições, teoremas, definições e algumas demonstrações sobre limites e derivadas.

Em geral, os alunos conseguiram compreender a noção intuitiva de limites e os métodos algébricos utilizados para a resolução de alguns limites envolvendo polinômios. Quanto ao estudo das derivadas, ficou claro para os alunos a importância do limite para a sua definição.

Porém, o grupo se mostrou desinteressado nos instantes em que o professor realizava alguma demonstração, ou até mesmo, desenvolvia um raciocínio totalmente algébrico. Infelizmente, parte dos alunos considerou muito extenso todo o conteúdo trabalhado. Mas acredita-se, ainda que com todas as dificuldades apresentadas por este grupo, que a noção de alguns tópicos do cálculo foram assimiladas e os ajudarão de forma eficiente quando se depararem com a disciplina de cálculo no ensino superior. 


\title{
Capítulo 3
}

\section{Análise dos Dados}

\author{
Resumo \\ Neste capítulo apresentamos uma análise dos principais dados considerados para esta \\ pesquisa. Resumidamente, estes dados são a observação pelo professor com relação a \\ participação, interesse e aprendizado dos dois grupos durante as aulas ministradas e uma \\ avaliação final aplicada para cada grupo.
}

No que segue deste capítulo apresentamos uma análise comparativa com relação a participação, interesse e aprendizado dos dois grupos no decorrer das aulas ministradas. Além disso, apresentamos uma avaliação desenvolvida e aplicada pelo professor aos dois grupos. Esta avaliação envolveu os principais assuntos abordados durante as aulas e para sua resolução cada grupo pôde contar com a participação de todos os integrantes. Especificamente, apresentamos a resolução elaborada por cada grupo e uma análise do desempenho de cada um deles.

Com relação às observações realizadas durante o acompanhamento das aulas, referente a cada um dos grupos, percebeu-se uma maior participação e motivação dos integrantes do grupo 1. Em geral, constatou - se que, enquanto o primeiro grupo apresentava facilidade para realizar as atividades propostas, demonstrando a compreensão concreta do assunto, o segundo grupo apresentou dificuldades, sendo necessário revisar o conteúdo e a forma de resolução e, muitas vezes, só chegando aos resultados com a interferência contínua do professor.

Nas aulas expostas ao primeiro grupo, para cada atividade desenvolvida foi observado que o conhecimento foi construído passo a passo pelo aluno. A intervenção do professor sempre ocorreu 
como forma de sugestão. Na visão dos alunos, os motivos que os ajudaram na aprendizagem dos conteúdos abordados foram principalmente:

1) o fato da disciplina apresentar grande aplicabilidade no cotidiano;

2) a ocorrência de que os conceitos de cálculo não foram apresentados de forma isolada, e sim relacionados com os conteúdos do ensino médio;

3) a atitude do professor, indagando a todo instante para os alunos, se haviam realmente realizado uma interpretação correta de cada exemplo ou exercício apresentado.

Através dessa postura, foi possível observar que os alunos não realizavam a absorção do conteúdo de forma mecânica, apenas memorizando, e sim com o aprendizado dando-se de maneira compreensiva e estendendo-se para além das fórmulas e dos cálculos tradicionais, despertando maior interesse e envolvimento nos integrantes do grupo. Assim, foi possível verificar que essa forma de abordagem colaborou de maneira eficiente para que os estudantes observassem o cálculo como uma continuação avançada da matemática básica, bem como um tema essencial em assuntos que tratam diretamente ou indiretamente do nosso dia a dia.

Com relação aos alunos do segundo grupo, percebeu-se certa insatisfação com a disciplina. Os mesmos apresentaram algumas dificuldades ao realizarem as atividades propostas. Alguns membros do grupo definiram o conteúdo como difícil e abstrato. Outro fator negativo, exposto por parte dos estudantes, foi o excesso de símbolos matemáticos utilizados durante o desenvolvimento das atividades propostas, em especial, no que se refere às demonstrações de alguns teoremas e proposições.

No final do curso, optamos por aplicar uma mesma avaliação aos dois grupos com o objetivo de comparar o desempenho de cada um. Os alunos tiveram três horas para realizá-la. A avaliação foi dividida em duas etapas: limites e derivadas e aconteceu de forma coletiva, permitindo a participação de todos os integrantes. Os alunos puderam utilizar todo o material desenvolvido em aula. Durante a realização da avaliação, o professor acompanhou o desempenho dos dois grupos continuamente, observou e anotou as atitudes dos alunos diante de cada uma das questões e, em alguns momentos, fez perguntas relevantes ao assunto em questão com a finalidade de observar se haviam realmente atingido o objetivo esperado. Ao final, solicitou-se para cada grupo que escolhesse um aluno para 
ser o relator, com a função de transcrever a resolução dos exercícios. Posteriormente, foi feita uma análise dessa avaliação, considerando a abordagem de resolução de cada grupo.

Complementando este capítulo, descreveremos como foi aplicada a avaliação e o que se esperava que os alunos desenvolvessem em cada questão. Também incluímos as resoluções entregues por cada grupo e fizemos algumas considerações que julgamos importantes com relação às mesmas. Inicialmente, apresentamos 4 questões $(L 1-L 4)$, referentes ao estudo dos limites, como podemos observar abaixo.

A primeira questão dessa avaliação teve como objetivo verificar se o grupo compreendeu o significado de continuidade e descontinuidade. Dada a função $f(x)=\frac{3}{x-4}$, pediu-se para analisarem sua continuidade nos pontos $x=1$ e $x=4$, como podemos observar na Figura 3.1.

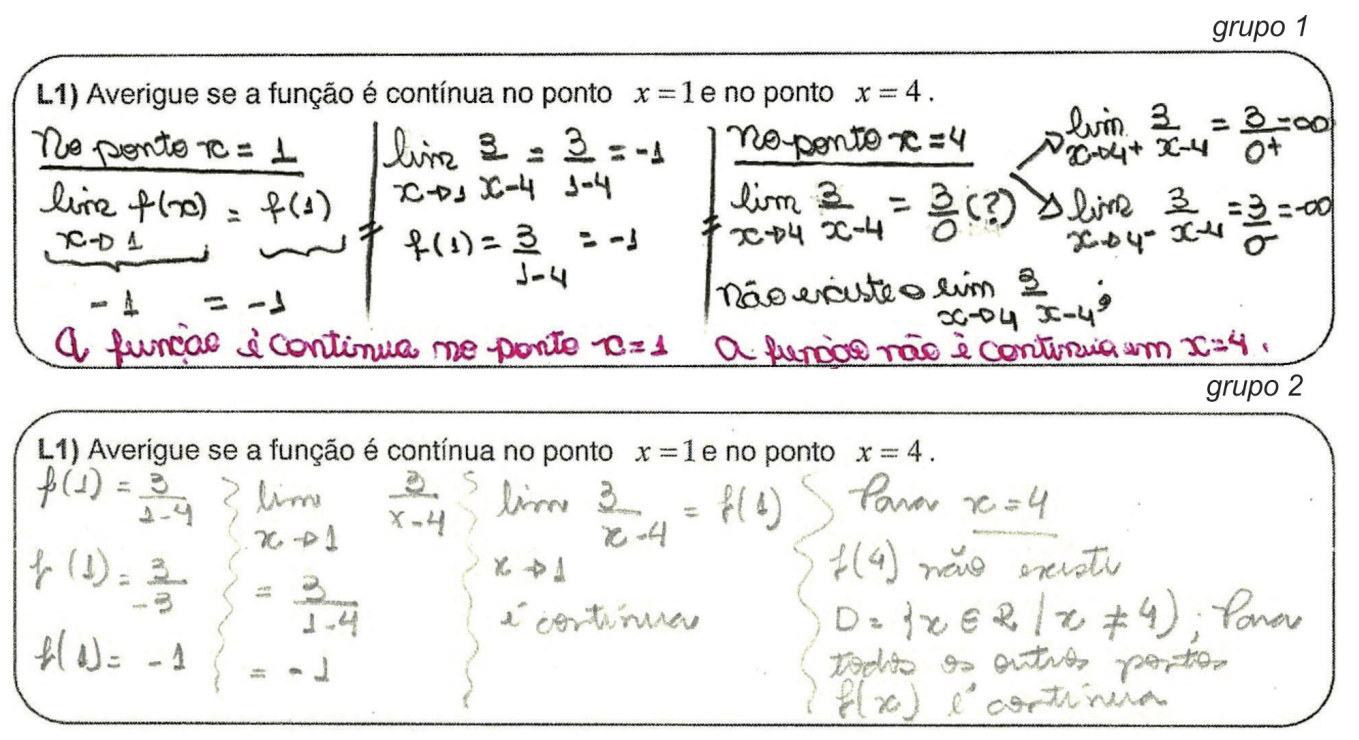

Figura 3.1: Desenvolvimento da primeira questão sobre limites.

Como é possível constatar, houve diferenças de resolução apenas para o ponto $x=4$. O grupo 1 apresentou uma resposta utilizando a definição formal de continuidade, ou seja, $\lim _{x \rightarrow a} f(x)=f(a)$. Quanto a solução apresentada pelo Grupo 2, o professor percebeu que os alunos apenas estudaram a condição de existência da função. Quando questionados sobre a continuidade para os demais pontos, com exceção do ponto $x=4$, apenas o grupo 1 apresentou uma justificativa correta.

Posteriormente, os alunos foram desafiados a calcular as assíntotas horizontais da função $f(x)=$ $\frac{3}{x-4}$. Tais resultados estão expressos na Figura 3.2. 


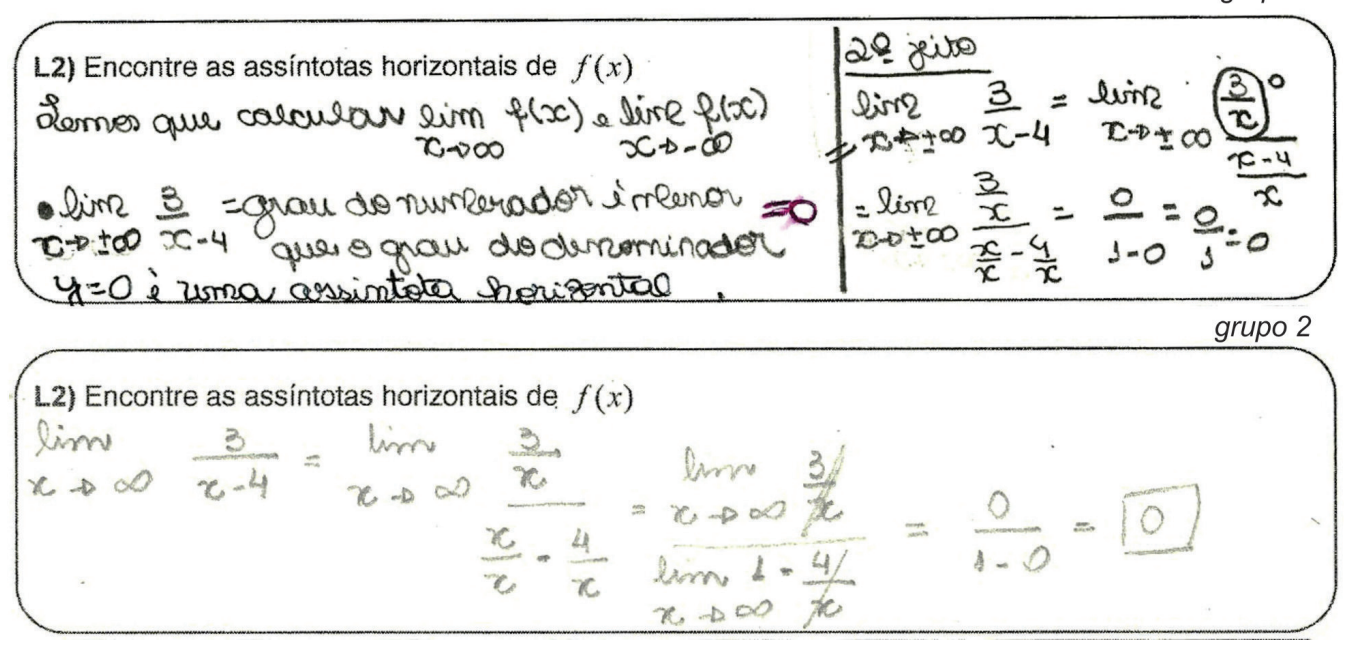

Figura 3.2: Desenvolvimento da segunda questão sobre limites.

Para encontrar as assíntotas horizontais, os alunos do grupo 2 recorreram ao material didático, e assim, verificaram que deveriam calcular $\lim _{x \rightarrow \pm \infty} f(x)$, o que segundo a percepção do professor, mostra que não compreenderam de maneira eficaz o assunto em questão. Os alunos do primeiro grupo, além de apresentarem uma solução semelhante ao do segundo grupo, demonstraram outra forma de resolução, mais intuitiva do que algébrica.

Na terceira questão pediu-se que os alunos encontrassem as assíntotas verticais da função $f(x)=$ $\frac{3}{x-4}$, veja na Figura 3.3 .

grupo 1

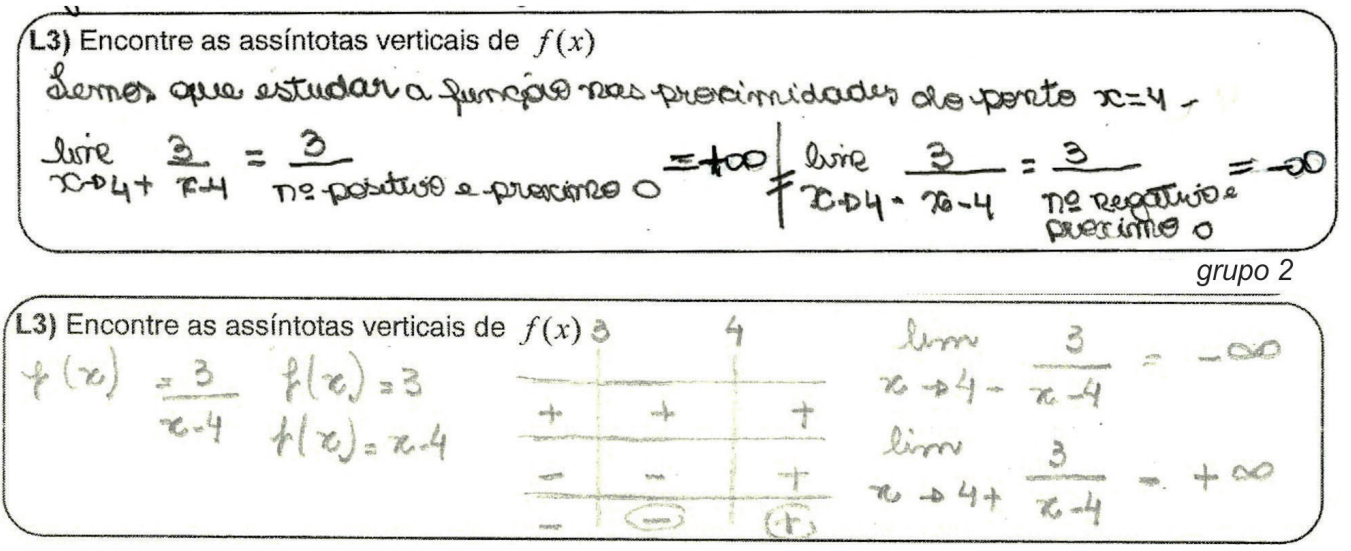

Figura 3.3: Desenvolvimento da terceira questão sobre limites. 
Os alunos do primeiro grupo observaram que a função $f(x)$ está definida para todo $x \in \mathbb{R}$ com $x \neq 4$. Como haviam verificado que no ponto $x=4$ existe uma descontinuidade, comentaram que para encontrar a assíntota vertical de $f(x)$, deveriam estudar o seu comportamento nas proximidades do ponto $x=4$. Os alunos do segundo grupo consultaram o material para chegarem a essa conclusão. É possível observar, pela Figura 3.3, que o grupo 2 apresentou uma resposta formal, enquanto os alunos do primeiro grupo apresentaram uma solução lógica, mais intuitiva.

Finalizando as questões referentes ao estudo dos limites, pediu-se que os alunos desenhassem o gráfico de $f(x)=\frac{3}{x-4}$, conforme ilustrado pela Figura 3.4.

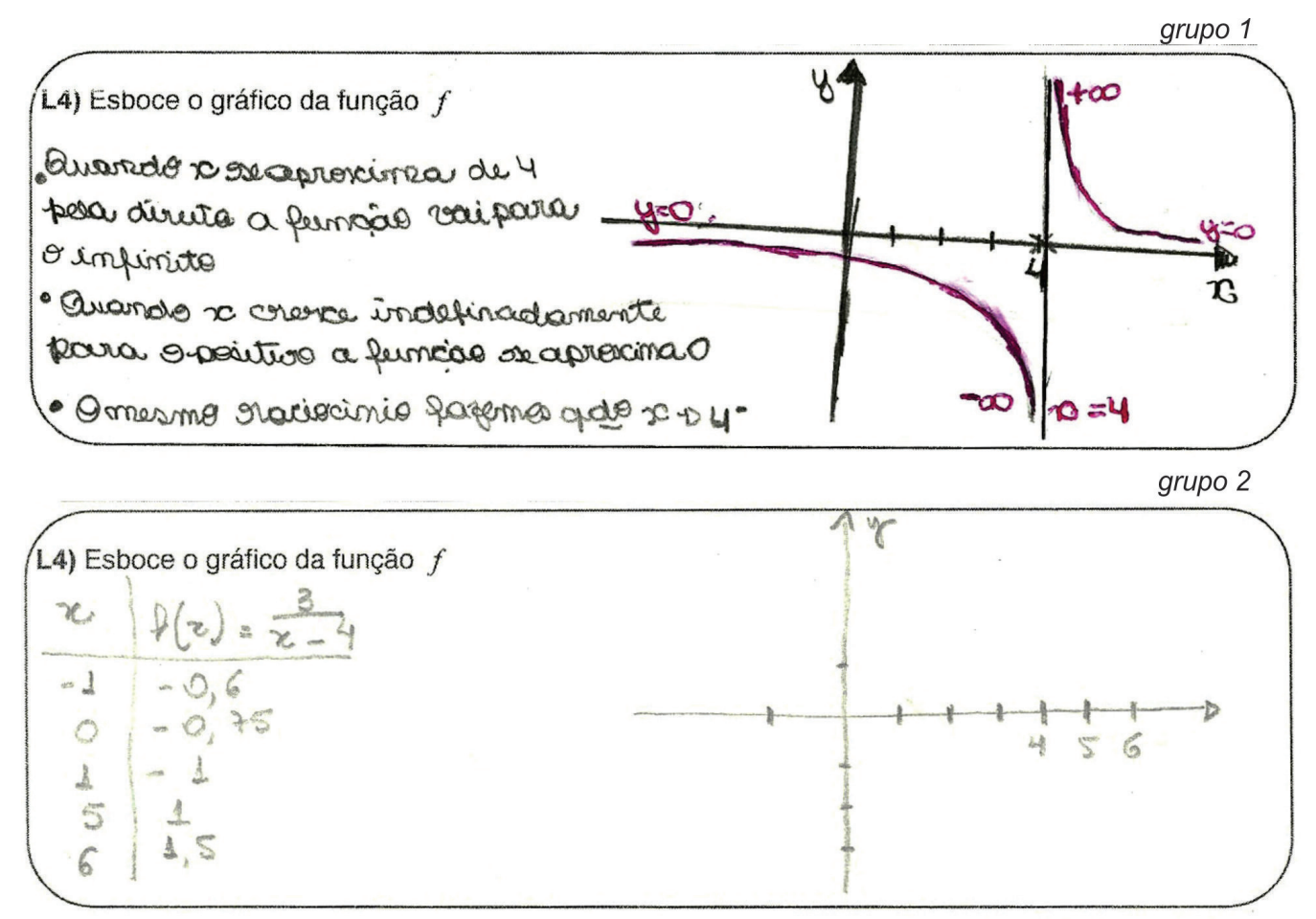

Figura 3.4: Desenvolvimento da quarta questão sobre limites.

Com a elaboração dessa questão, foi possível constatar que o grupo 1 esboçou corretamente o gráfico da função $f(x)$, fazendo uso dos resultados obtidos nas questões $L 2$ e $L 3$. O professor observou que os alunos conseguiram atingir o objetivo esperado ao compreenderem a importância das assíntotas horizontais e verticais no esboço de gráficos.

Os alunos do segundo grupo conseguiram encontrar as assíntotas verticais e horizontais da função $f(x)$, porém não atingiram o objetivo esperado em representá-las graficamente. Ao analisar as 
informações inseridas nesta questão, o professor constatou que os integrantes do segundo grupo não perceberam a importância dos limites na construção de gráficos, em especial, de funções racionais. Observou-se também, que tentaram desenhar o gráfico da função $f(x)$, atribuindo pontos aleatórios para $x$, forma estudada no ensino médio para funções do $1^{\circ}$ e do $2^{\circ}$ grau.

Quanto ao estudo das derivadas, foi aplicado um mesmo questionário para os dois grupos, contendo oito questões $(D 1-D 8)$.

Inicialmente, apresentamos a função $s(t)=t^{3}-6 t^{2}+9 t$ e pediu-se que os alunos calculassem os pontos críticos dessa função, como mostra a Figura 3.5.

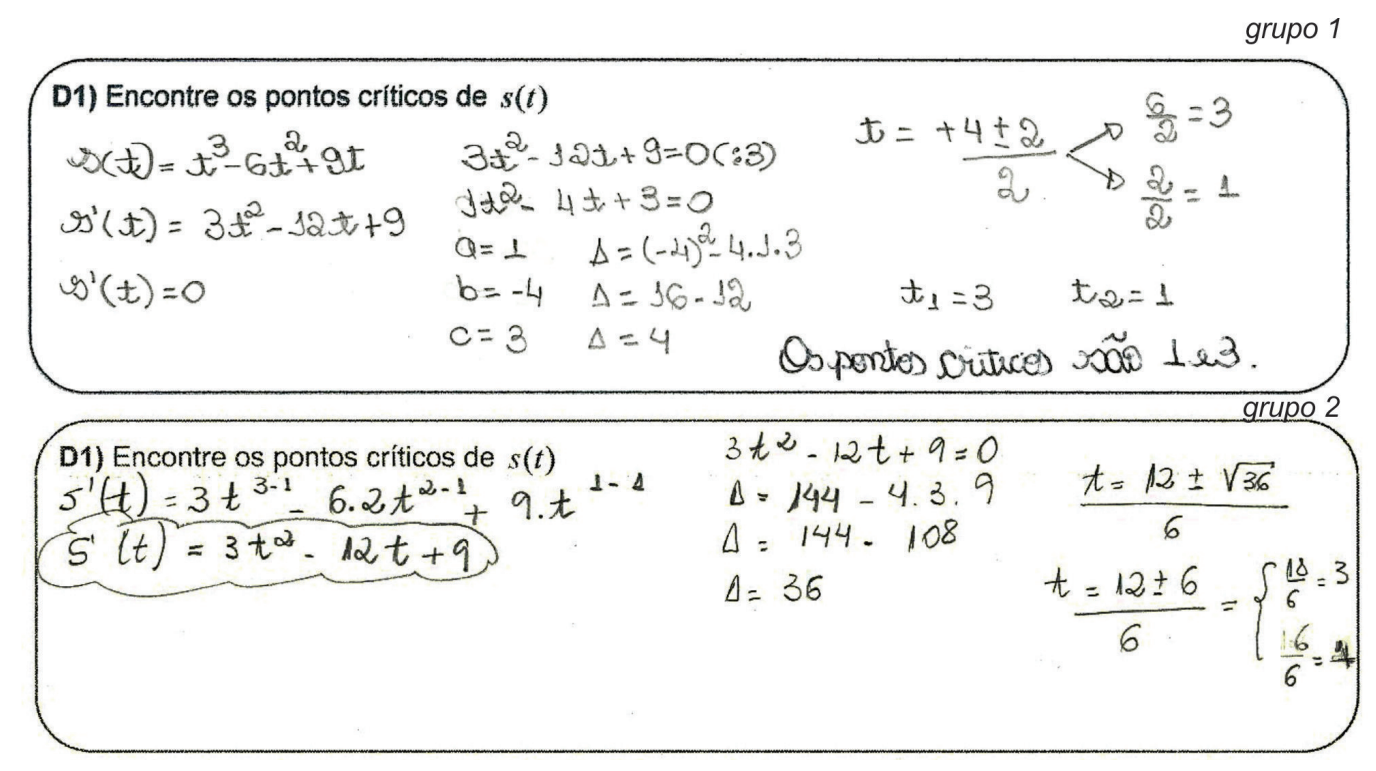

Figura 3.5: Desenvolvimento da primeira questão sobre derivadas.

Ao analisar a questão $D 1$, observou-se que nenhum dos dois grupos apresentou dificuldade. Em geral, os alunos conseguiram derivar a função polinomial e encontraram os pontos críticos, conforme podemos observar na Figura 3.5.

Ao serem questionados sobre o procedimento utilizado para descobrirem os pontos críticos da função $s(t)$, os dois grupos, de forma satisfatória, responderam que os pontos críticos em uma função ocorrem onde $s^{\prime}(t)=0$ ou $s^{\prime}(t)$ não existe, porém apenas os alunos do primeiro grupo comentaram que $s^{\prime}(t)$ existe para qualquer $t \in \mathbb{R}$.

Outro fator positivo observado pelo professor, é que nenhum dos dois grupos utilizou o material pedagógico como forma de consulta. 
Posteriormente, os alunos foram desafiados a descobrirem os pontos de máximo e mínimo de $s(t)=t^{3}-6 t^{2}+9 t$, conforme ilustrado pela Figura 3.6.

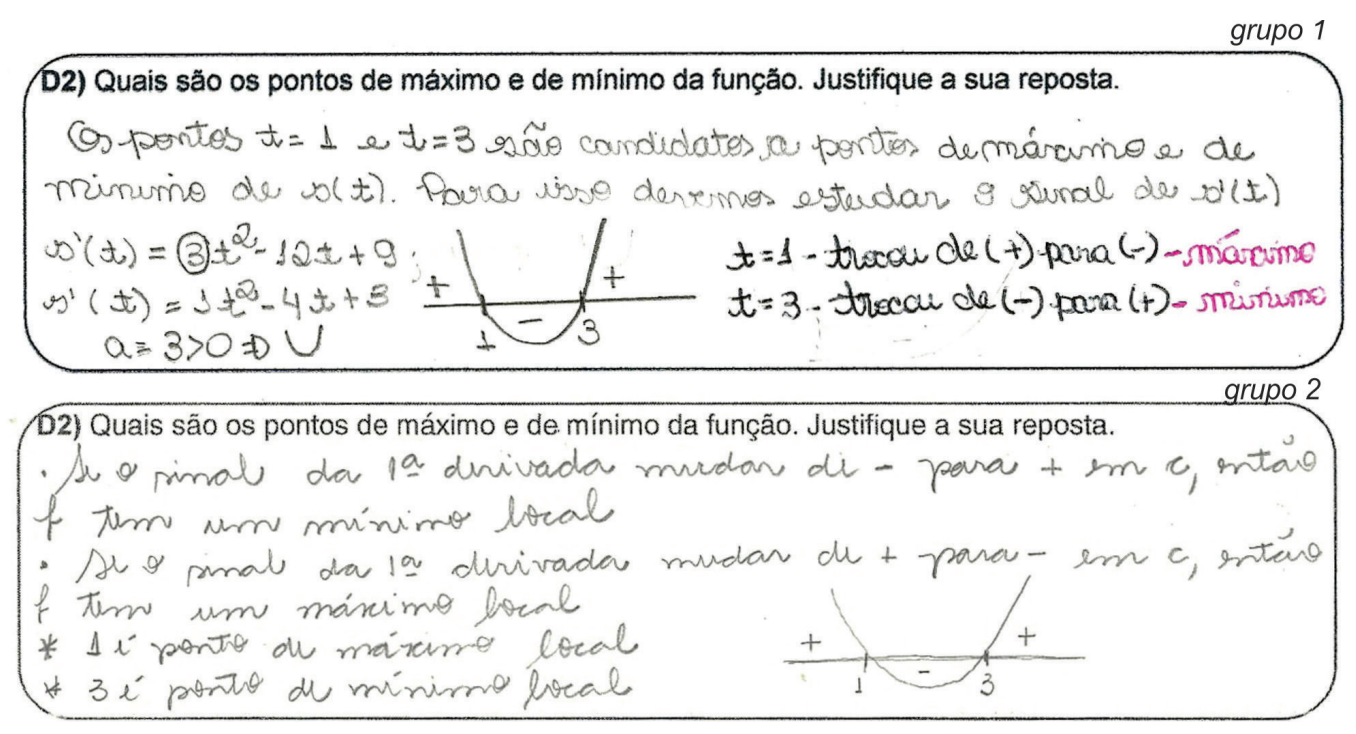

Figura 3.6: Desenvolvimento da segunda questão sobre derivadas.

Ao analisar o desenvolvimento desta questão o professor percebeu que:

1) os alunos do primeiro grupo não memorizaram o método utilizado para descobrirem se um ponto é de máximo ou de mínimo e em quais condições isso ocorre. Percebeu-se pelas atitudes dos alunos uma compreensão sobre inclinações de retas tangentes crescentes e decrescentes e a sua relação com os pontos de máximo e mínimo. Além do mais, não houve consulta ao material didático, apenas questionaram ao professor se a resolução estava correta;

2) os alunos do segundo grupo fizeram uso do material pedagógico e, ao apresentarem a resposta, fizeram uma cópia do teste da primeira derivada. Quando questionados sobre o motivo da troca de sinal para a existência de um ponto de mínimo ou de máximo, não souberam argumentar de maneira eficaz. O professor teve a impressão de que estavam tentando decorar o procedimento, ao invés de compreendê-lo.

Na questão $D 3$, solicitou-se aos grupos que encontrassem os pontos de inflexão da função $s(t)=$ $t^{3}-6 t^{2}+9 t$, conforme podemos observar na Figura 3.7. 


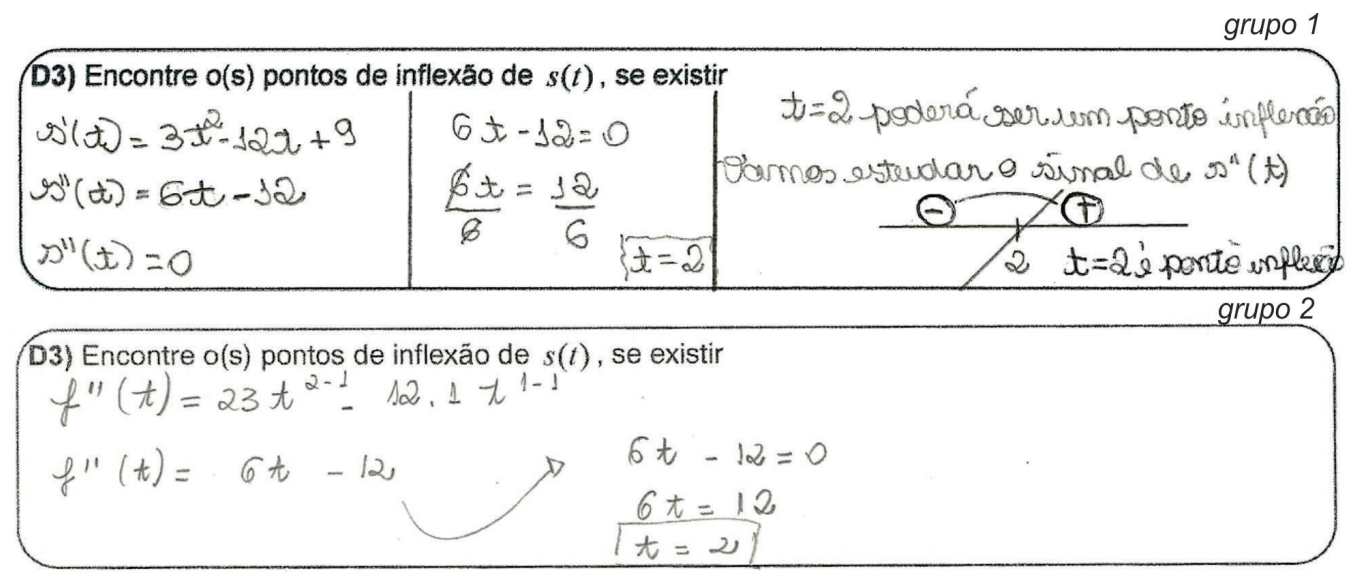

Figura 3.7: Desenvolvimento da terceira questão sobre derivadas.

O primeiro grupo conseguiu atingir o objetivo esperado, visto que justificaram através do estudo do sinal de $s^{\prime \prime}(t)$ que o ponto $t=2$ é um ponto de inflexão, pois comentaram que para $t$ menor que 2 a função é negativa e para $t$ maior que 2 a função é positiva, e justificaram que quando existe uma troca de sinal na função que representa a segunda derivada ocorre uma mudança de concavidade.

Os alunos do segundo grupo não terminaram de realizar a atividade. Concluíram que $t=2$ é um ponto de inflexão. Quando indagados pelo professor, o que é um ponto de inflexão e o porquê de $t=2$ ser um ponto de inflexão, responderam que ponto de inflexão é onde ocorre uma troca de concavidade, porém não desenvolveram mais nenhum argumento.

Em geral, nesta questão todos os alunos fizeram uso do material didático e, durante a aplicação, percebeu - se uma maior dificuldade com os alunos do segundo grupo. Com a finalidade em auxiliá - los, após a avaliação foi feita uma revisão com esses alunos e aplicou - se uma lista de atividades. Nessa lista de exercícios os alunos foram solicitados a encontrarem os pontos de inflexão de inúmeras funções, e assim, apresentarem uma justificativa em forma de seminário para a sala. O resultado foi positivo.

Em seguida pediu - se que os alunos esboçassem o gráfico da função $s(t)=t^{3}-6 t^{2}+9 t$.

Espera - se que nesta atividade os alunos utilizem os resultados obtidos nas questões $D 2$ e D3, pois desta forma é possível analisar se perceberam a importância dos conceitos de pontos de máximo, mínimo e de inflexão como auxiliadores na construção de gráficos. Veja a Figura 3.8. 


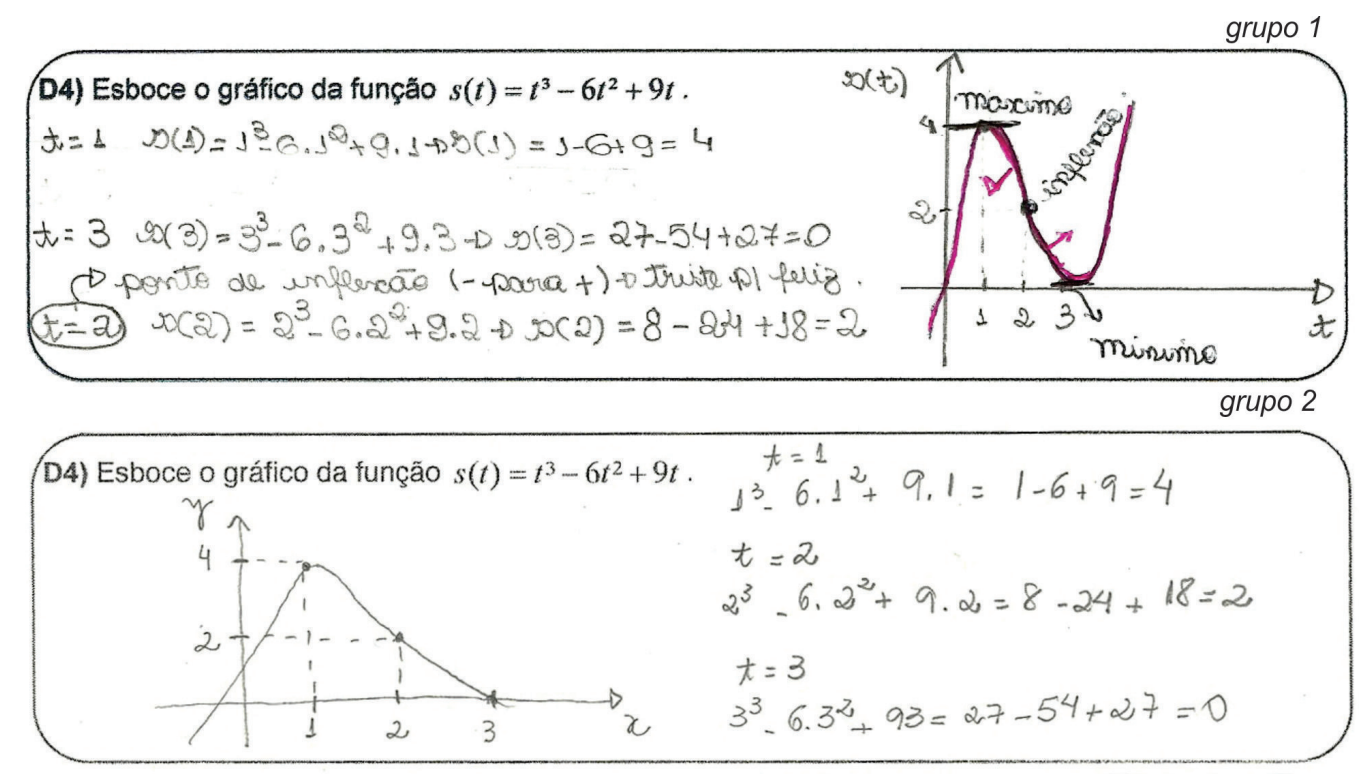

Figura 3.8: Desenvolvimento da quarta questão sobre derivadas.

O primeiro grupo conseguiu esboçar o gráfico de $s(t)$, destacando os pontos de mínimo, máximo e de inflexão. Satisfatoriamente, demonstraram graficamente que, no intervalo de $] 1,2[$ existe uma concavidade voltada para baixo, e no intervalo ]2,3[ existe uma concavidade voltada para cima.

O segundo grupo apresentou de forma indireta o ponto de máximo e de mínimo. O professor percebeu que os alunos não utilizaram os conceitos de primeira derivada para encontrarem esses valores, simplesmente, atribuíram valores aleatórios a $t$ obtendo $s(t)$. Comentou - se com os alunos que, caso tivéssemos uma função polinomial mais complexa necessitaríamos dos conceitos de primeira e segunda derivada para desenharmos e destacarmos os principais pontos no gráfico.

Por fim, o professor perguntou aos dois grupos o porquê de não utilizarem o cálculo do limite para desenharem o gráfico da função $s(t)$. Como nenhum dos alunos argumentou de forma correta, o professor disse que os limites no infinito e limites infinitos nos auxiliam a encontrar as assíntotas verticais e horizontais de uma função. Como a função $s(t)$ é uma função polinomial (contínua para todo $x \in \mathbb{R})$, não teríamos assíntotas horizontais e nem verticais.

Em seguida, ainda considerando a função $s(t)=t^{3}-6 t^{2}+9 t$, apresentou-se a questão $D 5$, com a finalidade de verificar se os alunos conseguiram perceber a aplicação de derivadas na Física. Especificamente, supondo que $s(t)$ representasse a função posição de um objeto no tempo $t$, aplicouse as questões expostas na Figura 3.9. 

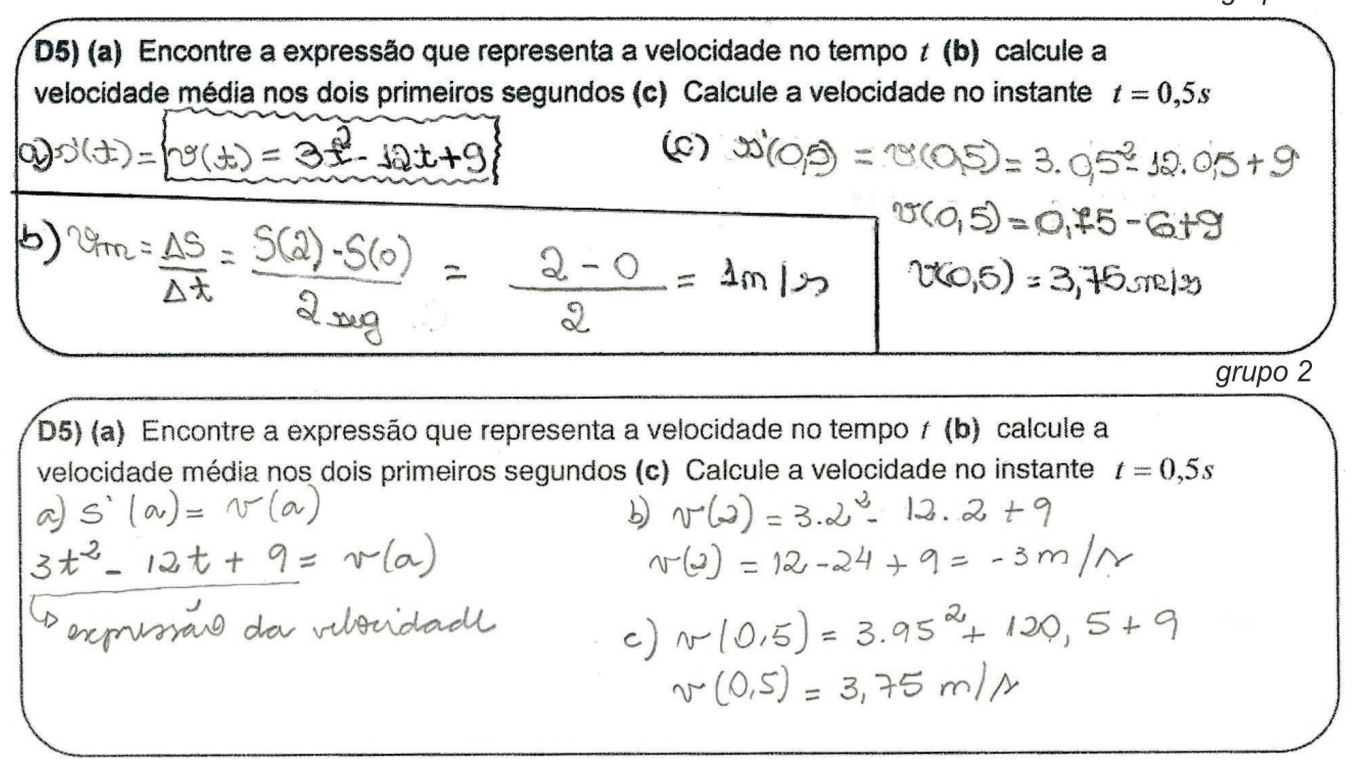

Figura 3.9: Desenvolvimento da quinta questão sobre derivadas.

O grupo 1 conseguiu realizar corretamente a atividade proposta, enquanto o grupo 2 não obteve sucesso no cálculo da velocidade média (item b). Ao questionarmos o primeiro grupo sobre a diferença entre velocidade média e instantânea, os alunos apresentaram uma resposta coerente, comentando que a velocidade instantânea é o limite da velocidade média quando a variação do tempo se aproxima de zero. Entretanto, os alunos do segundo grupo disseram que a velocidade instantânea representa a primeira derivada da função.

Diante das respostas apresentadas pelos dois grupos, o professor percebeu que, enquanto os alunos do grupo 1 compreenderam o processo para o cálculo da velocidade instantânea, os alunos do grupo 2 decoraram o processo algébrico a ser realizado.

Após a avaliação, o professor comentou com os alunos do segundo grupo o que é velocidade média e instantânea, bem como as diferenças entre si. Abordou uma metodologia similar a adotada com os alunos do primeiro grupo, com o intuito em sanar as dificuldades apresentadas. Percebeu se que alguns alunos compreenderam de forma satisfatória a proposta

Na questão $D 6$, pediu-se que os alunos desenhassem o gráfico da função $v(t)=3 t^{2}-12 t+9$, com a finalidade de interpretar as informações referentes à velocidade do móvel, conforme podemos observar na Figura 3.10 


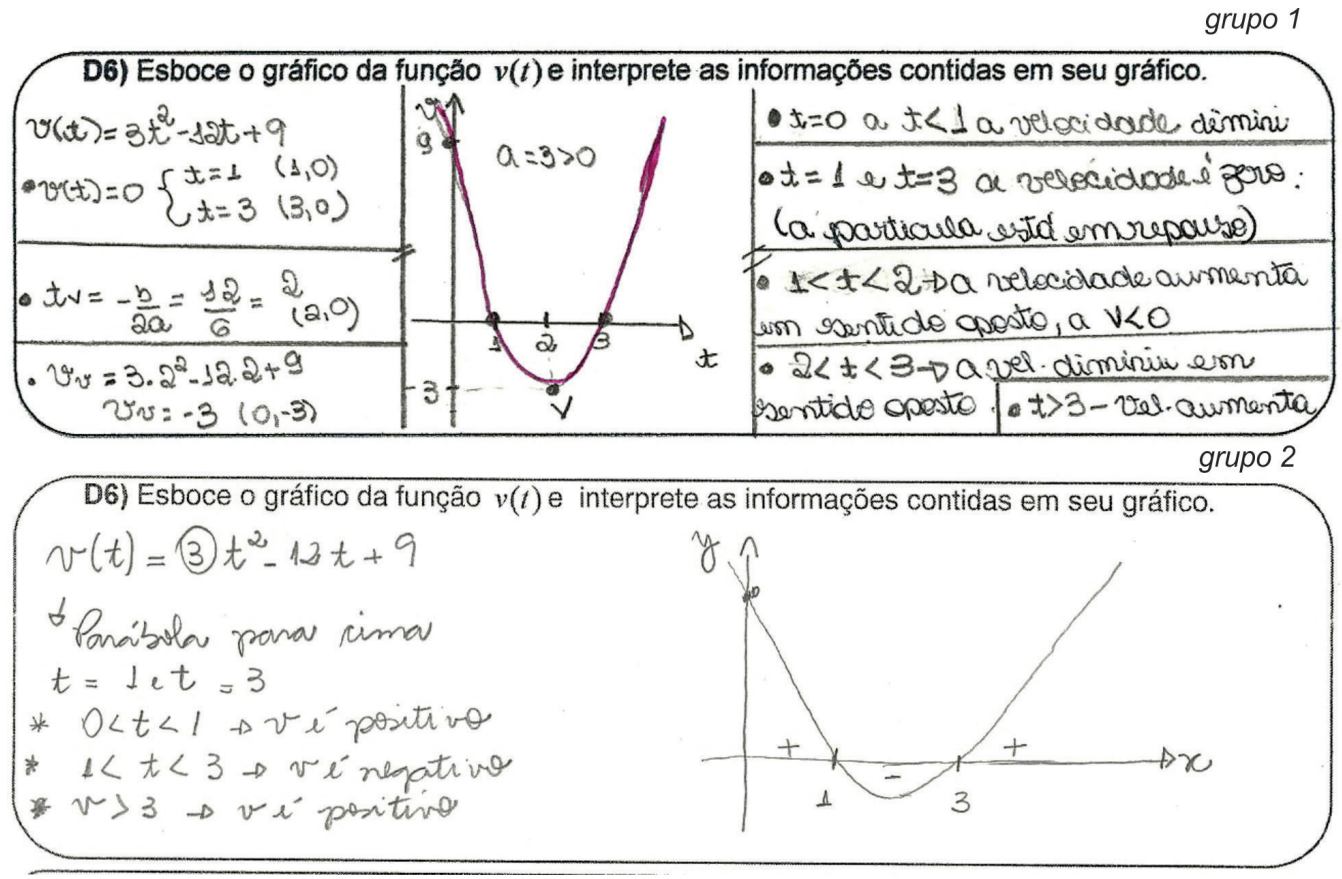

Figura 3.10: Desenvolvimento da sexta questão referente a derivadas.

Os integrantes dos dois grupos esboçaram o gráfico da função de forma coerente, entretanto o importante nesta questão era a análise que fariam sobre as informações contidas no gráfico de $v(t)$. Ao observar a resolução descrita pelos alunos na Figura 3.10, percebe-se que o primeiro grupo conseguiu, com êxito, descrever os instantes em que a velocidade do móvel diminui, se torna nula e aumenta.

Os alunos do segundo grupo apresentaram o estudo do sinal da função $v(t)$. Visto o erro de interpretação cometido, o professor pediu que observassem a curva, descrita pela parábola da função $s(t)$, e indicassem os intervalos em que o móvel aumenta e diminui a sua velocidade. Mesmo diante das sugestões apresentadas, o grupo não alcançou uma interpretação coerente para esta atividade.

Durante a correção da avaliação, o professor apresentou e explicou a solução dessa questão aos alunos do Grupo 2. Entretanto, percebeu - se que o objetivo não foi plenamente atingido.

Após a aplicação de velocidade média e instantânea com respeito à função posição $s(t)=t^{3}-$ $6 t^{2}+9 t$, pediu-se que os alunos calculassem a aceleração do objeto, conforme ilustrado pela Figura 3.11 . 


\begin{tabular}{|c|c|}
\hline $\begin{array}{l}\text { D7) Encontre a aceleração no tempo } t \text { e depois de } 4 s \\
a(t)=g^{\prime \prime}(t) \\
s^{\prime}\left(t_{0}\right)=3 t^{2}-12 t+9 \leadsto g^{\prime \prime}(t)=a(t)=6 t-12\end{array}$ & $\begin{array}{l}a(4)=6 \cdot 4-12 \\
a(4)=24-12 \\
a(4)=12 \mathrm{~m} / \mathrm{s}^{2}\end{array}$ \\
\hline & grupo 2 \\
\hline $\begin{array}{l}\text { D7) Encontre a aceleração no tempo } t \text { e depois de } 4 s \\
\begin{aligned} S^{\prime \prime}(t)=a^{\prime \prime}(t) \quad & S^{\prime}(t)=3 t^{2} \cdot 12 t+9 \\
& S^{\prime \prime}(t)=3 \cdot 2 \cdot t^{2}-1-12- \\
& S^{\prime \prime}(t)=6 t-12\end{aligned}\end{array}$ & $\begin{array}{l}s^{n}(4)=24-12 \\
s^{n}(4)=12 \\
a=12 \mathrm{~m} / \mathrm{s}\end{array}$ \\
\hline
\end{tabular}

Figura 3.11: Desenvolvimento da sétima questão referente a derivadas.

Esta atividade foi concluída sem dificuldade pelos dois grupos. Ambos conseguiram recordar a relação entre segunda derivada e aceleração instantânea. Por fim, o professor pediu que os alunos do $2^{\circ}$ grupo observassem que a unidade da aceleração correta é $12 \mathrm{~m} / \mathrm{s}^{2}$ e não $12 \mathrm{~m} / \mathrm{s}$, como haviam apresentado.

Posteriormente, o professor questionou os dois grupos se saberiam apresentar uma interpretação para a unidade da aceleração, no caso, $12 \mathrm{~m} / \mathrm{s}^{2}$. O primeiro grupo respondeu que $12 \mathrm{~m} / \mathrm{s}^{2}$ é o mesmo que $\frac{12 \mathrm{~m} / \mathrm{s}}{\mathrm{s}}$, ou seja, o móvel varia a sua velocidade em $12 \mathrm{~m} / \mathrm{s}$ a cada $1 \mathrm{~s}$. Os alunos do segundo grupo não conseguiram responder qual o motivo da unidade de tempo estar elevada ao quadrado.

Para finalizar, apresentamos a questão $D 8$, ainda com relação à função $s(t)=t^{3}-6 t^{2}+9 t$. O objetivo principal desta questão era de que os alunos apresentassem uma interpretação para os conceitos de aceleração e frenagem, conforme ilustra a Figura 3.12.

grupo 1

D8) Em que momentos a partícula acelera ? e em que instantes a partícula freia?

Quando a partlcular aumenter avara velocidode, scorre une movimento

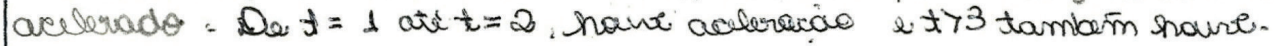

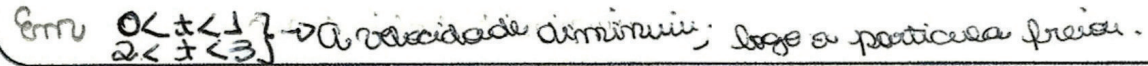

D8) Em que momentos a partícula acelera? e em que instantes a partícula freia?

De $t=0$ ate $t=1$ acelera

De $1<t<3$ fria

De $t>3$ acelera

Figura 3.12: Desenvolvimento da oitava questão sobre derivadas. 
Ao analisar as respostas apresentadas pelos dois grupos notamos que o grupo 1 atentou-se ao fato de que quando aumentamos a velocidade de um móvel estamos realizando uma aceleração e quando essa velocidade diminui está ocorrendo uma frenagem, ou seja, a aceleração está diminuindo.

Os integrantes do primeiro grupo utilizaram as informações contidas em $D 6$ para encontrarem os instantes em que o corpo acelera ou freia. Pelo fato desta questão estar relacionada com a questão $D 6$ e o segundo grupo não ter concluído de forma satisfatória esta questão, apresentaram dificuldades de interpretação para a questão $D 8$, conforme pode ser observado pela Figura 3.12.

O professor percebeu que o segundo grupo não conseguiu interpretar que, quando o sinal da velocidade é negativo, não significa que o móvel esteja freiando, e sim se movendo em sentido contrário ao referencial adotado, enquanto que este conceito ficou claro aos alunos do primeiro grupo.

Finalmente, baseado nas observações e nos resultados obtidos pela avaliação exposta acima, constatou-se, de forma geral, que o grupo 1 realizou as questões propostas com mais facilidade, demonstrando domínio do conteúdo e aplicabilidade do mesmo, enquanto o grupo 2 apresentava dúvidas e dificuldades para chegar em sua conclusões.

Outro aspecto observado durante o dia a dia, é que os dois grupos começaram o curso aparentemente motivados, realizando todas as atividades propostas. Com o decorrer das aulas, o primeiro grupo manteve-se realizando os exercícios propostos e apresentou uma participação diária maior e mais significativa que os alunos do segundo grupo. 


\section{Conclusão}

Acreditamos que os dois grupos que fizeram parte deste estudo foram beneficiados, já que tiveram a oportunidade de enriquecer seus conhecimentos através do estudo de uma disciplina muito importante nas áreas de ciências exatas e aplicadas. No entando, diante dos resultados obtidos, concluímos que o grupo 1 alcançou um grau de "interesse e aprendizado" mais satisfatório do que o grupo 2. Especificamente, pensamos que isto se deve ao fato que o método adotado com grupo 1 lançou mão, a todo momento, da intuição e de muitos exemplos algébricos ou ligados ao nosso cotidiano (sempre que possível), fazendo com que os alunos chegassem a definições, resultados ou conclusões com naturalidade e sem muitas formalidades.

Assim, percebemos que é possível ensinar cálculo diferencial e integral no ensino médio. Porém, devemos ter a preocupação em apresentar situações de aprendizagens contextualizadas e relacionadas com outras disciplinas do currículo do ensino básico como, por exemplo, Química e Física, e com algumas aplicações (mesmo que simples) do nosso cotidiano como, por exemplo, na economia. Dessa forma será possível beneficiar os alunos de uma maneira geral, pois o estímulo à reflexão e os exemplos voltados para o cotidiano e relacionados a outras disciplinas farão com que os alunos se sintam mais atraídos pela matemática e não a considerem como um conhecimento desconexo. De maneira especial, acreditamos que os alunos que pretendem continuar seus estudos em nível superior na área de exatas serão ainda mais beneficiados, pois estarão preparados e motivados para enfrentar o cálculo diferencial e integral no ensino superior, o qual é apresentado de maneira mais formal e com rigor nas ferramentas matemáticas.

Finalmente, concluímos que inserir o cálculo diferencial e integral no ensino médio, através de métodos similares ao que utilizamos com o grupo 1, poderão contribuir na qualidade da formação matemática do aluno, bem como em suas atividades cotidianas ou profissionais. 


\section{Referências Bibliográficas}

[1] Amore, B.D. Matemática, estupefação e poesia, 1. ed. São Paulo: Livraria da Física, 2012.

[2] Ávila, G. Análise Matemática para Licenciatura, 3. ed. São Paulo: Blucher, 2006.

[3] Ávila, G. O Ensino do Cálculo no $2^{\circ}$ Grau, Revista do Professor de Matemática (RPM), SBM, São Paulo, 1991.

[4] Baquero, R. Vygotsky e a aprendizagem escolar. Porto Alegre: Artes Médicas, p.27,2000.

[5] Guidorizzi, H.L. Um curso de Cálculo, volume 1, 5. ed. Rio de Janeiro:LTC, 2008.

[6] Iezzi, G.; Murakami, C.e Machado, N.J.Fundamentos de Matemática Elementar, volume 8, 5. ed. São Paulo: Atual, 1993.

[7] Janos, M. O Cálculo é Belo, 1. ed. São Paulo: Scortcecci, 2010.

[8] Lopes, A. Algumas reflexões sobre a questão do índice de reprovação nos cursos de Cálculo da UFRGS. SBM. Rio de Janeiro, n.26/27, p.118-126, jun./dez.1999.

[9] Machado, L.E.M. O Hipertexto na Aprendizagem do Cálculo Diferencial e Integral, 2002, 94p. Dissertação (Mestrado em Engenharia de Produção e Sistemas).Florianópolis: UFSC.

[10] Marchilik, M. Cálculo para que?, Revista Cálculo, São Paulo, ed. nº 24, p.19, jan/2013.

[11] Meyer, C. Derivada/Reta Tangente: Imagem Conceitual e Definição Conceitual. Tese de Mestrado em Educação Matemática. PUC - SP. São Paulo, 2003. Thomson Learning, 2004.

[12] Ryan, M. Cálculo para Leigos, 2. ed. Rio de Janeiro:Alta Books, 2012. 
[13] Salvador, N. Infinito,esse troço que não acaba, Revista Super Interessante, São Paulo, v. 227, p.16, jun/2006.

[14] Stewart, J. Cálculo, volume 1, 7. ed. São Paulo: Cengage Learning, 2013.

[15] Swokowski, E.W. Cálculo com geometria analítica, volume 1, 2. ed. São Paulo: Makron Books, 1994.

[16] Tan, S.T. "Matemática Aplicada à administração e economia", 1. ed. São Paulo: Thomson Learning, 2004.

[17] Wagner,E.; Morgado, A.C; Zani, S. Progressões e matemática financeira. Coleção Professor de Matemática, SBM, Rio de Janeiro, 2005. 


\section{Anexo 1}

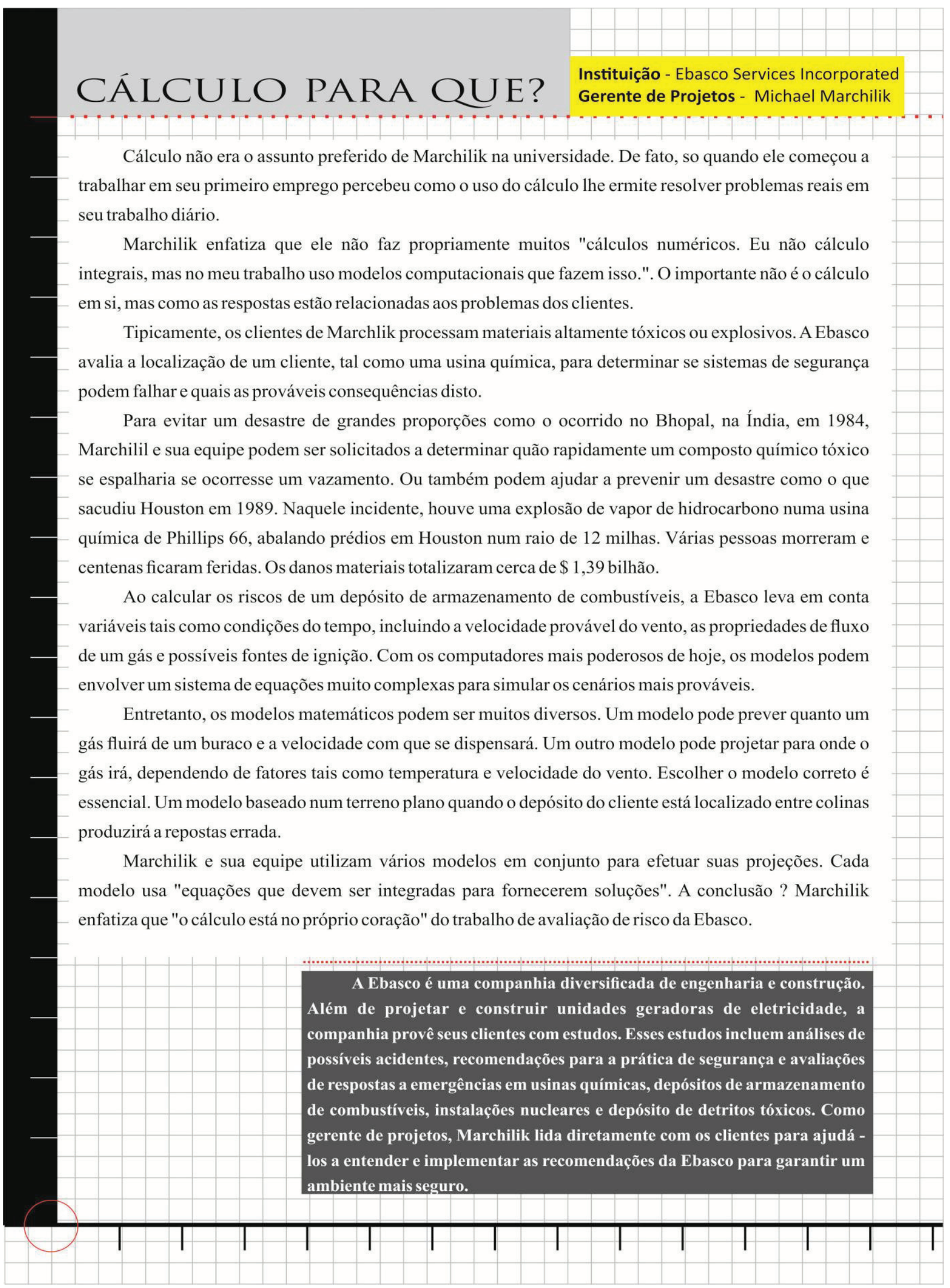


